Chapman University

Chapman University Digital Commons

$2-2020$

Working Too Much for Too Little: Stochastic Rewards Cause Work Addiction

Brice Corgnet

Simon Gaechter

Roberto Hernán González

Follow this and additional works at: https://digitalcommons.chapman.edu/esi_working_papers

Part of the Econometrics Commons, Economic Theory Commons, and the Other Economics Commons 
Working Too Much for Too Little: Stochastic Rewards Cause Work Addiction

Comments

ESI Working Paper 20-04 


\title{
WORKING TOO MUCH FOR TOO LITTLE: STOCHASTIC REWARDS CAUSE WORK ADDICTION
}

\author{
Brice Corgnet, Simon Gaechter and Roberto Hernán González
}

\begin{abstract}
People are generally assumed to shy away from activities generating stochastic rewards, thus requiring extra compensation for handling any additional risk. In contrast with this view, neuroscience research with animals has shown that stochastic rewards may act as a powerful motivator. Applying these ideas to the study of work addiction in humans, and using a new experimental paradigm, we demonstrate how stochastic rewards may lead people to continue working on a repetitive and effortful task even after monetary compensation becomes saliently negligible. In line with our hypotheses, we show that persistence on the work task is especially pronounced when the entropy of stochastic rewards is high, which is also when the work task generates more stress to participants. We discuss the economic and managerial implications of our findings.
\end{abstract}

Keywords: Incentives; Work Addiction; Occupational Health; Experiments

JEL codes: C92, D87, D91, M54

Brice Corgnet: Univ Lyon, emlyon business school, GATE UMR 5824, F-69130 Ecully, France. Email: corgnet@em-lyon.com. Simon Gaechter, Nottingham University, UK. Email: Simon.Gaechter@nottingham.ac.uk Roberto, Hernán-González, CEREN EA 7477, Burgundy School of Business, Université Bourgogne Franche-Comté, Dijon, France. Email: Roberto.hernan-gonzalez@bsb-education.com. This work was supported by the European Research Council (grant number ERC-AdG 295707 COOPERATION), and the Economic and Social Research Council (grant numbers ES/K002201/1). Brice Corgnet acknowledges that this research was performed within the framework of the LABEX CORTEX (ANR-11-LABX-0042) of Universite de Lyon, within the program Investissements d'Avenir (ANR-11-IDEX-007) operated by the French National Research Agency. The authors acknowledge the continuous support of the Economic Science Institute at Chapman University. Roberto Hernán-González also acknowledges financial support from Burgundy School of Business, the Spanish Ministerio de Economía y Competitividad [2016/00122/001], Ministerio de Ciencia, Innovación y Universidades [PGC2018-093506-B-I00], and Proyectos de Excelencia de la Junta Andalucía. This research started when the first author was at Chapman University and the third author was visiting Chapman University. 


\section{Introduction}

In this paper, we study the incentive effects of stochastic rewards. Economic agents are generally assumed to dislike risk and uncertainty, thus requiring extra compensation to engage in any activity in which rewards are stochastic. ${ }^{1}$ For example, there is overwhelming evidence that people are generally risk-averse (e.g., Holt \& Laury, 2002; Dohmen et al. 2011; Falk et al. 2018) or ambiguity-averse (e.g., Epstein \& Schneider, 2008). In the economic theory of incentives (Jensen \& Meckling, 1976; Holmström, 1979; Hart \& Holmström, 1986; Milgrom \& Roberts, 1992; Laffont \& Martimort, 2002; Bolton \& Dewatripont, 2004) as well as in the influential expectancy theory in management research (Vroom, 1964), workers are expected to shy away from contractual environments in which rewards are stochastic. ${ }^{2}$ As expressed by Nadler \& Lawler (2007, p. 177): “The supervisor's role in the motivation process becomes one of defining clear goals, setting clear reward expectancies, and providing the right rewards for different people."

However, research with non-human animals (rodents, pigeons and primates) has shown a positive relationship between reward uncertainty and motivation to complete effortful tasks (Davison, 1969; Boakes, 1977; Collins et al., 1983; Forkman, 1993; Hurly \& Orseen, 1999; Fiorillo, Tobler, \& Schultz, 2003; Anselme et al., 2013; Robinson et al., 2014; Anselme, 2015). For example, Anselme et al., (2013) show that reward uncertainty leads rodents to more actively press a lever indicating the possible imminent release of a sucrose reward. Anselme et al. (2013) interpreted pushing the lever as a sign of addictive behavior because it did not affect food delivery. Besides, rodents did not value sugary rewards more highly when they were uncertain than when they were certain. These findings suggest that reward uncertainty may trigger addictive behavior.

The positive relationship between uncertain rewards and lever activation in rodents can be reconciled with economic models if we assume that the experimental subjects (rodents, pigeons, and primates) generally love risk. However, there seems to be as much evidence of uncertainty-averse as uncertainty-seeking behavior in rodents and primates (see Paglieri et al., 2014). An alternative explanation pioneered by Berridge \& Robinson (1998) posits that uncertainty motivates individu-

\footnotetext{
${ }^{1}$ We do not distinguish between risk (known probabilities) and ambiguity (unknown probabilities) in the present discussion (see Wakker, 2010 for a review). Note that the animal research that motivated our study does not make that distinction because the probability distribution of rewards can never be fully known by animal subjects.

2 One exception to this rule is when risk leads workers to exert more effort (see e.g., Corgnet \& Hernán-González, 2019; Sloof \& Van Praag, 2010).
} 
als to pursue an action by means of a release of dopamine in the brain's mesolimbic system (Fiorillo et al., 2003; Preuschoff et al., 2006; Berridge, 2007; Linnet et al., 2012). This reactivity of the mesocorticolimbic dopamine system, which they refer to as incentive salience, would lead animals to 'want' to perform actions that they may not 'like'. As such, this constitutes a theory of addiction. Anselme et al., (2013) also put forward the argument that the positive effect of stochastic rewards can be due to the increase in stress levels that uncertainty generates, which, in turn, leads to narrow focusing and the inability to switch to a more desirable course of action.

In this paper, we are interested in whether the results from animal research carry over to humans. Although most of the incentive salience research was conducted with animals, the framework ultimately aims at explaining human addictive behavior (Berridge, 2003). Because the brain circuitry associated to 'wanting' by incentive salience researchers is identically present in rats, primates as well as humans, it is not surprising that recent studies have identified such brain centers in humans (Berridge \& Robinson, 2016).

Inspired by the experiments of Anselme et al., (2013), we designed a lab environment to test our hypotheses. We considered a setup in which participants could work on an effortful summation task for a total of 60 minutes with the possibility of quitting the task at any moment in time to browse the internet. After quitting the task, participants were not able to switch back to the task screen and could only browse the web until the end of the experiment. In the deterministic treatment (baseline), participants were always rewarded 12 tokens for each correct summation. However, the value of each token varied across periods of 10 minutes. In the first period, the value of each token was equal to $1 \phi$. In the remaining five periods, the value of a token collapsed over time reaching $0.002 \varnothing$ in the last 10 minutes. In the stochastic treatment, participants received a stochastic reward for each correct summation. The number of rewarded tokens could be any integer value between 1 and 23 with equal probability, and participants knew the stochastic process that generated the rewards. Identical to the baseline, the value of a token was $1 \varnothing$ in the first period before declining in subsequent periods. The two treatments entailed the same expected value for completing the task correctly (12 tokens), thus only differing on whether rewards were stochastic or deterministic.

To derive our conceptual framework and our hypotheses, we built on related findings in the neuroscience literature, which have shown how acute stress can impair a person's level of attention to relevant information (see e.g., Sänger et al., 2014). Attentional costs increase with the level of 
uncertainty in the environment because more attentional resources are needed to process information when rewards are stochastic than when they are deterministic (see e.g., Sims, 2003). It follows that workers' response to a slash in monetary incentives on an effortful task will be slower in the case of stochastic rewards. We thus expect people to work longer in the absence of stochastic rewards than when rewards are deterministic (Hypothesis 1). We also expect people who possess high attentional capacity to be more likely to quit the work task when monetary rewards become negligible (Hypothesis 2). Finally, we conjecture that stochastic rewards will induce stress in workers (Hypothesis 3). Our conceptual framework also posits that the effect of stochastic rewards on stress and work persistence is driven by the level of unpredictability of rewards, which is formally defined by the concept of entropy (Shannon, 1948).

In line with our first hypothesis, we found a positive effect of stochastic rewards on workers' likelihood to continue working on the task in the absence of monetary incentives. In our first study conducted in the US, we found that people were half as likely to quit the task in the stochastic treatment as in the baseline when incentives became negligible. This difference is both statistically and economically significant even after controlling for a battery of individual characteristics such as cognitive ability, risk and loss attitudes, time and social preferences as well as workers' ability on the task. In the stochastic treatment, people are about $10 \%$ more likely to continue working on the task when rewards become negligible compared to the deterministic treatment. In line with our second hypothesis, we also found that people possessing higher attentional resources, as measured by cognitive reflection, were more likely to abandon the work task when the rewards were slashed to virtually zero.

In line with our third hypothesis, participants reported a higher level of stress in the stochastic treatment than in the baseline. Using validated scales, we also show that workers did not like the stochastic-reward environment more than the baseline, although they spent significantly more time on the task when rewards were stochastic. This finding echoes the incentive salience 'wanting' hypothesis (e.g., Berridge, 2003; Anselme et al., 2013) according to which stochastic rewards create addiction, leading workers to pursue a course of action ('wanting') they do not necessarily value ('liking'). Our findings put forward that neuroscience research conducted with small samples of animals in abstract settings can shed light on human behavior in economically relevant environments. 
Next, we studied the underlying mechanisms of the effect of stochastic rewards on work addiction by both replicating and extending our first study, thus conducting new experimental sessions with a new pool of participants in a different country (Spain). Despite observing lower quitting rates, we replicated the qualitative nature of our findings by showing that stochastic rewards fostered work addiction. We extended our analysis by conducting six additional treatments in which we varied the stochastic process generating rewards while keeping the expected value of rewards constant. In line with our model, we identified the entropy of random rewards rather than their variance as the key driver of the effect of stochastic rewards on work addiction. In addition, we showed that workers' levels of stress increased with the entropy of rewards whereas stress levels did not respond to the variance of the rewards.

Our work constitutes, to our knowledge, the first causal study of uncertainty on work addiction in humans. Our findings cannot be explained by standard economic models building on informational asymmetries, information avoidance, learning or risk attitudes (see e.g., Bernheim \& Whinston, 1998; Brunnermeier \& Parker, 2005; Bereby-Meyer \& Roth, 2006; Hogarth \& Villeval, 2014; Jehiel, 2014; Ederer et al., 2018; Huck et al., 2018) because these dimensions were absent from our experimental setting. Our findings cannot be explained by intrinsic motivation models either (see e.g., Deci \& Ryan, 2000) because workers tend to report a lower level of intrinsic motivation on the task when rewards are stochastic than when they are deterministic. Instead, reward uncertainty seems to trigger work addiction because of its effect on stress is consistent with results from animal research in neuroscience.

\section{Literature review: uncertainty, stress and addiction}

To develop our conceptual framework which will culminate with three hypotheses, we start by a succinct review of the neuroscience literature on uncertainty, stress, and addiction. This is a necessary step given that these different strands of the literature have been developed in isolation without almost any cross referencing.

\subsection{Uncertainty and stress}

A number of authors have established a close link between uncertainty and stress responses at both empirical (e.g., Coates \& Herbert, 2008; De Berker et al., 2016) and theoretical levels (e.g., Peters et al., 2017). Uncertainty over the environment makes it more difficult for people to achieve their goals, thus generating frustration and prompting stress responses (e.g., Mason, 1968; Miller, 
1979). For example, there is ample evidence suggesting that performance-contingent pay systems are associated with higher levels of stress of the employees compared with fixed wages (Levi, 1972; Timio and Gentili, 1976; Timio, Gentili and Pede, 1979; Schleifer and Amick, 1989; Schleifer and Okobaga, 1990; Shirom, Westman and Melamed, 1999). In a review of this literature, Ganster et al., (2011) argue that this effect may be mediated by uncertainty and lack of job control, so performance-contingent rewards are especially stressful when the uncertainty about the relationship between effort and rewards is high. De Berker et al., (2016) have recently shown that the perceived uncertainty regarding the occurrence of an aversive stimulus (i.e., electric shock) was closely related to both self-reported and physiological measures of stress. The authors assessed the uncertainty of the random process generating the aversive stimulus using the concept of entropy (Shannon, 1948).

At a conceptual level, Hirsh et al., (2012) view stress as a natural reaction to uncertain situations. Peters et al., (2017) go one step further by equating stress and uncertainty. Hirsh et al., (2012) and Peters et al., (2017) agree on identifying unpredictability, formalized using the concept of entropy, as the critical driver of stress.

\subsection{Stress, attentional resources, and addiction}

Stress has been shown to impair cognitive flexibility, which is the ability to switch from one course of action to another (see e.g., Shields et al., 2016). ${ }^{3}$ This means that an increase in stress will tend to prevent a person from comprehensively assessing all alternative courses of action, focusing instead on maintaining the current action. A reason why stress makes it more difficult to consider alternative actions is that it limits a person's ability to process all relevant information (see e.g., Sänger et al., 2014). Stress thus increases a person's attentional costs.

A large number of studies have also shown that stress can promote automatic rather than deliberative thinking (see Yu, 2016 for a review). Research has also produced evidence that stress prompts habitual behavior in humans (Schwabe \& Wolf, 2009, 2011). Habitual behavior is observed when people engage in actions independently of the value of the outcome (see Adams \& Dickinson, 1981; Adams, 1982; Dickinson, 1985; Balleine \& Dickinson, 1991). In the context of the experiment of Anselme et al., (2013), habit behavior is observed when rats push the lever

\footnotetext{
${ }^{3}$ Cognitive flexibility is one of the three major executive functions along with working memory and inhibitory control (Diamond, 2013).
} 
frenetically, although it does not affect food delivery. Complementary evidence that stress can promote harmful habits comes from the vast literature linking stress with addictive behavior (see Sinha et al., 2011 and Mantsch et al., 2016 for reviews). This literature has shown that inducing stress, by applying intermittent electric shocks, can lead to drug relapse in animals (e.g., Shalev et al., 2001). Evidence of the effect of stressors on drug relapse has also been found in humans (e.g., Back et al., 2010; Sinha et al., 2011).

In sum, neuroscientists, using different methodologies, seem to converge toward a common understanding of reward uncertainty as a decisive source of stress, which in turn can alter executive functions and lead to addictive behaviors. Despite this growing consensus, we are not aware of any human study assessing the role of uncertainty on work addiction. This may be explained by the fact that the previously mentioned strands of literature have been developed in isolation preventing the link between uncertainty and work addiction to be clearly established. We propose to fill this gap by providing a unified conceptual framework along with an experimental paradigm to study the connection between uncertainty and work addiction.

\subsection{Stochastic rewards, attentional resources, and work addiction}

Previous research allowed us to identify a direct link between uncertainty and stress and between stress and addiction. Connecting the dots between these different strands of literature, we conjecture that unpredictability of rewards, as measured by entropy, will induce stress, which in turn will trigger work addiction. More specifically, high entropy in the environment will tend to deplete attentional resources because of the higher number of pieces of information that have to be attended (see Sims, 2003; Marois and Ivanoff, 2005; Mackowiak et al., 2018 for a review). In a related literature in neuroscience, high levels of entropy have also been associated with high communication costs between different brain areas, which will mechanically limit attentional resources (e.g., Dimitrov et al., 2011; Friston et al., 2013; 2017a,b).

Reward uncertainty will thus generate attentional costs, which will impair workers' effort decisions and favor the status-quo (Dean et al., 2017). This is the case because workers in high-entropy environments will have less attentional resources available to process new relevant information about work rewards. In a setup in which a worker's decision is to abandon the current task to engage in a leisure activity, the status-quo will induce work persistence. Entropy in rewards will thus lead to inertia, which will lead workers to continue working even after the monetary incentives for completing the task become negligible. Workers' inertia will also depend on their individual 
level of attentional capacity. We thus expect workers possessing high attentional capacity to be less likely to continue working on the task after monetary rewards have become negligible.

In the next section, we develop a stylized framework aiming at capturing the main insights that stochastic rewards foster stress and persistence at work.

\section{Conceptual framework and hypotheses}

We consider a setup in which a worker can decide, at any moment in time $t \in\{0, \ldots, T\}$, whether to complete an effortful task $\left(e_{t}=1\right)$ at a fixed $\operatorname{cost} C>0$ or quit the task $\left(e_{t}=0\right)$ to enjoy leisure. When workers quit, they cannot come back to the work task at a later period.

If workers decide to complete the task at any time, they obtain a monetary prize $\left(z_{t}\right)$. This monetary payment depends on the realization of a reward random variable $R$ and the realization of an exchange rate random variable Q (or the monetary incentives per unit of reward). The monetary prize associated with the reward $r$ received at time $t$ is defined as $z_{t}:=r_{t} q_{t}$, where $q_{t}$ denotes the exchange rate at time $t$. Each time a worker completes the task, a reward is drawn from $R$ and the worker is informed about its value and the corresponding monetary payment.

To study work addiction, we investigate the persistence of work effort when incentives are substantially devalued. We thus consider the case in which incentives are decreased at time $\tau$ so that $q_{t}=q_{H}$ for any $t<\tau$ and $q_{t}=q_{L}$ for any $t \geq \tau$, where $q_{L} \ll q_{H}{ }^{4}$ We assume that the exchange rates values are such that any worker basing their effort decision on all available information about rewards and exchange rates would be willing to exert effort for any $t<\tau$ while being willing to quit the task for $\geq \tau .^{5}$

Even though monetary incentives are slashed at time $\tau$, workers who dislike the task $(C>0)$ may still refrain from quitting the task to enjoy leisure. In our model, this is the case because switching from a habitual course of action (working on the task) to an alternative action (the leisure activity) is assumed to be costly. We refer to these costs as attentional costs.

Attentional costs come from the fact that the information on rewards and the exchange rate used to make switching decisions are costly to process. More precisely, we can model attentional costs

\footnotetext{
${ }^{4}$ Note that even if the sequence of exchange rates is known in advance, workers still need to be attentive to this piece of information so as to identify the exact exchange rate value at a specific moment in time. This implies that, while completing a task, workers are not necessarily fully certain of which exchange rate applies. The exchange rate can thus be modeled as a random variable.

${ }^{5}$ By focusing on the worker's decision at the time monetary incentives become negligible, we abstract from dynamic programming issues. This is the case as long as we assume that any worker are willing to quit the work task whenever they are aware of the devalued monetary incentives.
} 
using entropy following the literature on rational inattention (see Sims, 2003; Mackowiak et al., 2018 for a review). ${ }^{6}$ In this literature, attentional costs are measured as the expected reduction in the level of uncertainty associated with attending a given piece of information $(s)$. In our setup this means attentional costs $(\chi)$ can be defined as follows:

$$
\chi:=\lambda_{i} \mathrm{~K}=\lambda_{i}(H(R, Q)-H(R, Q \mid s))
$$

where $\lambda_{i}>0$ is the unit cost of information of individual $i$, and $\mathrm{k}$ is the amount of information measured as the expected reduction in uncertainty (entropy, $H(\cdot)$ ) from observing a piece of information $(s)$, which in our setup consists of observing the actual value of the reward and the exchange rate.

In our context, we have $H(R, Q)=H(R)+H(Q)$ and $H(R, Q \mid s)=0$, so that equation [1] boils down to: $\lambda_{i}(H(R)+H(Q)) .^{7}$ The unit cost of information $\lambda_{i}$ is likely to vary widely across individuals. It captures people's inherent attentional capacity, which can be measured, for example, using the cognitive reflection test (e.g., Hasher et al., 2007; Toplak et al., 2011).

If we interpret the unit cost of information $\lambda_{i}$ as the time needed to process an extra bit of information, it follows that an increase in the entropy of rewards $H(R)$ might prevent workers from making a timely effort decision based on all currently available information. The interpretation of the unit cost of information in terms of processing time is consistent with the evidence in the attention literature (see Pashler, 1998). For example, it takes more time to identify a given symbol when the number of items to be searched for increases.

In our setup, we assume that no new effort decision can be made in a given period if attentional costs are above a given threshold $\chi^{+}$. In the absence of a timely decision, we assume that the level of effort is set to be equal to its previous level. This is in line with the status-quo model in Dean et al., (2017), who assume that a previous action tends to be selected if attentional costs are high. As a result, inertia increases as the attentional costs associated with rewards $(H(R))$ increase. Entropy will lead to inertia, which in our setup implies workers will continue to work on the task even after monetary incentives become negligible. This result is captured in Hypothesis 1.

\footnotetext{
${ }^{6}$ For a discrete random variable $(X)$ taking $n$ possible values, each with probability $p_{i}$, Shannon (1948) entropy is calculated as follows: $H(X):=-\sum_{i=1}^{n} p_{i} \log _{2} p_{i}$. Tsallis (1988) entropy of order 2 is also widely used: $1-\sum_{i=1}^{N} p_{i}^{2}$. This uncertainty measure has recently been characterized and axiomatized by economists (Caplin et al., 2017; Frankel \& Kamenica, 2019).

7 The first part follows from the fact that the exchange rate is determined independently of the actual value of the reward. The second part follows from the fact that the reward and the exchange rate can be known for sure after a task has been completed.
} 
Hypothesis 1 (Work addiction and stochastic rewards) Workers facing higher entropy of rewards will be more likely to continue completing the task after monetary incentives have become negligible.

It also follows from [1] that workers possessing higher attentional capacity (lower $\lambda_{i}$ ) will be less likely to continue working on the task when the exchange rate becomes negligible, regardless of the uncertainty of rewards (see Hypothesis 2 below).

Hypothesis 2 (Work addiction and attentional resources) Workers possessing higher attentional capacity will be more likely to switch to the leisure task after monetary incentives have become negligible.

Recent works in neuroscience posit a close connection between stress and the level of entropy in the environment (e.g., Coates \& Herbert, 2008; De Berker et al., 2016; Peters et al., 2017). As in our framework, these authors assessed the uncertainty of the random process generating the aversive stimulus using the concept of entropy. Intuitively, uncertainty over the environment makes it more difficult for people to achieve their goals, thus generating frustration and prompting stress responses. In our model, this will occur in an environment in which attentional costs are high, which is when the cognitive burden of making decisions is high. This is the case when the entropy of the random reward is high. In that case, workers will be more likely to fail to process any new information regarding the exchange rate. As a result, workers will continue working on the task despite low monetary incentives. In that case, workers will be exerting an inefficiently high level of effort, where the efficient level of effort is defined as the one chosen in the absence of attentional costs.

In our setup, this means that the slower workers are to adapt their effort decision to the new reward conditions, the higher will be their stress levels. It follows that an increase in the entropy of rewards will increase stress levels. This effect is captured in Hypothesis 3.

Hypothesis 3 (Stress and entropy) Workers facing higher entropy of rewards will experience higher stress levels.

By connecting uncertainty in rewards and stress, our framework also helps account for the recent findings showing that tournament incentives lead to unusually high levels of stress (assessed 
using either cortisol, heart-rate variability or self-reported measures) compared to individual incentives (see Buckert et al., 2017; Buser et al., 2017; Halko \& Sääksvuori, 2017; Zhong et al. 2018) or fixed wages (Stolp et al., 2017). ${ }^{8}$ Because tournament incentives generate substantial uncertainty regarding the identity of the prize winner, our framework correctly predicts that they would generate higher stress levels than other payment schemes such as individual incentives and fixed wages for which rewards are highly predictable.

In Appendix E1, we discuss existing models that relate to our conceptual framework.

\section{Experimental design}

\subsection{Treatments}

To study work addiction we used a real-effort task in which participants had to make summations of five one-digit numbers for up to 60 minutes. They could quit the task at any moment in time to browse the internet by clicking the corresponding button (see Figure 1). After quitting the task, participants were not able to go back to the task screen and faced an internet browser until the end of the experiment.

In the deterministic treatment (baseline), participants were rewarded 12 tokens per correct answer (see Table 1). The reward per correct summation was equal to the number of tokens divided by an exchange rate, which varied across the six 10-minute periods of the experiment. In the first period, the exchange rate was equal to one, so that each summation was rewarded $12 \phi$. In the following five periods, the exchange rate was equal to 2, 4, 8, 80 and 500. This information was known by the participants and displayed on their screen at all times. It follows that in the last period of 10 minutes, participants did not obtain any meaningful monetary reward $(0.024 \varnothing$ per correct summation) for completing the task. During the first five periods of the baseline, participants produced, on average, about 80 tables per period of 10 minutes, which would imply, if performance was sustained at previous levels, a reward of $1.92 \varnothing$ in the last period of 10 minutes.

\footnotetext{
${ }^{8}$ Cahlikova et al., (2019) also show that inducing stress exogenously lowers a worker's propensity to enter in a tournament competition. We could account for this finding if we consider that the status-quo (or default) decision is to choose piece-rate compensation. Stressed workers who are endowed with limited cognitive flexibility might then be unable to consider the alternative compensation scheme (tournament incentives).
} 


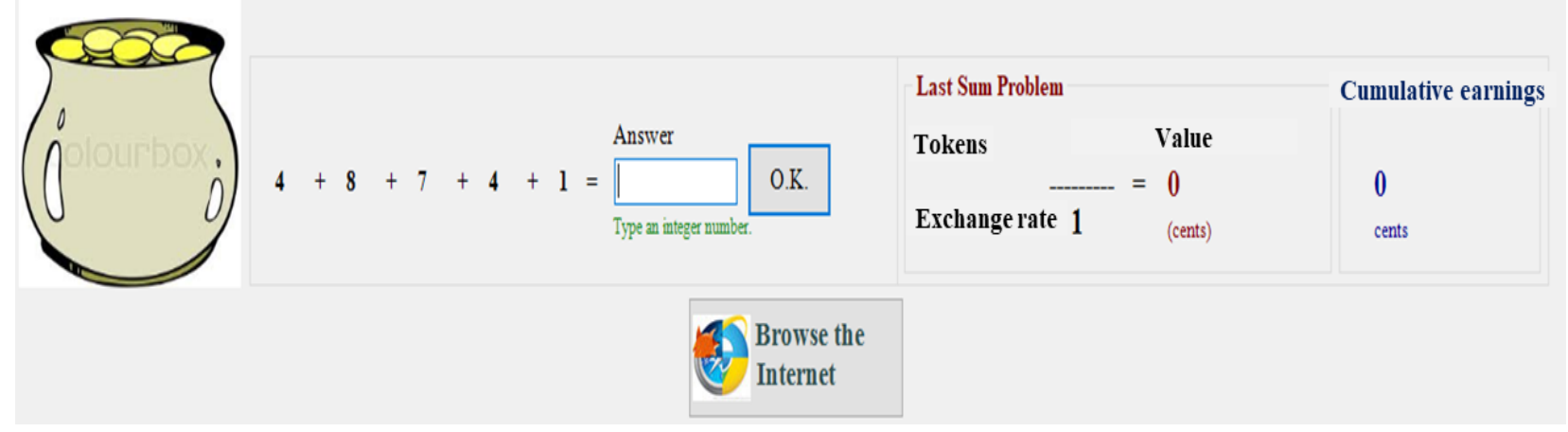

FIGURE 1. Task screen.

In the stochastic treatment, the number of tokens received by participants for each correct summation followed a random pattern. The token value was an integer number between 1 and 23 with equal probability. The token value was drawn after each correct summation, and participants knew the stochastic process generating the token value. Similar to the baseline, the reward was divided by an exchange rate equal to 2, 4, 8, 80, and 500 in the last five periods of the experiment. The two treatments entailed the same expected value for the rewards thus only differing on the dispersion of rewards.

We considered additional stochastic treatments that only varied in the probability distribution used to generate the token value. The expected value of the token and the exchange rates across periods were the same (see Table 1). In particular, we conducted treatments with a lower level of entropy than the main stochastic treatment to assess the extent to which the level of entropy of a random reward distribution could explain work persistence (see Hypothesis 1). These additional treatments involved stochastic rewards that are characterized by a low level of entropy because they can only take two possible values (see Table 1). At the same time, these reward distributions had a higher variance than the main stochastic treatment, except for the 'Uncertain $(13,90 \%$; 0$)$ ' treatment. 
TABLE 1. Description of treatments

\begin{tabular}{|c|c|c|c|c|c|}
\hline Treatment & $\begin{array}{c}\text { Token value distri- } \\
\text { bution }\end{array}$ & $\begin{array}{l}\text { Shannon } \\
\text { Entropy }^{\text {a }}\end{array}$ & Variance & $\begin{array}{c}\text { Loss } \\
\text { Domain } \\
\end{array}$ & $\begin{array}{c}\text { Number } \\
\text { participants }\end{array}$ \\
\hline Deterministic & 12 & 0 & 0 & No & $\begin{array}{l}62 \text { (Study 1), } \\
91 \text { (Study 2) }\end{array}$ \\
\hline Stochastic & $\mathrm{U}\{1,23\}$ & 4.5 & 44 & No & $\begin{array}{l}51 \text { (Study 1), } \\
90(\text { Study } 2)\end{array}$ \\
\hline $\begin{array}{c}\text { Stochastic } \\
(1,50 \% ; 23)\end{array}$ & $\{1,50 \% ; 23,50 \%\}$ & 1 & 121 & No & 60 (Study 2) \\
\hline $\begin{array}{l}\text { Stochastic } \\
(5,90 \% ; 75)\end{array}$ & $\{5,90 \% ; 75,10 \%\}$ & 0.5 & 441 & No & 59 (Study 2) \\
\hline $\begin{array}{c}\text { Stochastic } \\
(13,90 \% ; 0)\end{array}$ & $\{13,90 \% ; 0,10 \%\}$ & 0.5 & 15.21 & No & 60 (Study 2) \\
\hline $\begin{array}{c}\text { Stochastic } \\
(-51,10 \% ; 19)\end{array}$ & $\{-51,10 \% ; 19,90 \%\}$ & 0.5 & 441 & Yes & 53 (Study 2) \\
\hline $\begin{array}{c}\text { Stochastic } \\
(-23,50 \% ; 47)\end{array}$ & $\{-23,50 \% ; 47,50 \%\}$ & 1 & 1,225 & Yes & 54 (Study 2) \\
\hline $\begin{array}{c}\text { Stochastic } \\
(-1,90 \% ; 129)\end{array}$ & $\{-1,90 \% ; 129,10 \%\}$ & 0.5 & 1,521 & Yes & 59 (Study 2) \\
\hline
\end{tabular}

${ }^{a}$ Note that the observed error rate of $10 \%$ on the summation task (no significant differences across treatments), will result in higher than reported entropy levels. However, this increment will be less pronounced for the 'Uncertain (13, $90 \%$; 0)' treatment because a zero reward, in that case, could be due to either bad luck or a mistake.

We also conducted treatments involving losses to increase the variance of rewards further while keeping entropy at a low level and maintaining the same expected value of rewards. We do not speculate on the potential effect of losses on work persistence because the neuroscience literature reviewed above does not offer any insight regarding the effect of losses. Any significant results associated with loss treatments would thus be surprising. ${ }^{9}$

The two-outcome stochastic treatments will help us test whether the entropy of stochastic rewards is indeed the key driver of the positive effect of stochastic rewards on work persistence. These stochastic treatments will also help us test whether any effect of stochastic rewards can solely be ascribed to their entropy or whether it can also be explained by their variance. Variance might play a role if we believe participants' willingness to gamble on low-probability events generating large monetary prizes (see Barberis, 2012; Kahneman \& Tversky, 1979) can help explain

\footnotetext{
${ }^{9}$ Taking into account participants' loss aversion would not help predict lower work persistence in loss treatments, because we assess work persistence when monetary payoffs have become negligible. Any cost associated to losses must then be of a non-monetary nature.
} 
work persistence in our setup. One issue for the taste-for-gambling argument is to explain the positive effect of stochastic rewards on work persistence after monetary payoffs have become negligible. One would then have to posit that there exists a taste for inconsequential gambling, which we are not aware of in the literature.

\subsection{Procedure}

We conducted two studies. The first one took place at a major US lab. We recruited a total of 113 participants, 62 of which were assigned to the baseline and 51 were assigned to the stochastic treatment. These participants also took part in an extensive survey which was conducted at the beginning of the academic year and for which all the participants registered in the laboratory database $(n=1,963)$ were invited. ${ }^{10}$ This survey includes a large number of individual characteristics such as fluid intelligence (Raven, 1936), verbal reasoning skills (Wonderlic, 1992), social intelligence (Baron-Cohen et al., 1997; Baron-Cohen et al., 2001), students' score in the Scholastic Aptitude Test (SAT), cognitive reflection (Frederick, 2005), risk attitudes (Holt \& Laury, 2002), time preferences (Laibson, 1997) ${ }^{11}$, loss aversion (Mrkva et al., 2019), summation skills (see Corgnet et al., 2015e), and distributional social preferences (Bartling et al., 2009; Corgnet et al., 2015a). Finally, participants spent the last five minutes of the experiment answering survey questions assessing how tense and nervous they felt as well as how motivated they were to complete the task. These questions were taken from the validated work climate questionnaire developed by the proponents of the self-determination theory of motivation (e.g., Deci \& Ryan, 2000) (see Appendix A). ${ }^{12}$ Our aim was to assess the effect of uncertain rewards on workers' stress levels and on their intrinsic motivation to complete the task. We also measured workers' satisfaction by assessing their self-reported affective reaction to completing the task using the emotional valence dimension of the self-assessment manikin (SAM) developed by Bradley \& Lang (1994) (see Appendix A). This short questionnaire was completed right before and after the work task. Participants earned an average of $\$ 24.8$, including a $\$ 7$ show-up fee for an experiment lasting one hour and fifteen minutes.

\footnotetext{
${ }^{10}$ Two participants in our study did not complete the survey.

${ }^{11}$ We elicit participants' time preferences with a hypothetical payoffs task comparing payoffs today (in one month) with payoffs in one month (in seven months). This task allows us to estimate the parameters beta (present bias) and delta (exponential discount) of a quasi-hyperbolic specification of discounting.

${ }^{12}$ These survey questions are available at: http://www.selfdeterminationtheory.org.
} 
In the second study, we recruited a total of 526 students at a major Spanish lab. Participants were randomly assigned to one of the treatments described in Table 1 . They earned an average of $€ 20.5$, including a $€ 5$ show-up fee for an experiment lasting 90 minutes. The experiment was slightly longer than in Study 1 because the lab in which the study was conducted had not implemented a beginning-of-the-year survey for participants registered in the pool. We thus assessed participants' abilities on the task at the beginning of the experiment and collected additional information at the end of the experiment. ${ }^{13}$ As in Study 1, we collected the self-determination theory scales on tension and intrinsic motivation as well as the cognitive reflection test. We also collected the SAM at the beginning and at the end of the work task. Finally, we implemented a validated survey on work/studying addiction (Bergen Work Addiction Scale; Andreassen et al., 2012).

In Appendix E2, we discuss related experimental designs.

\section{Results}

We start by testing our first two hypotheses comparing the two main treatments (deterministic and stochastic) which were conducted in both studies.

\subsection{Work persistence}

We first assess the percentage of participants who decided to quit at different times during the 60-minute experiment. In Figure 2, we show the proportion of people who had quit the task before a certain number of minutes had elapsed for both studies. In line with Hypothesis 1, workers are more likely to quit the work task in the deterministic treatment than in the stochastic treatment whenever monetary rewards are muted. Very few people quit in the first 30 minutes $(1.96 \%$ and $1.42 \%$ in the deterministic and stochastic treatments, respectively); at minute $45,16.34 \%$ of the subjects had quit in the deterministic treatment and $7.09 \%$ in the stochastic treatment.

${ }^{13}$ The ability task was the same as the one used in the survey conducted at the beginning of the year in Study 1. 


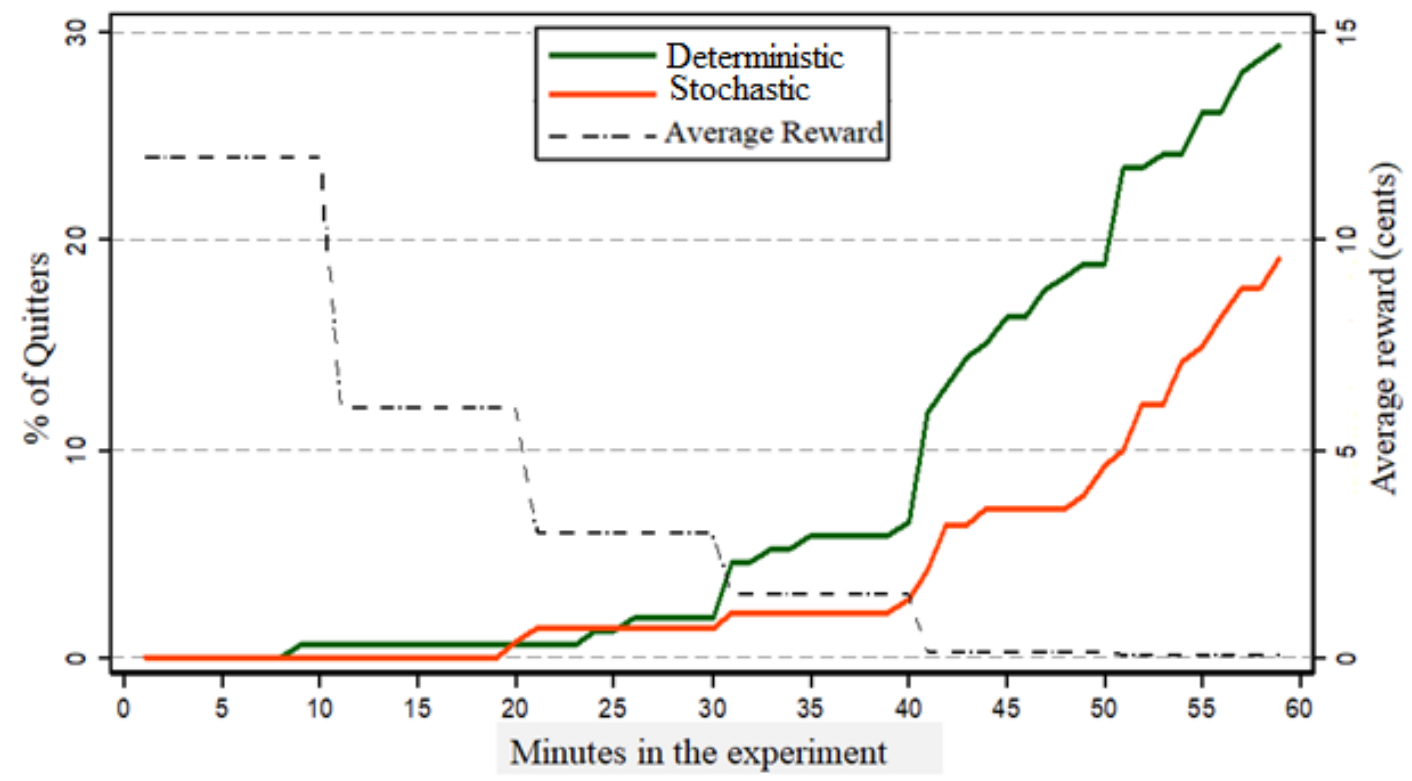

FIGURE 2. Percentage of participants who had quit the task (quitters, left axis) after a given number of minutes had elapsed in the experiment across the two main treatments in both studies. The average reward is represented in the right axis.

Regardless of the lab, quitting rates appear to be relatively low because a large majority of participants are still completing the task despite monetary incentives being essentially muted from period 5 (minute 40) onwards. ${ }^{14}$ A priori, the low quitting rates in the deterministic treatment would seem to make it more difficult for us to spot a negative effect of stochastic rewards on quitting. Nonetheless, Table 2 reports a negative and significant effect of stochastic rewards on the likelihood of quitting the task, whether we assess quitting at minute 45, 50 or 55 . This is the case because the stochastic treatment dummy, which takes value one if a participant was assigned to the stochastic treatment and value zero otherwise, is negative and significant across the three regressions. Marginal effects indicate that being assigned to the stochastic treatment decreases one's probability of quitting by about $10 \%$, whether quitting is assessed at minute 45,50 , or 55 . $^{15}$

\footnotetext{
${ }^{14}$ One possible explanation could be that the tokens used to translate performance on the task into money was not decreased in the course of the experiment (see Hsee et al., 2003). However, in contrast with Hsee et al., (2003), the monetary equivalent of the number of tokens was very salient and continuously displayed on the screen (see Figure 2).

${ }^{15}$ We do not find significant differences in the percentage of quitters before period 4 (see Table B1 in Appendix B). In Study 1, 8.1\% (8.1\%) quitted before minute 35 (40) in the baseline compared with 5.9\% (5.9\%) in the stochastic treatment. In Study 2, only 3.3\% (4.4\%) quitted before minute 35 (40) in the baseline whereas no participant quitted before minute 40 in the stochastic treatment.
} 
TABLE $2^{\mathrm{a}}$

Probit regression for probability of quitting at different time intervals for both studies

\begin{tabular}{|c|c|c|c|}
\hline Studies $1 \& 2$ & $t<45$, & $\mathrm{t}<50^{\prime}$ & $t<55^{\prime}$ \\
\hline Constant & $\begin{array}{c}-1.089^{* * * *} \\
(0.387)\end{array}$ & $\begin{array}{c}-1.129 * * * \\
(0.354)\end{array}$ & $\begin{array}{c}-1.360 * * * \\
(0.313)\end{array}$ \\
\hline $\begin{array}{l}\text { Stochastic } \\
\text { Treatment Dummy }\end{array}$ & $\begin{array}{c}-\mathbf{0 . 4 7 9} * * \\
(\mathbf{0 . 2 4 4 )} \\
{[-\mathbf{0 . 0 7 0} * *]}\end{array}$ & $\begin{array}{c}-\mathbf{0 . 5 9 8} * * * \\
(0.229) \\
{[-0.101 * * *]}\end{array}$ & $\begin{array}{c}-\mathbf{0 . 3 5 7 *} \\
(\mathbf{0 . 1 9 3 )} \\
{[-\mathbf{0 . 0 7 9 *}]}\end{array}$ \\
\hline Summation Skills & $\begin{array}{c}-0.090 * * * \\
(0.028) \\
{[-0.013 * * *]}\end{array}$ & $\begin{array}{c}-0.068 * * * \\
(0.025) \\
{[-0.011 * * *]}\end{array}$ & $\begin{array}{c}-0.031 \\
(0.021) \\
{[-0.007]}\end{array}$ \\
\hline Cognitive Reflection & $\begin{array}{c}0.169 * * \\
(0.072) \\
{[0.025 * *]}\end{array}$ & $\begin{array}{c}0.154 * * \\
(0.066) \\
{\left[0.026^{* *}\right]}\end{array}$ & $\begin{array}{c}0.129 * * \\
(0.058) \\
{[0.029 * *]}\end{array}$ \\
\hline Male Dummy & $\begin{array}{c}0.855^{* * *} \\
(0.246) \\
{[0.125 * * *}\end{array}$ & $\begin{array}{c}0.680 * * * \\
(0.224) \\
{[0.114 * * *]}\end{array}$ & $\begin{array}{c}0.679 * * * \\
(0.189) \\
{[0.150 * * *]}\end{array}$ \\
\hline Study 1 Dummy & $\begin{array}{c}0.934 * * * \\
(0.245) \\
{\left[0.136^{* * *}\right]}\end{array}$ & $\begin{array}{c}1.038^{* * *} \\
(0.222) \\
{[0.174 * *]}\end{array}$ & $\begin{array}{c}0.981 * * * \\
(0.194) \\
{[0.217 * * *]}\end{array}$ \\
\hline $\mathrm{N}^{\mathrm{b}}$ & 292 & 292 & 292 \\
\hline $\mathrm{R}^{2}$ & 0.237 & 0.229 & 0.189 \\
\hline$\chi^{2}$ & $34.293 * * *$ & $42.928 * * *$ & $44.713 * * *$ \\
\hline
\end{tabular}

${ }^{\mathrm{a}}$ Robust standard errors are in parentheses and marginal effects in square brackets.

b The number of observations is 292 (instead of 294) because two participants did not complete the beginning-of-the-year survey in Study 1, so we do not have data on their summation skills or cognitive reflection.

*** Significant at the 0.01 level; ** at the 0.05 level; * at the 0.1 level.

We find a similar effect using proportional hazards models (see Table B2 in Appendix B). The results also hold when analyzing each study separately although statistical significance is decreased (see Table 3). All these findings support Hypothesis 1.

In Tables 2 and 3, we also report individual differences in work persistence (see more in Section 5.4) as workers who score high on cognitive reflection and low on summation skills were most likely to stop working on the task after monetary incentives had become negligible. Workers who possess high summation skills tend to have a lower cost of effort which would make the work task more appealing compared to the leisure alternative. Because workers who possess high cognitive reflection possess more attentional resources (e.g., Hasher et al., 2007; Toplak et al., 2011), they 
tend to react more quickly to the decrease in the exchange rate thus quitting the task earlier than other workers. ${ }^{16}$ This finding supports Hypothesis 2.

TABLE $3^{\text {a }}$

Probit regression for probability of quitting at different time intervals.

\begin{tabular}{|c|c|c|c|c|c|c|}
\hline & \multicolumn{3}{|c|}{ Study 1} & \multicolumn{3}{|c|}{ Study 2} \\
\hline & $\mathrm{t}<45^{\prime}$ & $\mathrm{t}<50^{\prime}$ & $\mathrm{t}<55^{\prime}$ & $\mathrm{t}<45$ & $\mathrm{t}<50$ & $\mathrm{t}<55$ \\
\hline Constant & $\begin{array}{l}-0.211 \\
(0.489)\end{array}$ & $\begin{array}{l}-0.084 \\
(0.444)\end{array}$ & $\begin{array}{l}-0.016 \\
(0.410)\end{array}$ & $\begin{array}{l}-0.951 * \\
(0.552)\end{array}$ & $\begin{array}{c}-1.142 * * \\
(0.508)\end{array}$ & $\begin{array}{c}-1.845^{* * * *} \\
(0.483)\end{array}$ \\
\hline $\begin{array}{l}\text { Stochastic } \\
\text { Treatment Dummy }\end{array}$ & $\begin{array}{c}-0.344 \\
(0.324) \\
{[-0.080]}\end{array}$ & $\begin{array}{c}-0.511 * \\
(0.294) \\
{[-0.145 *]}\end{array}$ & $\begin{array}{c}-\mathbf{0 . 4 8 7} * \\
(0.265) \\
{[-0.162 *]}\end{array}$ & $\begin{array}{c}-\mathbf{0 . 6 8 6} * \\
(0.398) \\
{\left[-0.060^{*}\right]}\end{array}$ & $\begin{array}{c}-0.748 * \\
(0.388) \\
{[-0.072 *]}\end{array}$ & $\begin{array}{c}-0.227 \\
(0.286) \\
{[-0.034]}\end{array}$ \\
\hline Summation Skills & $\begin{array}{c}-0.095 * * \\
(0.038) \\
{[-0.022 * * *]}\end{array}$ & $\begin{array}{c}-0.072 * * \\
(0.033) \\
{[-0.020 * * *]}\end{array}$ & $\begin{array}{c}-0.047 \\
(0.029) \\
{\left[-0.016^{*}\right]}\end{array}$ & $\begin{array}{c}-0.089^{*} \\
(0.046) \\
{[-0.008 *]}\end{array}$ & $\begin{array}{c}-0.065 * \\
(0.039) \\
{[-0.006]}\end{array}$ & $\begin{array}{c}-0.014 \\
(0.029) \\
{[-0.002]}\end{array}$ \\
\hline Cognitive Reflection & $\begin{array}{c}0.150 * \\
(0.090) \\
{\left[0.035^{*}\right]}\end{array}$ & $\begin{array}{c}0.148 * \\
(0.082) \\
{[0.042 *]}\end{array}$ & $\begin{array}{c}0.104 \\
(0.074) \\
{[0.035]}\end{array}$ & $\begin{array}{c}0.223 * * \\
(0.113) \\
{[0.020 *]}\end{array}$ & $\begin{array}{c}0.181 * \\
(0.101) \\
{[0.017 *]}\end{array}$ & $\begin{array}{c}0.203 * * \\
(0.094) \\
{[0.030 * *]}\end{array}$ \\
\hline Male Dummy & $\begin{array}{c}1.108 * * * \\
(0.327) \\
{[0.258 * * *]}\end{array}$ & $\begin{array}{c}0.734 * * \\
(0.297) \\
{[0.208 * * *]}\end{array}$ & $\begin{array}{c}0.664 * * \\
(0.272) \\
{[0.222 * * *]}\end{array}$ & $\begin{array}{c}0.511 \\
(0.359) \\
{[0.045]}\end{array}$ & $\begin{array}{c}0.606 * \\
(0.348) \\
{[0.058 *]}\end{array}$ & $\begin{array}{c}0.683 * * \\
(0.282) \\
{[0.101 * *]}\end{array}$ \\
\hline $\begin{array}{l}\mathrm{N}^{\mathrm{b}} \\
\mathrm{R}^{2} \\
\text { Prob }>\chi^{2}\end{array}$ & $\begin{array}{c}111 \\
0.189 \\
17.503 * * *\end{array}$ & $\begin{array}{c}111 \\
0.132 \\
13.230 * *\end{array}$ & $\begin{array}{c}111 \\
0.097 \\
13.144 * *\end{array}$ & $\begin{array}{c}181 \\
0.160 \\
8.225^{*}\end{array}$ & $\begin{array}{c}181 \\
0.148 \\
8.582 *\end{array}$ & $\begin{array}{c}181 \\
0.124 \\
9.591 * *\end{array}$ \\
\hline
\end{tabular}

${ }^{a}$ Robust standard errors are in parentheses and marginal effects in square brackets.

${ }^{\mathrm{b}}$ For Study 1, the number of observations is 111 -instead of 113- because two participants did not complete the survey, so we do not have data on their summation skills or cognitive reflection.

$* * *$ Significant at the 0.01 level; ** at the 0.05 level; * at the 0.1 level.

In Appendix B, we show the robustness of our results to including additional controls for Study 1 , which is the study for which we have additional individual information (see Table B3). This analysis shows, for example, that risk and loss attitudes do not affect workers' quitting decisions in line with the argument that our work task does not involve risk or loss considerations. This is the case because, by the time monetary rewards become negligible at the end of Period 4, workers had completed an average of 320 summations, thus making the risk associated with random rewards practically absent. ${ }^{17}$ Even if random rewards had induced some level of risk, it would still

\footnotetext{
16 The fact that reflective workers produce less in our setting, as they stop working earlier, is particularly noteworthy given that cognitive reflection has been commonly associated with diligence on the job and high performance levels (e.g. Burks et al., 2015; Corgnet et al., 2015c).

${ }^{17}$ If participants in the stochastic treatment had received 12 tokens for each correct sum, as in the baseline treatment, the difference with the number of tokens they actually obtained would have been negligible, $\mathrm{CI}(95 \%)=(-0.5 \%, 1.4 \%)$ for Study 1 and CI $(95 \%)=(-1.0 \%, 0.6 \%)$ for Study 2 .
} 
not be straightforward to explain how stochastic rewards could affect workers' decision to quit the task when monetary incentives are absent unless we consider the unlikely scenario in which people react to inconsequential risk. In Appendix B, we also show that workers' quitting decisions are not affected by time preferences, distributional social preferences or other cognitive skills. ${ }^{18}$

Our findings thus support Hypothesis 1, although the two studies differed in the magnitude of quitting rates. Participants in Study 1 were more likely to quit the work task compared to Study 2 participants. These differences are likely to echo lab idiosyncrasies which have been observed in a previous real-effort task experiment (see Brandts et al., 2017) in which participants at the Study 2 lab were shown to be less likely to browse the internet when given the option to do so than in a similar experiment conducted at the Study 1 lab. This is likely to be explained, beyond participants' differences, by the fact that Study 1 lab is one in which a large number of studies give participants the option to browse the internet instead of completing the main experimental task thus largely attenuating the commonly-observed active participation in real-effort experiments (see Corgnet et al., 2015e). ${ }^{19}$ More generally, differences in levels of quitting rates across studies put forth the heterogeneity in people's reactions to stochastic rewards (see also Section 5.4).

The fact that workers stayed longer on the task in the stochastic treatment mechanically implied that average production on the task was higher in the stochastic treatment than in the deterministic treatment when monetary incentives became negligible (see Figure B1 and Table B4 in Appendix B). ${ }^{20}$ The reason why the reduced quitting rate in the stochastic treatment mechanically engendered an increase in production compared to the deterministic treatment was that productivity levels, as measured by the number of correct summations completed per time spent on the task, did not substantially vary across treatments (see Table B6 in Appendix B).

In the next section, we go beyond the comparison of the stochastic and deterministic treatments to assess the extent to which varying the level of entropy of the random reward distribution can explain work persistence. To that end, we make use of the six additional treatments which were conducted in Study 2. All these treatments have the same expected value for the reward (12 tokens)

\footnotetext{
${ }^{18}$ We estimate participants' level of behindness and aheadness aversion using the task proposed by Bartling et al., (2009).

${ }^{19}$ In addition, screen resolution was substantially lower in the Spanish lab, thus possibly reducing the enjoyment of browsing the internet.

${ }^{20}$ In Table B5, we show the robustness of our results to including additional controls.
} 
as our two original treatments. These stochastic treatments are characterized by a low level of entropy because rewards could only take two possible values (see Table 1).

\subsection{Entropy and work behavior}

In Figure 3, we show that work persistence increases with the level of entropy. We define as 'average entropy' all the stochastic treatments in which a reward can only take two possible values except for treatment $(13,90 \% ; 0)$. We assign the treatment $(13,90 \%$; 0$)$ to the 'low-entropy' category along with the deterministic treatment because mistakes (which produce a zero reward) reduce the level of entropy of this treatment compared with the other two-outcome treatments. ${ }^{21}$ 'High entropy' corresponds to the original stochastic treatment in which rewards could take any of 23 possible integer values (see Table 1). In line with Hypothesis 1, work persistence increased when the entropy of the random rewards was higher. At minute 45 in Study 2,9.93\% of the subjects in the low entropy treatments had quit, $5.61 \%$ in the average entropy treatments, and only $2.22 \%$ in the high entropy treatments. Of particular interest is the fact that 'average entropy' treatments which are characterized by a high variance of rewards led to less work persistence than the 'high entropy' treatment which is characterized by a lower variance of rewards. This implies that entropy rather than variance is the main driver of the positive effect of stochastic rewards on work persistence.

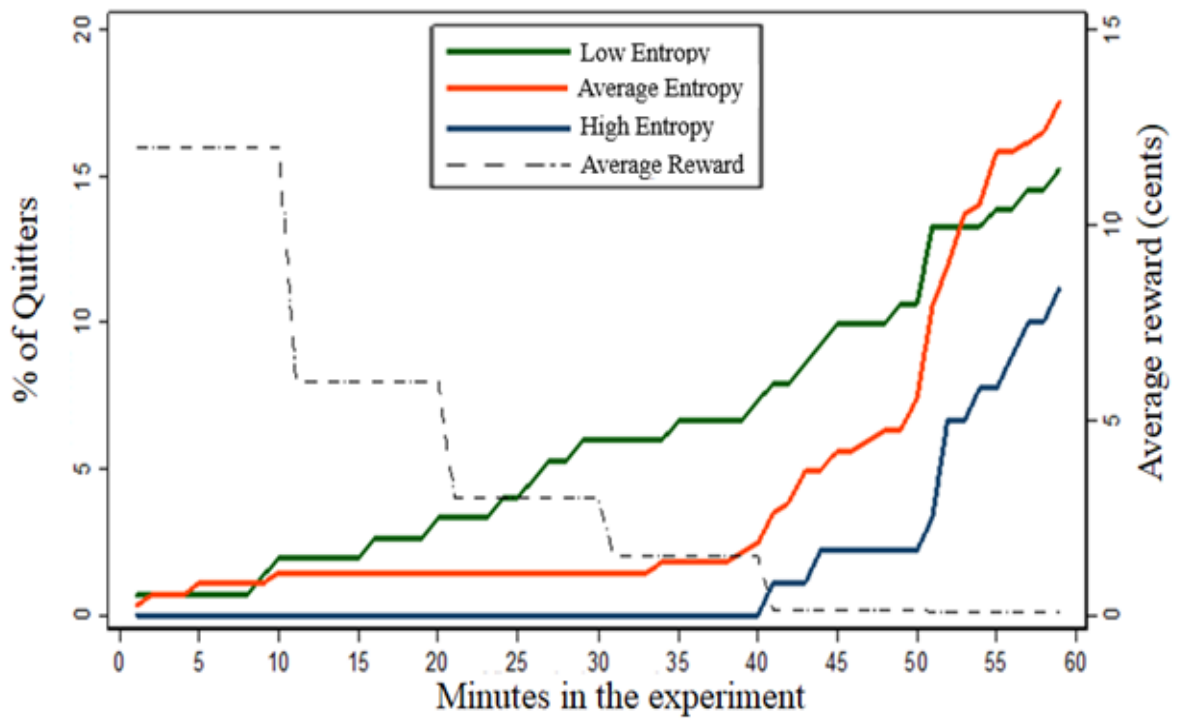

FIGURE 3. Percentage of participants (Study 2) who had quit the task (quitters, left axis) after a given number of minutes had elapsed in the experiment. The average reward is represented in the right axis.

${ }^{21}$ Our results are robust to including the treatment $(13,90 \% ; 0)$ in the 'average entropy' category. 
Our regression analysis in Table 4 confirms the positive effect of the entropy of stochastic rewards on work persistence, whereas the variance of rewards and the presence of losses did not significantly affect work persistence.

TABLE $4^{\mathrm{a}}$

Probit regression for probability of quitting at different time intervals

\begin{tabular}{|c|c|c|c|c|c|c|}
\hline & \multicolumn{3}{|c|}{ Studies $1 \& 2$} & \multicolumn{3}{|c|}{ Study 2} \\
\hline & $\mathrm{t}<45^{\prime}$ & $\mathrm{t}<50^{\prime}$ & $\mathrm{t}<55^{\prime}$ & $\mathrm{t}<45^{\prime}$ & $\mathrm{t}<50^{\prime}$ & $\mathrm{t}<55^{\prime}$ \\
\hline Constant & $\begin{array}{c}-1.816^{* * * *} \\
(0.273)\end{array}$ & $\begin{array}{c}-1.840^{* * * *} \\
(0.256)\end{array}$ & $\begin{array}{c}-1.642 * * * \\
(0.220)\end{array}$ & $\begin{array}{c}-1.982 * * * \\
(0.304)\end{array}$ & $\begin{array}{c}-2.090 * * * \\
(0.298)\end{array}$ & $\begin{array}{c}-1.846^{* * *} \\
(0.251)\end{array}$ \\
\hline $\begin{array}{l}\text { Entropy } \\
\text { (standardized) }\end{array}$ & $\begin{array}{c}-\mathbf{0 . 1 5 8} * * \\
(\mathbf{0 . 0 7 2}) \\
{[-0.021 * *]}\end{array}$ & $\begin{array}{c}-0.194 * * * \\
(0.069) \\
{[-0.029 * * *]}\end{array}$ & $\begin{array}{c}-\mathbf{0 . 1 2 0} * * \\
(0.061) \\
{[-0.026 * *]}\end{array}$ & $\begin{array}{c}-0.213 * * \\
(0.109) \\
{[-0.023 *]}\end{array}$ & $\begin{array}{c}-\mathbf{0 . 2 2 9} * * \\
(\mathbf{0 . 1 0 2}) \\
{[-\mathbf{0 . 0 2 8} * *]}\end{array}$ & $\begin{array}{c}-0.087 \\
(0.080) \\
{[-0.016]}\end{array}$ \\
\hline $\begin{array}{l}\text { Variance } \\
\text { (standardized) }\end{array}$ & $\begin{array}{c}-0.108 \\
(0.162) \\
{[-0.014]}\end{array}$ & $\begin{array}{c}-0.041 \\
(0.155) \\
{[-0.006]}\end{array}$ & $\begin{array}{c}0.134 \\
(0.131) \\
{[0.029]}\end{array}$ & $\begin{array}{l}-0.085 \\
(0.158) \\
{[-0.009]}\end{array}$ & $\begin{array}{c}-0.033 \\
(0.156) \\
{[-0.004]}\end{array}$ & $\begin{array}{c}0.142 \\
(0.135) \\
{[0.026]}\end{array}$ \\
\hline Loss Dummy & $\begin{array}{c}0.219 \\
(0.310) \\
{[0.029]}\end{array}$ & $\begin{array}{c}0.025 \\
(0.309) \\
{[0.004]}\end{array}$ & $\begin{array}{c}-0.050 \\
(0.277) \\
{[-0.011]}\end{array}$ & $\begin{array}{c}0.163 \\
(0.300) \\
{[0.018]}\end{array}$ & $\begin{array}{c}0.001 \\
(0.306) \\
{[0.000]}\end{array}$ & $\begin{array}{c}-0.055 \\
(0.284) \\
{[-0.010]}\end{array}$ \\
\hline $\begin{array}{l}\text { Summation } \\
\text { Skills }\end{array}$ & $\begin{array}{c}-0.034 * * \\
(0.017) \\
{\left[-0.005^{* *}\right]}\end{array}$ & $\begin{array}{c}-0.023 \\
(0.015) \\
{[-0.004]}\end{array}$ & $\begin{array}{c}-0.011 \\
(0.013) \\
{[-0.002]}\end{array}$ & $\begin{array}{c}-0.015 \\
(0.018) \\
{[-0.002]}\end{array}$ & $\begin{array}{c}-0.008 \\
(0.017) \\
{[-0.001]}\end{array}$ & $\begin{array}{c}-0.002 \\
(0.014) \\
{[-0.000]}\end{array}$ \\
\hline $\begin{array}{l}\text { Cognitive } \\
\text { Reflection }\end{array}$ & $\begin{array}{c}0.112 * * \\
(0.049) \\
{[0.015 * *]}\end{array}$ & $\begin{array}{c}0.134 * * * \\
(0.047) \\
{[0.020 * * *]}\end{array}$ & $\begin{array}{c}0.114 * * * \\
(0.043) \\
{[0.024 * * *]}\end{array}$ & $\begin{array}{c}0.117^{*} \\
(0.060) \\
{[0.013 *]}\end{array}$ & $\begin{array}{c}0.156^{* * *} \\
(0.058) \\
{[0.019 * * *]}\end{array}$ & $\begin{array}{c}0.142 * * * \\
(0.053) \\
{[0.026 * * *]}\end{array}$ \\
\hline Male Dummy & $\begin{array}{c}0.658 * * * \\
(0.168) \\
{\left[0.088^{* * *}\right]}\end{array}$ & $\begin{array}{c}0.618 * * * \\
(0.155) \\
{[0.093 * * *]}\end{array}$ & $\begin{array}{c}0.754 * * * \\
(0.135) \\
{[0.160 * * *]}\end{array}$ & $\begin{array}{c}0.474 * * \\
(0.195) \\
{[0.051 * *]}\end{array}$ & $\begin{array}{c}0.561 * * * \\
(0.190) \\
{[0.068 * * *]}\end{array}$ & $\begin{array}{c}0.780 * * * \\
(0.162) \\
{[0.145 * * *]}\end{array}$ \\
\hline Study 1 Dummy & $\begin{array}{c}0.819 * * * \\
(0.191) \\
{[0.109 * * *]}\end{array}$ & $\begin{array}{c}0.901 * * * \\
(0.182) \\
{[0.136 * * *]}\end{array}$ & $\begin{array}{c}0.954 * * * \\
(0.168) \\
{[0.203 * * *]}\end{array}$ & & & \\
\hline $\mathrm{N}$ & 637 & 637 & 637 & 526 & 526 & 526 \\
\hline $\mathrm{R}^{2}$ & 0.143 & 0.160 & 0.147 & 0.065 & 0.093 & 0.115 \\
\hline$\chi^{2}$ & $41.680 * * *$ & $58.669 * * *$ & $71.357 * * *$ & $11.380^{*}$ & $18.513 * * *$ & $35.372 * * *$ \\
\hline
\end{tabular}

${ }^{a}$ Robust standard errors are in parentheses and marginal effects in square brackets.

*** Significant at the 0.01 level; ** at the 0.05 level; * at the 0.1 level.

In Appendix B, we report the results for work persistence using proportional hazards models (see Table B7). Given the positive effect of entropy on work persistence and its null effect on 
productivity (see Table B9), it is not surprising to find a positive effect of entropy on work production (see Table B8). These findings are in line with our first hypothesis.

\subsection{Entropy and stress}

We now test our third hypothesis regarding the effect of stochastic rewards on self-reported stress. We measure self-reported stress using the tension and nervousness scale of the validated self-determination questionnaire (see Deci et al., 1994; Deci \& Ryan, 2000; Ryan, 1982). This scale includes items such as 'I was anxious while working on this task' (see Appendix A). ${ }^{22}$ In Figure 4, we show tension scores across entropy levels. In line with Hypothesis 3, tension levels were higher for higher entropy levels.

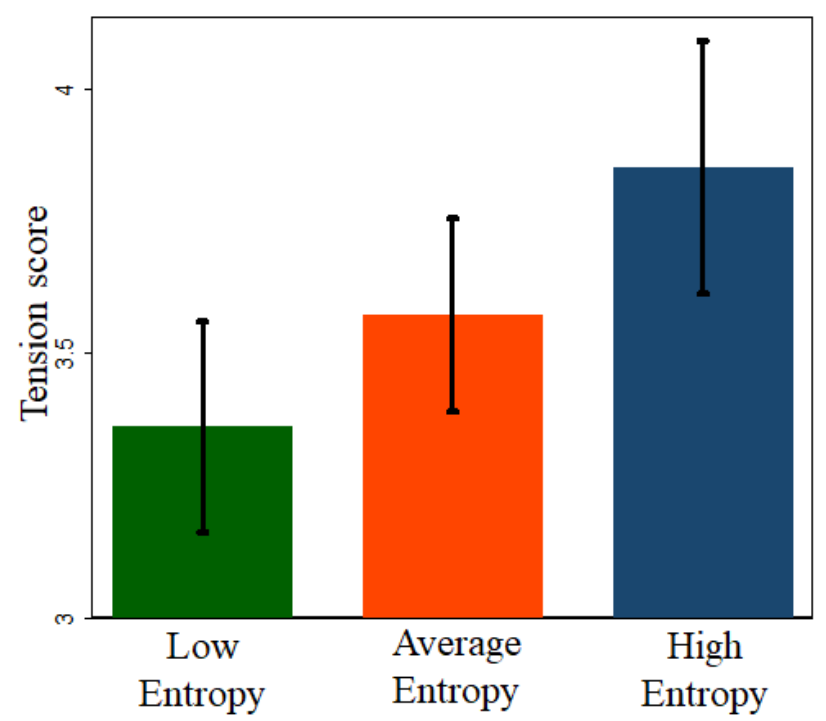

FIGURE 4. Average tension scores for treatments with zero, average, and high entropy treatments across the two studies. Error bars represent $95 \%$ confidence intervals.

In Table 5, we show that, in line with our third hypothesis, entropy levels tend to increase tension. This effect also holds when controlling for participants' initial emotional valence (measured at the beginning of the work task using the SAM) and the amount of time spent working on the task. ${ }^{23}$ Similar results are obtained when comparing the baseline with our original stochastic treatment (see Figure B2 and Table B10 in Appendix B). The negative effect of ability on stress is in

\footnotetext{
${ }^{22}$ The Cronbach alpha coefficient for the scale was 0.863 .

${ }^{23}$ Note that participants who quit the task earlier had more time to rest and browse the internet before completing the questionnaire on stress.
} 
line with the empirical evidence suggesting that low performers experience more stress from performance-contingent rewards compared to fixed wages (Williams and Livingstone, 1994; Ganster et al., 2011).

TABLE $5^{\mathrm{a}}$

Linear regressions for stress (standardized tension scale)

\begin{tabular}{|c|c|c|c|}
\hline Studies $1 \& 2$ & [1] & [2] & [3] \\
\hline Constant & $\begin{array}{c}0.460^{* * * *} \\
(0.126)\end{array}$ & $\begin{array}{l}-0.308 \\
(0.275)\end{array}$ & $\begin{array}{c}0.323 \\
(0.284)\end{array}$ \\
\hline $\begin{array}{l}\text { Entropy } \\
\text { (standardized) }\end{array}$ & $\begin{array}{c}0.112 * * * \\
(\mathbf{0 . 0 3 8})\end{array}$ & $\begin{array}{c}0.100 * * * \\
(\mathbf{0 . 0 3 9})\end{array}$ & $\begin{array}{c}0.103 * * * * \\
(0.038)\end{array}$ \\
\hline $\begin{array}{l}\text { Variance } \\
\text { (standardized) }\end{array}$ & $\begin{array}{l}-0.021 \\
(0.080)\end{array}$ & $\begin{array}{l}-0.020 \\
(0.079)\end{array}$ & $\begin{array}{l}-0.021 \\
(0.077)\end{array}$ \\
\hline Loss Dummy & $\begin{array}{c}0.013 \\
(0.183)\end{array}$ & $\begin{array}{c}0.015 \\
(0.180)\end{array}$ & $\begin{array}{l}0.013 \\
(0.175)\end{array}$ \\
\hline Summation Skills & $\begin{array}{c}-0.025^{* * *} \\
(0.008)\end{array}$ & $\begin{array}{c}-0.026^{* * * *} \\
(0.008)\end{array}$ & $\begin{array}{c}-0.023^{* * * *} \\
(0.008)\end{array}$ \\
\hline Cognitive Reflection & $\begin{array}{c}0.012 \\
(0.027)\end{array}$ & $\begin{array}{c}0.019 \\
(0.027)\end{array}$ & $\begin{array}{c}0.019 \\
(0.027)\end{array}$ \\
\hline Male Dummy & $\begin{array}{c}-0.271 * * * * \\
(0.084)\end{array}$ & $\begin{array}{c}-0.238 * * * * \\
(0.084)\end{array}$ & $\begin{array}{c}-0.259 * * * \\
(0.083)\end{array}$ \\
\hline Study 1 Dummy & $\begin{array}{l}-0.036 \\
(0.110)\end{array}$ & $\begin{array}{c}0.021 \\
(0.110)\end{array}$ & $\begin{array}{c}0.007 \\
(0.110)\end{array}$ \\
\hline Working Time on the task & & $\begin{array}{c}0.790 * * * \\
(0.249)\end{array}$ & $\begin{array}{c}0.795 * * * \\
(0.233)\end{array}$ \\
\hline $\begin{array}{l}\text { SAM Valence } \\
\text { (before the work task) }\end{array}$ & & & $\begin{array}{c}-0.104 * * * \\
(0.022)\end{array}$ \\
\hline $\mathrm{N}$ & 637 & 637 & 637 \\
\hline $\mathrm{R}^{2}$ & 0.056 & 0.068 & 0.098 \\
\hline$\chi^{2}$ & $5.330 * * *$ & $6.448 * * *$ & $9.780 * * *$ \\
\hline
\end{tabular}




\subsection{Individual differences}

\subsubsection{Gender}

In Appendix $\mathrm{C}$, we show that men tend to quit earlier than women. For example, pooling both studies, we find that $30.16 \%$ of male subjects in the deterministic treatment had quit at minute 45 , compared with only $6.67 \%$ of females (p-value $<0.001$ ) ${ }^{24}$ Interestingly, we find that men are more responsive than women to stochastic rewards. In the stochastic treatment, $8.77 \%$ of the males and $5.95 \%$ of females had quit at minute 45 (vs. $30.16 \%$ and $6.67 \%$ in the deterministic treatment). This may be explained by the evidence suggesting that men and women react differently to stress (Taylor et al., 2000; Shalev et al., 2009). Our results are in line with previous literature in psychology, showing that stress has a stronger negative effect on cognitive flexibility for men than for women (Shields et al., 2016). Males are thus more likely to respond to the presence of stochastic rewards and the associated increase in stress by continuing on the work task for no pay rather than contemplating the possibly welfare-enhancing strategy of browsing the web (see Figure $\mathrm{C} 1$ as well as Tables $\mathrm{C} 1$ and $\mathrm{C} 2$ in Appendix C).

Our findings suggest that the presence of reward uncertainty might explain gender differences in work behavior. In particular, men might be more likely to end up addicted to their jobs when rewards are highly variable, which is often the case of executive compensation (e.g., Abowd \& Kaplan, 1999; Bertrand \& Mullainathan, 2001). It could then be interesting to assess the extent to which uncertain rewards might account for some of the gender wage gap beyond potential differences in competitiveness across genders (e.g. Niederle \& Vesterlund, 2007).

\subsubsection{Work addicts}

If uncertain rewards are critical for triggering work addiction, we should observe that people who can be categorized as work addicts will be especially responsive to uncertain rewards. In Appendix D, we provide a separate analysis to assess how individual scores on the Bergen Work Addiction Scale (Andreassen et al., 2012) can explain the effect of stochastic rewards on work persistence. Our findings suggest that work addicts, identified as scoring above the median on the

\footnotetext{
${ }^{24}$ This p-value is calculated for the coefficient of the male dummy in a probit regression that uses the same specification as in Table C1. Part of the difference in quitting rates across gender can be attributed to higher cognitive reflection scores and tension scores in males. However, this gender difference remains significant even after controlling for these individual factors.
} 
work addiction scale, are more likely to respond to stochastic rewards than non-addicts. ${ }^{25}$ In particular, we show that work addicts are more likely than non-addicts to persist longer on the task when rewards are stochastic than when they are deterministic. This finding is consistent with previous results showing that addicts are particularly reliant on habit actions (see Voong et al., 2015).

\subsection{Alternative interpretations of our findings}

One could argue that entropic rewards increase participants' intrinsic motivation to complete the task, thus providing an alternative explanation for our findings. This argument is, however, unlikely to be valid in our context since entropy generates tension, which according to self-determination theory (e.g., Ryan, 1982), would hamper rather than enhance intrinsic motivation. To assess intrinsic motivation, we use the interest/enjoyment subscale of the Intrinsic Motivation Inventory (e.g., 'I enjoyed doing this task very much'). ${ }^{26}$ In Appendix B, we show that, if anything, entropy harms intrinsic motivation, as self-determination theory suggests (see Tables B11 and B12 in Appendix B). ${ }^{27}$

Standard incentive theory (e.g., Laffont \& Martimort, 2002) cannot account for our findings because it predicts work persistence to be the same across treatments after monetary payoffs become negligible. Besides, any explanation of our findings based on risk considerations is undermined by the fact that the stochastic treatments were designed to have a negligible effect on the variability of workers' income in the course of the experiment. Risk does not play a role in our setup because participants face a large number of reward draws in the course of the experiment so that the actual variance of cumulative monetary rewards in the stochastic treatment is practically equal to zero. Unsurprisingly, our analysis of work behavior shows that risk attitudes do not affect work persistence (see Table B3 in Appendix B).

Explanations for our results that are based on the motivating role of losses (see Sloof \& Van Praag, 2010; Corgnet \& Hernán-González, 2019) are also inconsistent with our findings. This is the case because loss treatments do not lead to lower quitting rates or higher production levels (see Table 4 as well as Tables B7 and B8 in Appendix B). Importantly, workers cannot cover up their losses in the last two periods of the experiments, which is when the great majority of workers make

\footnotetext{
${ }^{25}$ Our results would supposedly be even more pronounced when considering only people who can be clinically defined as work addicts. This would consist of less than $10 \%$ of our current sample (see Andreassen et al., 2014).

26 The Cronbach alpha coefficient is 0.918 for this scale.

${ }^{27}$ Note that neither entropy nor the stochastic treatment dummy have a direct effect on intrinsic motivation.
} 
their decision on whether to continue on the task or not, as rewards for completing the tasks become negligible. In line with this argument, our analysis of individual work behavior shows that loss attitudes do not affect work persistence (see Table B3 in Appendix B). ${ }^{28}$

Our findings cannot be explained by models of information avoidance, which would imply that stochastic rewards might motivate workers by either triggering optimistic beliefs (Brunnermeier \& Parker, 2005; Huck et al., 2018) or by alleviating self-control issues (Carrillo and Mariotti, 2000; Bénabou and Tirole, 2002). In our setup, self-control issues are absent because workers are actually reluctant to quit the job even after rewards have become negligible. Besides, holding optimistic beliefs regarding which of the possible rewards will be received in the stochastic treatments should not impact workers' quitting decisions because those decisions are typically made when monetary rewards are valueless.

Furthermore, any effect of stochastic rewards in our setup cannot be explained by the positive implications of contractual opacity on work performance (e.g., Bernheim \& Whinston, 1998; Jehiel, 2014; Ederer et al., 2018). This is the case because, in our setting, workers know the probability distribution of rewards in advance. In addition, our setup abstracts from strategic issues such as informational asymmetry and verifiability which are crucial features for models establishing a positive relationship between vague rewards and workers' effort (Bernheim \& Whinston, 1998; Jehiel, 2014; Ederer, et al., 2018).

Finally, our findings cannot be easily accounted for by workers' natural curiosity for uncovering the realizations of uncertain rewards (e.g., Golman \& Loewenstein, 2015a,b) or by people's inner drive to resolve uncertainty (Friston et al., 2013, 2015, 2017a,b) and entertainment utility for suspense and surprise (Ely et al., 2015). In contrast with our findings, these theories would predict that workers value the stochastic-reward environment more than the deterministic-reward environment. Instead, we find that the level of stress reduces the level of satisfaction of participants as measured by the emotional valence dimension of SAM at the end of the work task (see models [1] and [3] in Table B14 in Appendix B). In addition, we do not find a significant effect of entropy on satisfaction (see models [2] and [3] in Table B14 in Appendix B). ${ }^{29}$

\footnotetext{
${ }^{28}$ Recent field (Fryer et al., 2012; Hossain \& List, 2012; Levitt et al., 2016) and lab experiments (Luft, 1994; Hannan et al., 2005; Armantier \& Boly, 2015; Imas et al., 2017) have put forward the motivational power of loss frames.

${ }^{29}$ Similar results are obtained comparing the baseline with our main stochastic treatment (see Table B13 in Appendix B).
} 


\section{Discussion: stress, work addiction and uncertain rewards in the gig economy}

Our findings highlight that reward uncertainty is a fundamental behavioral mechanism to explain workers' persistence on the job. In line with incentive salience theory (e.g., Berridge, 2003; Anselme et al., 2013), uncertain rewards may lead workers to hold on a task despite the extinction of monetary incentives, thus showing signs of work addiction.

It follows that managers could induce workers to spend long hours by promoting chaotic work environments that would trigger high stress levels (e.g., Selye, 1956; Mason, 1959, 1968; McEwen \& Stellar, 1993; McEwen \& Wingfield, 2003; Peters \& McEwen, 2015). Because managers are likely to pursue efficiency gains and because workers are not necessarily aware of their addictive behavior, there is no reason to believe that stress-related health concerns will be prominent when designing work environments. It then seems important to recognize the need to design compensation schemes in which reward uncertainty and stress levels are under control. This statement echoes a more general concern regarding the possibly excessive use of behavioral techniques such as loss framing (Fryer et al., 2012, Hossain \& List, 2012; Armantier \& Boly, 2015; Imas et al., 2017) or goal setting (Locke \& Latham, 2002; Wu et al., 2008; Goerg \& Kube, 2012; Corgnet et al., 2015b; Markle et al., 2018) to incite people to work longer hours (Alter, 2017; Scheiber, 2017).

The need for keeping workers on the job is especially critical for companies in the 'gig economy' (Alter, 2017; Cook et al., 2018) that rely on an independent workforce rather than on employees ascribed to a predefined work schedule. It is thus not surprising that major ridesharing companies have experimented with goal setting and loss frames to retain drivers (Scheiber, 2017; Allon et al., 2018). Furthermore, they have started new reward programs, which provide a variety of surprise gifts ranging from roadside assistance to dental repairs for the most active drivers (Hawkins, 2018). These programs mimic the already-widespread surprise schemes used by major online retailers to retain customers by offering unexpected discounts (Eyal, 2014; Alter, 2017). Our research suggests that these reward programs, which add to the high level of variability in hourly wages inherent to jobs in the gig economy (Abraham et al., 2018; Broughton et al., 2018), might be successful in leading drivers to work longer hours. In sum, the inherent variability associated with daily earnings of gig workers puts them at a higher risk of becoming work addicts. Our experimental findings illustrate how difficult it might be for these workers to stop working even though, in principle, "any driver can stop work literally at the tap of a button" (Uber spokesman as reported by Scheiber, 2017). Our study might explain why these workers report experiencing 
stress as a result of frequent changes in the reward system (Huws et al., 2017). In the absence of a fixed work schedule, stressed workers might thus end up spending excessive hours on the job. Relatedly, Allon et al., (2018) have identified inertia in the work decisions of drivers of a ridehailing company who were more likely to continue driving when they had spent more hours on the job. The findings of Butschek et al., (2019) that gig workers in the fashion industry do not typically increase their supply of labor when the variability of pay is exogenously decreased might also be partly explained by the positive effect of pay variability on work persistence.

Because of the rise of flexible work schedules (Council of Economic Advisors, 2010; Manyika et al., 2015; Katz \& Krueger, 2016; Oyer, 2016; Gallup's survey, 2018; Kässi and Lehdonvirta, 2018), individual decisions of when to start or stop working are becoming increasingly complex (Henly \& Lambert, 2014). Our work highlights that uncertain rewards and the stress levels that they induce might render these work decisions even more challenging.

It might be tempting to rationalize working over-time on the basis of reputational concerns and signaling motives (Spence, 1973; Corgnet et al. 2015d). However, our study shows that overwork can occur even in the absence of strategic motives. Actually, the non-strategic motives for work addiction, related to stress and attentional costs, might be especially relevant in the case of gig workers whose independent work status might weaken reputational and signaling concerns toward their employer.

\section{Conclusion}

Business and economics scholars have repeatedly argued that rewarding effort in a clear and predictable manner would most effectively motivate workers (see Nadler \& Lawler, 2007). Despite such calls, many organizations do not seem to follow these recommendations and instead often implement highly uncertain reward policies. In this work, we imported ideas from the neuroscience of incentives to develop a new paradigm allowing us to conduct what is, to our knowledge, the first controlled study on the link between uncertainty and work addiction in humans. In particular, we showed that stochastic rewards lead people to work longer on the task when monetary rewards are absent compared to deterministic rewards. Our work also demonstrates that only very specific types of stochastic rewards, characterized by high levels of entropy, can trigger work addiction.

Our work also suggests that attentional costs might trigger work persistence, thus implying that cognitive training (see Jaeggi et al., 2011) and meditation techniques (e.g., Jha et al., 2007; Tang et al. 2007; MacLean et al., 2010) targeting attentional control might alleviate work addiction. 
Finally, a major motivation for our work was to build bridges across the cognitive sciences by providing an experimental paradigm that can be used across disciplines. For example, neuroscientists could use our setup to identify the neural correlates of work addiction, whereas organizational scientists could extend our setup to study work addiction in hierarchical structures. Even though our lab study provides sharp results, we see our work as a first step in the analysis of stochastic rewards and work addiction. Further studies should assess the robustness of our findings to more complex tasks and more convoluted organizational settings. 


\section{References}

Abeles, M. \& Lass, Y. 1975. Transmission of information by the axon: II. The channel capacity. Biological Cybernetics, 19(3):121-125.

Abowd, J. M., \& Kaplan, D. S. 1999. Executive compensation: six questions that need answering. Journal of Economic Perspectives, 13(4):145-168.

Abraham, K. G., Haltiwanger, J. C., Sandusky, K., \& Spletzer, J. R. 2018. Measuring the gig economy: Current knowledge and open issues (No. w24950). National Bureau of Economic Research.

Acar, W. \& Sankaran, K. 1999. The myth of the unique decomposability: specializing the herfindahl and entropy measures? Strategic Management Journal, 20(10):969-975.

Adams, C. D. 1982. Variations in the sensitivity of instrumental responding to reinforcer devaluation. The Quarterly Journal of Experimental Psychology, 34(2):77-98.

Adams, C. D. \& Dickinson, A. 1981. Instrumental responding following reinforcer devaluation. The Quarterly Journal of Experimental Psychology Section B, 33(2b):109-121.

Allon, G., Cohen, M., \& Sinchaisri, P. 2018. The impact of behavioral and economic drivers on gig economy workers. Available at SSRN 3274628.

Alter, A. 2017. Irresistible: The rise of addictive technology and the business of keeping us hooked. Penguin.

Andreassen, C. S., Griffiths, M. D., Hetland, J. R. N., \& Pallesen, S. T. L. E. 2012. Development of a work addiction scale. Scandinavian Journal of Psychology, 53(3):265-272.

Andreassen, C. S., Griffiths, M. D., Hetland, J., Kravina, L., Jensen, F., \& Pallesen, S. 2014. The prevalence of workaholism: A survey study in a nationally representative sample of Norwegian employees. PloS one, 9(8), e102446.

Anselme, P. 2015. Incentive salience attribution under reward uncertainty: A pavlovian model. Behavioural Processes, 111:6-18.

Anselme, P., Robinson, M. J. F., \& Berridge, K. C. 2013. Reward uncertainty enhances incentive salience attribution as sign-tracking. Behavioural Brain Research, 238:53-61.

Armantier, O. \& Boly, A. 2015. Framing of incentives and effort provision. International Economic Review, 56(3):917-938.

Back, S. E., Hartwell, K., DeSantis, S. M., Saladin, M., McRae-Clark, A. L., Price, K. L., MoranSanta Maria, M. M., Baker, N. L., Spratt, E., \& Kreek, M. J. 2010. Reactivity to laboratory stress provocation predicts relapse to cocaine. Drug and Alcohol Dependence, 106(1):21-27.

Balleine, B. \& Dickinson, A. 1991. Instrumental performance following reinforcer devaluation depends upon incentive learning. The Quarterly Journal of Experimental Psychology, 43(3):279-296.

Barberis, N. 2012. A model of casino gambling. Management Science, 58(1):35-51.

Baron-Cohen, S., Jolliffe, T., Mortimore, C., \& Robertson, M. 1997. Another advanced test of theory of mind: Evidence from very high functioning adults with autism or asperger syndrome. Journal of Child Psychology and Psychiatry, 38(7):813-822.

Baron-Cohen, S., Wheelwright, S., Hill, J., Raste, Y., \& Plumb, I. 2001. The "reading the mind in the eyes" test revised version: A study with normal adults, and adults with asperger syndrome or highfunctioning autism. Journal of Child Psychology and Psychiatry, 42(2):241-251. 
Bartling, B., Fehr, E., Marechal, M. A., \& Schunk, D. 2009. Egalitarianism and competitiveness. American Economic Review, 99(2):93-98.

Becker, G. S. \& Murphy, K. M. 1988. A theory of rational addiction. Journal of Political Economy, 96(4):675-700.

Benabou, R. \& Tirole, J. 2002. Self-confidence and personal motivation. The Quarterly Journal of Economics, 117(3):871-915.

Benhabib, J. \& Bisin, A. 2005. Modeling internal commitment mechanisms and self-control: A neuroeconomics approach to consumption-saving decisions. Games and Economic Behavior, 52(2):460-492.

Bereby-Meyer, Y. \& Roth, A. E. 2006. The speed of learning in noisy games: Partial reinforcement and the sustainability of cooperation. American Economic Review, 96(4):1029-1042.

Bernheim, B. D. \& Rangel, A. 2004. Addiction and cue-triggered decision processes. American Economic Review, 94(5):1558-1590.

Bernheim, B. D. \& Whinston, M. D. 1998. Incomplete contracts and strategic ambiguity. American Economic Review, (88):902-932.

Berridge, K. C. 2003. Irrational pursuits: Hyper-incentives from a visceral brain. In I. Brocas \& J. D. Carrillo (Eds.), The psychology of economic decisions: 17-40. Oxford: Oxford University Press.

Berridge, K. C. 2007. The debate over dopamine's role in reward: the case for incentive salience. Psychopharmacology, 191(3):391-431.

Berridge, K. C. \& Robinson, T. E. 1998. What is the role of dopamine in reward: hedonic impact, reward learning, or incentive salience? Brain Research Reviews, 28(3):309-369.

Berridge, K. C., \& Robinson, T. E. 2016. Liking, wanting, and the incentive-sensitization theory of addiction. American Psychologist, 71(8), 670.

Bertrand, M., \& Mullainathan, S. 2001. Are CEOs rewarded for luck? The ones without principals are. The Quarterly Journal of Economics, 116(3):901-932.

Boakes, R. A. 1977. Performance on learning to associate a stimulus with positive reinforcement. $\boldsymbol{O p}$ erant-Pavlovian interactions, 67:97.

Bolton, P. \& Dewatripont, M. 2004. Contract Theory. MIT press.

Bradley, M. M. \& Lang, P. J. 1994. Measuring emotion: The self-assessment manikin and the semantic differential. Journal of Behavior Therapy and Experimental Psychiatry, 25(1):49-59.

Brandts, J., Corgnet, B., Hernán-González, R., Ortiz, J. M., \& Sola, C. 2017. A 'threat' is a 'threat': Firing with minimal information for maximal performance. Unpublished manuscript.

Brocas, I. \& Carrillo, J. D. 2008. The brain as a hierarchical organization. American Economic Review, 98(4):1312-46.

Broughton, A., Gloster, R., Marvell, R., Green, M., Langley, J., \& Martin, A. 2018. The experiences of individuals in the gig economy. HM Government.

Brunnermeier, M. K. \& Parker J. A. 2005. Optimal expectations. American Economic Review, 95(4), 1092-1118. 
Buckert, M., Schwieren, C., Kudielka, B. M., \& Fiebach, C. J. 2017. How stressful are economic competitions in the lab? an investigation with physiological measures. Journal of Economic Psychology, 62:231-245.

Burks, S., Lewis, C., Kivi, P. A., Wiener, A., Anderson, J. E., Goette, L., DeYoung, C. G., \& Rustichini, A. 2015. Cognitive skills, personality, and economic preferences in collegiate success. Journal of Economic Behavior \& Organization, 115:30-44.

Buser, T., Dreber, A., \& Mollerstrom, J. 2017. The impact of stress on tournament entry. Experimental Economics, 20(2): 506-530.

Butschek, S., González Amor, R., Kampkötter, P., \& Sliwka, D. 2019. Paying gig workers - Evidence from a field experiment. IZA Discussion Papers 12667.

Caplin, A., Dean, M., \& Leahy, J. 2017. Rationally inattentive behavior: Characterizing and generalizing Shannon entropy (No. w23652). National Bureau of Economic Research.

Carrillo, J. D. \& Mariotti, T. 2000. Strategic ignorance as a self-disciplining device. The Review of Economic Studies, 67, 529-544.

Cahlikova, J., Cingl, L., \& Levely, I. 2019. How stress affects performance and competitiveness across gender. Management Science, in press. https://doi.org/10.1287/mnsc.2019.3400

Coates, J. M. \& Herbert, J. 2008. Endogenous steroids and financial risk taking on a London trading floor. Proceedings of the National Academy of Sciences, 105(16):6167-6172.

Collins, L., Young, D. B., Davies, K., \& Pearce, J. M. 1983. The influence of partial reinforcement on serial autoshaping with pigeons. The Quarterly Journal of Experimental Psychology, 35(4):275290.

Cook, C., Diamond, R., Hall, J., List, J. A., \& Oyer, P. 2018. The gender earnings gap in the gig economy: Evidence from over a million rideshare drivers. Working Paper National Bureau of Economic Research.

Corgnet, B., Espín, A. M., \& Hernán-González, R. 2015a. The cognitive basis of social behavior: cognitive reflection overrides antisocial but not always prosocial motives. Frontiers in Behavioral Neuroscience, 9.

Corgnet, B., Gómez-Miñambres, J., \& Hernán-Gonzalez, R. 2015b. Goal setting and monetary incentives: When large stakes are not enough. Management Science, 61(12):2926-2944.

Corgnet, B. \& Hernán-Gonzalez, R. 2019. Revisiting the tradeoff between risk and incentives: The shocking effect of random shocks. Management Science, 65(3):955-1453 .

Corgnet, B., Hernán-González, R., \& Mateo, R. 2015c. Cognitive reflection and the diligent worker: an experimental study of millennials. PloS One, 10(11):e0141243.

Corgnet, B., Hernán-González, R., \& Rassenti, S. 2015d. Firing threats and tenure in virtual organizations: incentives effects and impression management. Games and Economic Behavior 91:97-113.

Corgnet, B., Hernán-González, R., \& Schniter, E. 2015e. Why real leisure really matters: incentive effects on real effort in the laboratory. Experimental Economics, 18(2):1-18.

Council of Economic Advisors. 2010. Work-life balance and the economics of workplace flexibility. Working paper, Executive Office of the President. 
Davison, M. C. 1969. Preference for mixed-interval versus fixed-interval schedules 1. Journal of the Experimental Analysis of Behavior, 12(2):247-252.

Dean, M, Kibris, O. \& Masatlioglu, Y. 2017. Limited attention with status-quo bias. Journal of Economic Theory, 169:93-127.

De Berker, A. O., Rutledge, R. B., Mathys, C., Marshall, L., Cross, G. F., Dolan, R. J., \& Bestmann, S. 2016. Computations of uncertainty mediate acute stress responses in humans. Nature Communications, 7:10996.

Deci, E. L., Eghrari, H., Patrick, B. C., \& Leone, D. R. 1994. Facilitating internalization: The self-determination theory perspective. Journal of Personality, 62(1):119-142.

Deci, E. L. \& Ryan, R. M. 2000. The" what" and" why" of goal pursuits: Human needs and the selfdetermination of behavior. Psychological Inquiry, 11(4):227-268.

Diamond, A. 2013. Executive functions. Annual Review of Psychology, 64:135-168.

Dickinson, A. 1985. Actions and habits: the development of behavioural autonomy. Philosophical Transactions of the Royal Society B, Biological Sciences, 308(1135):67-78.

Dickinson, A. \& Balleine, B. 1994. Motivational control of goal-directed action. Animal Learning \& Behavior, 22(1):1-18.

Dickinson, A. \& Balleine, B. 2002. The role of learning in the operation of motivational systems. In H. Pashler \& R. Gallistel (Eds.), Steven's handbook of experimental psychology: Learning, motivation, and emotion: 497-533. Hoboken, NJ, US: John Wiley \& Sons Inc.

Dimitrov, A. G., Lazar, A. A., \& Victor, J. D. 2011. Information theory in neuroscience. Journal of Computational Neuroscience, 30(1):1-5.

Dohmen, T., Falk, A., Huffman, D., Sunde, U., Schupp, J. \& Wagner, G. 2011. Individual risk attitudes: measurement, determinants, and behavioral consequences. Journal of the European Economic Association, 9(3): 522-50.

Ederer, F., Holden, R., \& Meyer, M. 2018. Gaming and strategic opacity in incentive provision. RAND Journal of Economics, 49(4):819-854.

Ely, J., Frankel, A., \& Kamenica, E. 2015. Suspense and surprise. Journal of Political Economy, 123(1):215-260.

Epstein, L. G. \& Schneider, M. 2008. Ambiguity, information quality, and asset pricing. The Journal of Finance, 63(1): 197-228.

Evans, J. S. B. T. 2003. In two minds: dual-process accounts of reasoning. Trends in Cognitive Sciences, 7(10):454-459.

Eyal, N., 2014. Hooked: How to build habit-forming products. Penguin.

Falk, A., Becker, A., Dohmen, T., Enke, B., Huffman, D. \& Sunde, U. 2018. Global evidence on economic preferences. Quarterly Journal of Economics 133(4): 1645-92.

Fiorillo, C. D., Tobler, P. N., \& Schultz, W. 2003. Discrete coding of reward probability and uncertainty by dopamine neurons. Science, 299(5614):1898-1902.

Forkman, B. A. 1993. The effect of uncertainty on the food intake of the Mongolian gerbil. Behaviour, 124(3):197-206. 
Frankel, A., \& Kamenica, E. 2019. Quantifying information and uncertainty. American Economic Review, 109(10), 3650-80.

Frederick, S. 2005. Cognitive reflection and decision making. Journal of Economic Perspectives, 19(4):25-42.

Friston, K., FitzGerald, T., Rigoli, F., Schwartenbeck, P., \& Pezzulo, G. 2017a. Active inference: a process theory. Neural Computation, 29(1):1-49.

Friston, K., Lin, M., Frith, C. D., Pezzulo, G., Hobson, J. A., \& Ondobaka, S. 2017b. Active inference, curiosity and insight. Neural Computation, 29(10):2633-2683.

Friston, K., Rigoli, F., Ognibene, D., Mathys, C., Fitzgerald, T., \& Pezzulo, G. 2015. Active inference and epistemic value. Cognitive Neuroscience, 6(4):187-214.

Friston, K., Schwartenbeck, P., FitzGerald, T., Moutoussis, M., Behrens, T., \& Dolan, R. J. 2013. The anatomy of choice: active inference and agency. Frontiers in Human Neuroscience, 7:598.

Fryer, R. G., Levitt, S. D., List, J., \& Sadoff, S. 2012. Enhancing the efficacy of teacher incentives through loss aversion: A field experiment. NBER Working Paper No. 18237.

Fudenberg, D. \& Levine, D. K. 2006. A dual-self model of impulse control. American Economic Review, 96(5):1449-1476.

Gächter, S., Johnson, E. J., \& Herrmann, A. 2007. Individual-level loss aversion in riskless and risky choices. CeDEx Discussion Paper No. 2007-02.

Gallup .2018. The gig economy and alternative work arrangements.

Ganster, D. C., Kiersch, C. E., Marsh, R. E., \& Bowen, A. 2011. Performance-based rewards and work stress. Journal of Organizational Behavior Management, 31(4), 221-235.

Glimcher, P. W. 2011. Foundations of neuroeconomic analysis. Oxford: Oxford University Press.

Gneezy, U. \& Rustichini, A. 2000a. A fine is a price. The Journal of Legal Studies, 29(1):1-17.

Gneezy, U. \& Rustichini, A. 2000b. Pay enough or don't pay at all. The Quarterly Journal of Economics, 115(3):791-810.

Goerg, S. J., \& Kube, S. 2012. Goals (th)at Work-Goals, Monetary Incentives, and Workers' Performance. MPI Collective Goods Preprint Working Paper, 2012/19.

Goldstein, D. G. \& Rothschild, D. 2014. Lay understanding of probability distributions. Judgment \& Decision Making, 9(1):1-14.

Golman, R. \& Loewenstein, G. 2015a. Curiosity, information gaps, and the utility of knowledge. SSRN Electronic Journal No. 2149362.

Golman, R. \& Loewenstein, G. 2015b. An information-gap framework for capturing preferences about uncertainty. In Proceedings of the fifteenth Conference on Theoretical Aspects of Rationality and Knowledge.

Halko, M. L. \& Sääksvuori, L. 2017. Competitive behavior, stress, and gender. Journal of Economic Behavior \& Organization, 141:96-109.

Hannan, R. L., Hoffman, V. B., \& Moser, D. V. 2005. Bonus versus penalty: does contract frame affect employee effort? In A. Rapoport \& R. Zwick (Eds.), Experimental Business Research: 151-169. Springer, Boston, MA. 
Hart, O. \& Holmstrom, B. 1986. The theory of contracts. Massachusetts Institute of Technology (MIT), Department of Economics Working Paper.

Hasher, L., Lustig, C., \& Zacks, R. T. 2007. Inhibitory mechanisms and the control of attention. In A. Conway, C. Jarrold, M. Kane, A. Miyake, \& J. Towse (Eds.), Variation in Working Memory: 227-249. Oxford: Oxford University Press.

Hawkins, A. 2018. Uber will start rewarding high-performing drivers with better earnings and free college tuition. The Verge.

Heckman, J. \& Singer, B. 1984. A method for minimizing the impact of distributional assumptions in econometric models for duration data. Econometrica, 52(2):271-320.

Henly, J. \& Lambert, S. 2014. Unpredictable work timing in retail jobs: Implications for employee work-life conflict. ILR Review, 67(3):986-1016.

Hirsh, J. B., Mar, R. A., \& Peterson, J. B. 2012. Psychological entropy: A framework for understanding uncertainty-related anxiety. Psychological Review, 119(2):304.

Hockey, R. 2013. The psychology of fatigue: Work, effort and control. Cambridge University Press.

Hogarth, R. M. \& Villeval, M. C. 2014. Ambiguous incentives and the persistence of effort: Experimental evidence. Journal of Economic Behavior \& Organization, 100:1-19.

Holmström, B. 1979. Moral hazard and observability. The Bell Journal of Economics, 10(1):74-91.

Holt, C. A. \& Laury, S. K. 2002. Risk aversion and incentive effects. American Economic Review, 92(5):1644-1655.

Hossain, T. \& List, J. A. 2012. The behavioralist visits the factory: Increasing productivity using simple framing manipulations. Management Science, 58(12):2151-2167.

Hsee, C. K., Yu, F., Zhang, J., \& Zhang, Y. 2003. Medium maximization. Journal of Consumer Research, 30(1):1-14.

Huck, S., Szech, N., \& Wenner, L. M. 2018. More effort with less pay: On information avoidance, optimistic beliefs. and performance. Working Paper.

Hurly, T. A. \& Oseen, M. D. 1999. Context-dependent, risk-sensitive foraging preferences in wild rufous hummingbirds. Animal Behaviour, 58(1):59-66.

Huws, U., Spencer, N., Syrdal, D. S., \& Holts, K. 2017. Work in the European gig economy: research results from the UK, Sweden, Germany, Austria, the Netherlands, Switzerland and Italy.

Iannaccone, L. R. 1986. Addiction and satiation. Economics Letters, 21(1):95-99.

Imas, A., Sadoff, S., \& Samek, A. 2017. Do people anticipate loss aversion? Management Science, 63(5):1271-1284.

Jaeggi, S. M., Buschkuehl, M., Jonides, J., \& Shah, P. 2011. Short- and long-term benefits of cognitive training. Proceedings of the National Academy of Sciences, 108(25):10081-10086.

Jehiel, P. 2014. On transparency in organizations. The Review of Economic Studies, 82(2):736-761.

Jensen, M. C. \& Meckling, W. H. 1976. Theory of the firm: Managerial behavior, agency costs and ownership structure. Journal of Financial Economics, 3(4), 305-360.

Jha, A.P., Krompinger, J. \& Baime, M.J. 2007. Mindfulness training modifies subsystems of attention. Cognitive, Affective, \& Behavioral Neuroscience, 7(2), 109-119.

Kahneman, D. 2011. Thinking, fast and slow. New York: Farrar, Straus, \& Giroux. 
Kahneman, D. \& Tversky, A. 1979. Prospect theory: An analysis of decision under risk. Econometrica, 47(2):263-292.

Kässi, O., \& Lehdonvirta, V. 2018. Online labour index: Measuring the online gig economy for policy and research. Technological Forecasting and Social Change, 137, 241-248.

Katz, L. \& Krueger, A. 2016. The rise and nature of alternative work arrangements in the united states, 1995-2015. NBER, Working Paper (22667).

Laffont, J. J. \& Martimort, D. 2002. The Theory of Incentives: The Principal-Agent Model. Princeton, N.J.; Oxford: Princeton University Press.

Laibson, D. 1997. Golden eggs and hyperbolic discounting. The Quarterly Journal of Economics, 112(2):443-478.

Lass, Y. \& Abeles, M. 1975. Transmission of information by the axon: I. Noise and memory in the myelinated nerve fiber of the frog. Biological Cybernetics, 19(2):61-67.

Levi, L. 1972. Conditions of work and sympathoadreno-medullary activity: Experimental manipulations in a real life setting. Acta Medica Scandinavica, 191(S528), 106-118.

Levitt, S. D., List, J. A., Neckermann, S., \& Sadoff, S. 2016. The behavioralist goes to school: Leveraging behavioral economics to improve educational performance. American Economic Journal: Economic Policy, 8(4):183-219.

Linnet, J., Mouridsen, K., Peterson, E., Møller, A., Doudet, D. J., \& Gjedde, A. 2012. Striatal dopamine release codes uncertainty in pathological gambling. Psychiatry Research: Neuroimaging, 204(1):55-60.

Locke, E. A., \& Latham, G. P. 2002. Building a practically useful theory of goal setting and task motivation: A 35-year odyssey. American psychologist, 57(9):705.

Luft, J. 1994. Bonus and penalty incentives contract choice by employees. Journal of Accounting and Economics, 18(2):181-206.

MacLean, K.A., Ferrer, E., Aichele, S.R., Bridwell, D.A., Zanesco, A.P., Jacobs, T.L., King, B.G., Rosenberg, E.L., Sahdra, B.K., Shaver, P.R. \& Wallace, B.A. 2010. Intensive meditation training improves perceptual discrimination and sustained attention. Psychological Science, 21(6), 829-839.

Mantsch, J. R., Baker, D. A., Funk, D., Lê, A. D., \& Shaham, Y. 2016. Stress-induced reinstatement of drug seeking: 20 years of progress. Neuropsychopharmacology, 41(1):335.

Manyika, J., Lund, S., Robinson, K., Valentino, J., \& Dobbs, R. 2015. A labor market that works: Connecting talent with opportunity in the digital age. June. McKinsey Global Institute.

Markle, A., Wu, G., White, R., \& Sackett, A. 2018. Goals as reference points in marathon running: a novel test of reference-dependence. Journal of Risk and Uncertainty 56, 1-3.

Marois, R. \& Ivanoff, J. 2005. Capacity limits of information processing in the brain. Trends in Cognitive Sciences, 9(6):296-305.

Mason, J. W. 1959. Visceral functions of the nervous system. Annual Review of Physiology, 21(1):353-380.

Mason, J. W. 1968. A review of psychoendocrine research on the sympathetic-adrenal medullary system. Psychosomatic Medicine, 30(5):631-653. 
Mather, M. \& Lighthall, N. R. 2012. Risk and reward are processed differently in decisions made under stress. Current Directions in Psychological Science, 21(1):36-41.

McEwen, B. S. \& Stellar, E. 1993. Stress and the individual: mechanisms leading to disease. Archives of Internal Medicine, 153(18):2093-2101.

McEwen, B. S. \& Wingfield, J. C. 2003. The concept of allostasis in biology and biomedicine. Hormones and Behavior, 43(1):2-15.

Mendes, R. S., Evangelista, L. R., Thomaz, S. M., Agostinho, A. A., \& Gomes, L. C. 2008. A unified index to measure ecological diversity and species rarity. Ecography, 31(4):450-456.

Meyer, B. D. 1990. Unemployment insurance and unemployment spells. Econometrica, 58(4):757782.

Milgrom, P. R. \& Roberts, J. D. 1992. Economics, organization and management. Prentice-hall.

Miller, S. M. 1979. Controllability and human stress: Method, evidence and theory. Behaviour Research and Therapy, 17(4):287-304.

Mrkva, K., Johnson, E. J., Gächter, S., \& Herrmann, A. 2019. Moderating loss aversion: loss aversion has moderators, but reports of its death are greatly exaggerated. Journal of Consumer Psychology, In Press.

Nadler, D. A. \& Lawler III, E. E. 2007. Motivation: A diagnostic approach. In J. S. Osland, M. E. Turner, D. A. Kolb, \& I. M. Rubin (Eds.), The organizational behavior reader: 171-180. Upper Saddle River, N.J.: Pearson Prentice Hall.

Neal, D. T., Wood, W., Wu, M., \& Kurlander, D. 2011. The pull of the past: When do habits persist despite conflict with motives? Personality and Social Psychology Bulletin, 37(11):1428-1437.

Niederle, M., \& Vesterlund, L. 2007. Do women shy away from competition? Do men compete too much? The Quarterly Journal of Economics 122(3):1067-1101.

Otto, A. R., Raio, C. M., Chiang, A., Phelps, E. A., \& Daw, N. D. 2013. Working-memory capacity protects model-based learning from stress. Proceedings of the National Academy of Sciences, 110(52):20941-20946.

Otto, A. R., Skatova, A., Madlon-Kay, S., \& Daw, N. D. 2015. Cognitive control predicts use of modelbased reinforcement learning. Journal of Cognitive Neuroscience, 27(2):319-333.

Oyer. P. 2016. The independent workforce in America: The economics of an increasingly flexible labor market. Technical report, Stanford University.

Paglieri, F., Addessi, E., De Petrillo, F., Laviola, G., Mirolli, M., Parisi, D., Petrosino, G., Ventricelli, M., Zoratto, F., \& Adriani, W. 2014. Nonhuman gamblers: lessons from rodents, primates, and robots. Frontiers in Behavioral Neuroscience, 8:33.

Pashler, H. E. 1998. The psychology of attention. Cambridge, MA, US: The MIT Press.

Peters, A. \& McEwen, B. S. 2015. Stress habituation, body shape and cardiovascular mortality. Neuroscience \& Biobehavioral Reviews, 56:139-150.

Peters, A., McEwen, B. S., \& Friston, K. 2017. Uncertainty and stress: Why it causes diseases and how it is mastered by the brain. Progress in Neurobiology, 156:164-188.

Prentice, R. L. \& Gloeckler, L. A. 1978. Regression analysis of grouped survival data with application to breast cancer data. Biometrics, (34):57-67. 
Preuschoff, K., Bossaerts, P., \& Quartz, S. R. 2006. Neural differentiation of expected reward and risk in human subcortical structures. Neuron, 51(3):381-390.

Raven, J. C. 1936. Mental tests used in genetic studies: The performance of related individuals on tests mainly educative and mainly reproductive. Master's thesis, University of London.

Rhoades, S. A. 1995. Market share inequality, the HHI, and other measures of the firm-composition of a market. Review of Industrial Organization, 10(6):657-674.

Robinson, M. J. F., Anselme, P., Fischer, A. M., \& Berridge, K. C. 2014. Initial uncertainty in pavlovian reward prediction persistently elevates incentive salience and extends sign-tracking to normally unattractive cues. Behavioural Brain Research, 266:119-130.

Ryan, R. M. 1982. Control and information in the intrapersonal sphere: An extension of cognitive evaluation theory. Journal of Personality and Social Psychology, 43(3):450-461.

Sänger, J., Bechtold, L., Schoofs, D., Blaszkewicz, M., \& Wascher, E. 2014. The influence of acute stress on attention mechanisms and its electrophysiological correlates. Frontiers in behavioral neuroscience, 8:353.

Schwabe, L. \& Wolf, O. T. 2009. Stress prompts habit behavior in humans. Journal of Neuroscience, 29(22):7191-7198.

Schwabe, L. \& Wolf, O. T. 2011. Stress-induced modulation of instrumental behavior: from goal-directed to habitual control of action. Behavioural Brain Research, 219(2):321-328.

Selye, H. 1956. What is stress? Metabolism, (5):525-530.

Shalev, U., Morales, M., Hope, B., Yap, J., \& Shaham, Y. 2001. Time-dependent changes in extinction behavior and stress-induced reinstatement of drug seeking following withdrawal from heroin in rats. Psychopharmacology, 156(1):98-107.

Shannon C., E. 1948. A mathematical theory of communication. Bell System Technical Journal, 27(3):379-423.

Scheiber, N. 2017. How Uber uses psychological tricks to push its drivers' buttons. New York Times.

Schleifer, L. M., \& Amick III, B. C. 1989. System response time and method of pay: Stress effects in computer-based tasks. International Journal of Human-Computer Interaction, 1(1): 23-39.

Schleifer, L. M., \& Okogbaa, O. G. 1990. System response time and method of pay: cardiovascular stress effects in computer-based tasks. Ergonomics, 33(12): 1495-1509.

Shalev, I., Lerer, E., Israel, S., Uzefovsky, F., Gritsenko, I., Mankuta, D., Ebstein, R. P., \& Kaitz, M. 2009. BDNF Val66Met polymorphism is associated with HPA axis reactivity to psychological stress characterized by genotype and gender interactions. Psychoneuroendocrinology, 34(3): 382388.

Shields, G. S., Sazma, M. A., \& Yonelinas, A. P. 2016. The effects of acute stress on core executive functions: a meta-analysis and comparison with cortisol. Neuroscience \& Biobehavioral Reviews, 68:651-668.

Shields, G. S., Trainor, B. C., Lam, J. C. W., \& Yonelinas, A. P. 2016. Acute stress impairs cognitive flexibility in men, not women. Stress, 19(5):542-546.

Sinha, R., Shaham, Y., \& Heilig, M. 2011. Translational and reverse translational research on the role of stress in drug craving and relapse. Psychopharmacology, 218(1):69-82. 
Shirom, A., Westman, M., \& Melamed, S. 1999. The effects of pay systems on blue-collar employees' emotional distress: The mediating effects of objective and subjective work monotony. Human Relations, 52(8): 1077-1097.

Sloof, R. \& Van Praag, C. M. 2010. The effect of noise in a performance measure on work motivation: A real effort laboratory experiment. Labour Economics, 17(5):751-765.

Spence, M. 1973. Job market signaling. The Quarterly Journal of Economics, 87:355-374.

Stanovich, K. E. 2009. Distinguishing the reflective, algorithmic, and autonomous minds: Is it time for a tri-process theory. In J. Evans \& K.Frankish (Eds.), In two minds: Dual processes and beyond: 55-88. Oxford: Oxford University Press.

Stigler, G. J. \& Becker, G. S. 1977. De gustibus non est disputandum. American Economic Review, 67(2):76-90.

Stolp, T., Dohmen, T., \& Rohde, I. 2017. Incentives and stress. Working Paper.

Tang, Y.Y., Ma, Y., Wang, J., Fan, Y., Feng, S., Lu, Q., Yu, Q., Sui, D., Rothbart, M.K., Fan, M. \& Posner, M.I. 2007. Short-term meditation training improves attention and self-regulation. Proceedings of the National Academy of Sciences, 104(43), 17152-17156.

Taylor, S. E., Klein, L. C., Lewis, B. P., Gruenewald, T. L., Gurung, R. A., \& Updegraff, J. A. 2000. Biobehavioral responses to stress in females: tend-and-befriend, not fight-or-flight. Psychological Review, 107(3): 411.

Thaler, R. H. \& Shefrin, H. M. 1981. An economic theory of self-control. Journal of Political Economy, 89(2):392-406.

Timio, M., \& Gentili, S. 1976. Adrenosympathetic overactivity under conditions of work stress. Journal of Epidemiology \& Community Health, 30(4): 262-265.

Timio, M., Gentili, S, \& Pede, S. 1979. Free adrenaline and noradrenaline excretion related to occupational stress. Heart, 42(4): 471-474.

Toplak, M. E., Stanovich, K. E., \& West, R. F. 2011. Intelligence and rationality. In R. Sternberg \& S. B. Kaufman (Eds.), Cambridge handbook of intelligence: 784-826. Cambridge: Cambridge University Press.

Tsallis, C. 1988. Possible generalization of boltzmann-gibbs statistics. Journal of Statistical Physics, 52(1-2):479-487.

Voon, V., Derbyshire, K., Rück, C., Irvine, M. A., Worbe, Y., Enander, J., Schreiber, L. R. N., Gillan, C., Fineberg, N. A., \& Sahakian, B. J. 2015. Disorders of compulsivity: a common bias towards learning habits. Molecular Psychiatry, 20(3):345.

Vroom, V. H. 1964. Work and motivation. New York: John Willey \& Sons.

Wakker, P. P. 2010. Prospect theory: For risk and ambiguity. Cambridge University Press.

Williams, C. R., \& Livingstone, L. P. 1994. Another look at the relationship between performance and voluntary turnover. Academy of Management Journal, 37(2), 269-298.

Wonderlic 1992. Wonderlic Personnel Test and Scholastic Level Exam: User's manual. Liberty, IL: Wonderlic Personnel Test, Inc.

Wood, W. \& Rünger, D. 2016. Psychology of habit. Annual Review of Psychology, 67:289-314. 
Wu G., Heath C., \& Larrick R. 2008. A prospect theory model of goal behavior. Working paper, University of Chicago, Chicago.

Yu, R. 2016. Stress potentiates decision biases: A stress induced deliberation-to-intuition (SIDI) model. Neurobiology of Stress, 3:83-95.

Zhong, S., Shalev, I., Koh, D., Ebstein, R. P., \& Chew, S. H. 2018. Competitiveness and stress. International Economic Review, 59(3): 1263-1281. 


\section{Online Appendix to \\ Working Too Much for Too Little: \\ Stochastic Rewards Cause Work Addiction}

\section{Contents:}

Appendix A. Experimental instructions and questionnaires.

Appendix B. Additional analyses of reward uncertainty and entropy.

Appendix C. Gender analysis.

Appendix D. Work addicts analysis.

Appendix E. Related models and designs. 


\section{Appendix A \\ Experimental instructions and questionnaires.}

Study 2 experiments were conducted in Spanish. The instructions in Spanish are available upon request.

\section{Instructions - Baseline [Stochastic rewards] treatment}

This task consists in adding five one-digit numbers. During 6 periods of 600 seconds each, you can solve as many problems as you want to. An example of the sum problem is displayed below. Next to the display, there is an input box and an O.K. button. You will have to enter the result into the box (only integer numbers are allowed) and then click on the O.K. button or press ENTER.

For each sum problem that you solve correctly, you will receive 12 tokens.

[For each sum problem that you solve correctly, you will receive a number of tokens. To determine the number of tokens for each sum problem, the computer will randomly generate an integer number between 1 and 23 all with equal chances.]

These tokens are converted to dollars using an exchange rate (=number of tokens you need to earn 1 cent) that varies each period.

The exchange rate will be $1,2,4,8,80$, and 500 in period $1,2,3,4,5$, and 6 , respectively. For each table you complete correctly you will receive an amount of cents equal to the number of tokens divided by the corresponding period exchange rate.

- Example 1: consider you complete a correct sum in period 2. In this period the exchange rate is 2 tokens per cent.

Therefore, you will receive 12 tokens which correspond to 6 cents $(=12 / 2)$.

[Suppose that the number of tokens randomly selected by the computer is 10. Therefore, you will receive 10 tokens which correspond to 5 cents $(=10 / 2)$.]

- Example 2: consider you complete a correct sum in period 4. In this period the exchange rate is 8 tokens per cent.

Therefore, you will receive 12 tokens which correspond to 1.5 cents $(=12 / 8)$.

[Suppose that the number of tokens randomly selected by the computer is 14. Therefore, you will receive 14 tokens which correspond to 1.75 cents $(=14 / 8)$.]

On the right hand side of the screen, you will see the current exchange rate, the number of tokens and its value in cents for the last sum problem you completed. You will also see your cumulative earnings.

Every time a correct answer is provided you will see the corresponding number of tokens falling into a pot (on the left hand side of the screen).

Important: note that the number of tokens must be divided by the corresponding period exchange rate to obtain your earnings in cents.

The current period and the time remaining in seconds for that period will be displayed in the upper right corner of the screen.

Any time, you can exit the task by clicking on the 'BROWSE THE INTERNET' button. 
IMPORTANT: once you exit the task you will be on the internet FOR THE REST of the experiment and you will not come back to the task screen.

Intrinsic Motivation Inventory - Self-Determination Theory

Participants were asked to indicate using a 7 points Likert scale how true the following statements were for them ( $1=$ not at all true; $7=$ very true $)$.

The pressure/tension scale

- I did not feel nervous at all while doing this Task.

- I felt very tense while doing this Task.

- I was very relaxed in doing this Task.

- I was anxious while working on this Task.

- I felt pressured while doing this Task.

The interest/enjoyment subscale

- I enjoyed doing this Task very much

- This Task was fun to do.

- I thought this was a boring Task.

- This Task did not hold my attention at all.

- I would describe this Task as very interesting.

- I thought this Task was quite enjoyable.

- While I was doing this Task, I was thinking about how much I enjoyed it.

The Intrinsic Motivation Inventory can be found here: http://selfdeterminationtheory.org/intrinsic-motivation-inventory/

\section{SAM (self-assessment manikin, Bradley and Lang, 1994)}

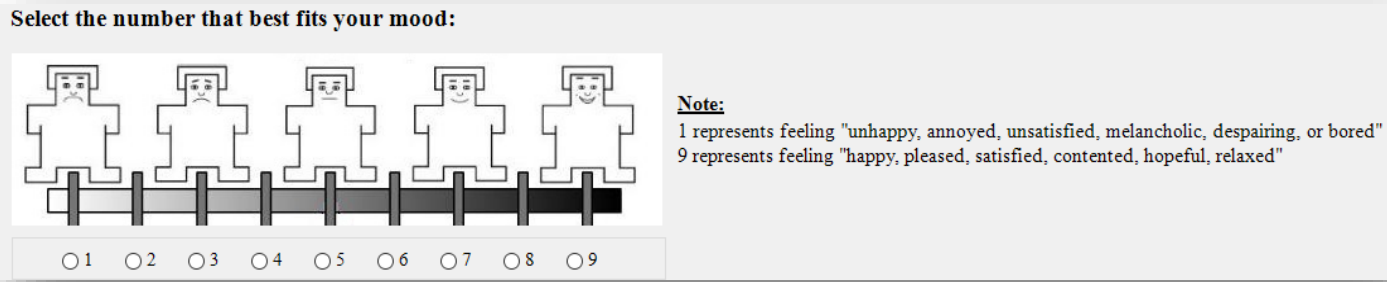




\section{Appendix B}

Additional analyses of reward uncertainty and entropy.

\section{TABLE B1 ${ }^{\mathrm{a}}$}

Quitting behavior before rewards are muted

Probit regressions for the probability of quitting before minutes 35 or 40 .

\begin{tabular}{|c|c|c|c|c|c|c|}
\hline & \multicolumn{2}{|c|}{ Studies $1 \& 2$} & \multicolumn{2}{|c|}{ Study 1} & \multicolumn{2}{|c|}{ Study $2^{b}$} \\
\hline & $\mathbf{t}<35$ & $\mathrm{t}<40$ & $\mathrm{t}<35$ & $\mathrm{t}<40$ & $\mathrm{t}<35$ & $\mathrm{t}<40$ \\
\hline Constant & $\begin{array}{c}-1.740 * * * \\
(0.571)\end{array}$ & $\begin{array}{c}-1.615 * * * \\
(0.543)\end{array}$ & $\begin{array}{c}-1.531 * * \\
(0.699)\end{array}$ & $\begin{array}{c}-1.531 * * \\
(0.699)\end{array}$ & $\begin{array}{l}-0.764 \\
(0.981)\end{array}$ & $\begin{array}{l}-0.812 \\
(0.856)\end{array}$ \\
\hline $\begin{array}{l}\text { Stochastic } \\
\text { Treatment Dummy }\end{array}$ & $\begin{array}{c}-0.409 \\
(0.302) \\
{[-0.030]}\end{array}$ & $\begin{array}{c}-0.464 \\
(0.303) \\
{[-0.036]}\end{array}$ & $\begin{array}{c}-0.061 \\
(0.383) \\
{[-0.008]}\end{array}$ & $\begin{array}{c}-0.061 \\
(0.383) \\
{[-0.008]}\end{array}$ & & \\
\hline Summation Skills & $\begin{array}{c}-0.053 \\
(0.033) \\
{[-0.004]}\end{array}$ & $\begin{array}{c}-0.062^{*} \\
(0.034) \\
{\left[-0.005^{*}\right]}\end{array}$ & $\begin{array}{c}-0.040 \\
(0.044) \\
{[-0.005]}\end{array}$ & $\begin{array}{c}-0.040 \\
(0.044) \\
{[-0.005]}\end{array}$ & $\begin{array}{c}-0.104 \\
(0.084) \\
{[-0.007]}\end{array}$ & $\begin{array}{c}-0.129 \\
(0.080) \\
{[-0.010]}\end{array}$ \\
\hline Cognitive Reflection & $\begin{array}{c}0.105 \\
(0.106) \\
{[0.008]}\end{array}$ & $\begin{array}{c}0.140 \\
(0.108) \\
{[0.011]}\end{array}$ & $\begin{array}{c}0.088 \\
(0.122) \\
{[0.011]}\end{array}$ & $\begin{array}{c}0.088 \\
(0.122) \\
{[0.011]}\end{array}$ & $\begin{array}{c}0.134 \\
(0.177) \\
{[0.009]}\end{array}$ & $\begin{array}{c}0.320 \\
(0.216) \\
{[0.026]}\end{array}$ \\
\hline Male Dummy & $\begin{array}{c}0.503 * \\
(0.263) \\
{\left[0.036^{*}\right]}\end{array}$ & $\begin{array}{c}0.562 * * \\
(0.260) \\
{[0.043 *]}\end{array}$ & $\begin{array}{c}0.848 * * * \\
(0.316) \\
{[0.105 * *]}\end{array}$ & $\begin{array}{c}0.848 * * * \\
(0.316) \\
{\left[0.105^{* *}\right]}\end{array}$ & $\begin{array}{c}-0.023 \\
(0.554) \\
{[-0.002]}\end{array}$ & $\begin{array}{c}0.156 \\
(0.522) \\
{[0.012]}\end{array}$ \\
\hline Study 1 Dummy & $\begin{array}{c}0.681 * * \\
(0.310) \\
{[0.049 * *]}\end{array}$ & $\begin{array}{c}0.571 * \\
(0.299) \\
{[0.044 *]}\end{array}$ & & & & \\
\hline $\mathrm{N}$ & 292 & 292 & 111 & 111 & 91 & 91 \\
\hline 11 & 0.137 & 0.148 & 0.109 & 0.109 & 0.086 & 0.157 \\
\hline $\mathrm{BIC}$ & $19.316^{* * * *}$ & $21.485^{* * * *}$ & $12.427 * *$ & $12.427 * *$ & $8.768 * *$ & $8.710 * *$ \\
\hline
\end{tabular}

${ }^{a}$ Robust standard errors are in parentheses and marginal effects in square brackets.

${ }^{\mathrm{b}}$ The stochastic treatment variable cannot be estimated for Study 2 as none of the participants in the stochastic treatment quitted until minute 41 whereas in the deterministic treatment only 3.3\% (3 out of 91) and $4.4 \%$ (4 out of 91) of the participants had quitted before minute 35 and 40 , respectively.

*** Significant at the 0.01 level; ** at the 0.05 level; * at the 0.1 level. 
TABLE B2 $2^{\mathrm{a}, \mathrm{b}}$

Proportional hazards models.

\begin{tabular}{lccc}
\hline \hline Studies 1 \& 2 & {$[1]$} & {$[2]$} & {$[3]$} \\
\hline Constant & $-21.504^{* * *}$ & $-12.173^{* * *}$ & $-14.278^{* * *}$ \\
& $(1.984)$ & $(1.420)$ & $(1.725)$ \\
Stochastic & $-1.351^{* *}$ & -0.604 & $-0.859^{* *}$ \\
Treatment Dummy & $(0.556)$ & $(0.375)$ & $(0.371)$ \\
& {$\left[0.259^{*}\right]$} & {$[0.547]$} & {$[0.424 * *]$} \\
Summation Skills & $-0.142^{* *}$ & -0.071 & $-0.086^{*}$ \\
& $(0.061)$ & $(0.047)$ & $(0.046)$ \\
& {$\left[0.868^{* *}\right]$} & {$[0.932]$} & {$\left[0.917^{*}\right]$} \\
Cognitive Reflection & $0.529^{* * *}$ & $0.293^{* *}$ & $0.326^{* * *}$ \\
& $(0.168)$ & $(0.123)$ & $(0.105)$ \\
& {$[1.697 * * *]$} & {$\left[1.341^{* *}\right]$} & {$\left[1.386^{* * *}\right]$} \\
Male Dummy & $2.082^{* * *}$ & $1.252^{* * *}$ & $1.177^{* * *}$ \\
& $(0.568)$ & $(0.469)$ & $(0.417)$ \\
& {$\left[8.021^{* * *}\right]$} & {$\left[3.496^{* * *}\right]$} & {$\left[3.243^{* * *}\right]$} \\
Study 1 Dummy & $3.654^{* * *}$ & $2.162^{* * *}$ & $2.209^{* * *}$ \\
& $(0.556)$ & $(0.518)$ & $(0.403)$ \\
& {$\left[38.641^{* * *}\right]$} & {$\left[8.686^{* * *}\right]$} & {$\left[9.105^{* * *}\right]$} \\
Period & & $1.325^{* * *}$ & $1.440^{* * *}$ \\
& $2.408^{* * *}$ & $(0.277)$ & $(0.232)$ \\
& $(0.298)$ & {$\left[3.762^{* * *}\right]$} & {$\left[4.223^{* * *}\right]$} \\
$\mathrm{N}$ & {$\left[11.115^{* * *}\right]$} & 16255 & 16255 \\
Ll & 16255 & -377.535 & -376.637 \\
BIC & -372.159 & 832.638 & 840.539 \\
\hline
\end{tabular}

${ }^{a}$ Robust standard errors are in parentheses and hazard ratios in square brackets.

${ }^{\mathrm{b}}$ Model [1] refers to a discrete-time proportional hazard model without unobserved individual heterogeneity (Prentice \& Gloeckler, 1978), whereas [2] and [3] assume either a gamma distribution (Meyer, 1990) or a discrete mixture distribution (Heckman \& Singer, 1984) to summarize unobserved individual heterogeneity. BIC represents the Bayesian information criterion.

"Similar results are obtained when instead of controlling for the variable "period" we control for "last 2 periods" or "last 3 periods" dummies, period exchange rate, period dummies or none of them. In some of these cases, models [2] and [3] did not converge. The results reported here have the lowest BIC values.

*** Significant at the 0.01 level; ** at the 0.05 level; * at the 0.1 level. 


\section{TABLE B3}

Quitting behavior and additional controls

Probit regressions for the probability of quitting, with additional controls for Study 1.

\begin{tabular}{|c|c|c|c|c|c|c|c|c|c|c|}
\hline \multirow[b]{2}{*}{ Study 1} & \multicolumn{5}{|c|}{$\mathrm{t}<50$} & \multicolumn{5}{|c|}{$\mathrm{t}<55$} \\
\hline & {$[1]$} & {$[2]$} & [3] & [4] & {$[5]$} & {$[1]$} & {$[2]$} & {$[3]$} & [4] & {$[5]$} \\
\hline \multirow[t]{2}{*}{ Constant } & -0.084 & 5.572 & -0.147 & 0.206 & 4.618 & -0.016 & 1.821 & -0.048 & -2.079 & -1.766 \\
\hline & $(0.444)$ & (5.909) & $(0.529)$ & $(2.186)$ & (7.143) & $(0.410)$ & $(5.422)$ & $(0.473)$ & $(2.068)$ & $(6.954)$ \\
\hline Stochastic & $-0.511 *$ & -0.447 & $-0.551 *$ & -0.385 & -0.230 & $-0.487 *$ & $-0.458 *$ & $-0.520 *$ & $-0.564 *$ & $-0.628 *$ \\
\hline \multirow[t]{2}{*}{ Treatment Dummy } & $(0.294)$ & $(0.301)$ & $(0.295)$ & $(0.350)$ & $(0.358)$ & $(0.265)$ & $(0.268)$ & $(0.269)$ & $(0.308)$ & $(0.330)$ \\
\hline & {$[-0.145 *]$} & {$[-0.124]$} & {$[-0.155 * *]$} & {$[-0.097]$} & {$[-0.055]$} & {$[-0.162 *]$} & {$[-0.151 *]$} & {$[-0.172 * *]$} & {$[-0.177 *]$} & {$[-0.191 * *]$} \\
\hline \multirow[t]{3}{*}{ Summation Skills } & $-0.072 * *$ & $-0.078 * *$ & $-0.075^{* *}$ & $-0.114 * *$ & $-0.142 * * *$ & -0.047 & $-0.051 *$ & $-0.051 *$ & $-0.067^{*}$ & $-0.088 * *$ \\
\hline & $(0.033)$ & $(0.034)$ & $(0.033)$ & $(0.046)$ & $(0.054)$ & $(0.029)$ & $(0.030)$ & $(0.029)$ & $(0.036)$ & $(0.040)$ \\
\hline & {$[-0.020 * *]$} & {$[-0.022 * *]$} & {$[-0.021 * *]$} & {$[-0.029 * * *]$} & {$[-0.034 * * *]$} & {$\left[-0.016^{*}\right]$} & {$[-0.017 *]$} & {$[-0.017 *]$} & {$[-0.021 *]$} & {$[-0.027 * *]$} \\
\hline \multirow[t]{3}{*}{ Cognitive Reflection } & $0.148^{*}$ & $0.187 * *$ & $0.147 *$ & 0.165 & 0.179 & 0.104 & 0.126 & 0.101 & 0.047 & 0.056 \\
\hline & $(0.082)$ & $(0.090)$ & $(0.082)$ & $(0.118)$ & $(0.131)$ & $(0.074)$ & $(0.080)$ & $(0.076)$ & (0.099) & $(0.108)$ \\
\hline & {$[0.042 *]$} & {$[0.052 * *]$} & {$\left[0.041^{*}\right]$} & [0.042] & [0.043] & {$[0.035]$} & {$[0.041]$} & {$[0.033]$} & {$[0.015]$} & {$[0.017]$} \\
\hline \multirow[t]{3}{*}{ Male Dummy } & $0.734 * *$ & $0.744 * *$ & $0.783 * * *$ & $1.111 * * *$ & $1.409 * * *$ & $0.664 * *$ & $0.688 * *$ & $0.708 * *$ & $0.869 * * *$ & $0.976 * * *$ \\
\hline & $(0.297)$ & $(0.300)$ & $(0.301)$ & $(0.384)$ & $(0.391)$ & $(0.272)$ & $(0.287)$ & $(0.279)$ & $(0.337)$ & $(0.370)$ \\
\hline & {$[0.208 * * *]$} & {$[0.206 * * *]$} & {$[0.220 * * *]$} & {$[0.281 * * *]$} & {$[0.339 * * *]$} & {$[0.222 * * *]$} & {$[0.227 * * *]$} & {$[0.234 * * *]$} & {$[0.272 * * *]$} & {$[0.296 * * *]$} \\
\hline \multirow[t]{3}{*}{ Risk Aversion } & & -0.094 & & & -0.166 & & -0.048 & & & -0.090 \\
\hline & & $(0.077)$ & & & $(0.102)$ & & $(0.069)$ & & & $(0.088)$ \\
\hline & & {$[-0.026]$} & & & {$[-0.040 *]$} & & {$[-0.016]$} & & & {$[-0.027]$} \\
\hline \multirow[t]{3}{*}{ Loss Aversion } & & -0.034 & & & 0.072 & & 0.065 & & & 0.111 \\
\hline & & $(0.126)$ & & & $(0.165)$ & & $(0.117)$ & & & $(0.154)$ \\
\hline & & {$[-0.009]$} & & & {$[0.017]$} & & {$[0.022]$} & & & {$[0.034]$} \\
\hline \multirow{3}{*}{$\begin{array}{l}\text { Time Preferences } \\
\text { (Beta) }\end{array}$} & & 0.830 & & & 2.035 & & 0.316 & & & -0.588 \\
\hline & & $(1.616)$ & & & $(2.085)$ & & $(1.607)$ & & & $(1.917)$ \\
\hline & & {$[0.230]$} & & & {$[0.490]$} & & [0.104] & & & {$[-0.179]$} \\
\hline Time Preferences & & -5.983 & & & -4.143 & & -2.224 & & & 0.701 \\
\hline (Delta) & & $(7.027)$ & & & $(8.136)$ & & $(6.460)$ & & & $(7.752)$ \\
\hline
\end{tabular}




\begin{tabular}{|c|c|c|c|c|c|c|c|c|c|c|}
\hline & & {$[-1.660]$} & & & {$[-0.998]$} & & {$[-0.734]$} & & & {$[0.213]$} \\
\hline \multirow[t]{3}{*}{ Aheadness Aversion } & & & 0.250 & & -0.075 & & & 0.254 & & 0.267 \\
\hline & & & $(0.290)$ & & $(0.368)$ & & & $(0.274)$ & & $(0.332)$ \\
\hline & & & {$[0.070]$} & & {$[-0.018]$} & & & {$[0.084]$} & & {$[0.081]$} \\
\hline \multirow[t]{3}{*}{ Behindness Aversion } & & & 0.012 & & -0.372 & & & -0.044 & & -0.349 \\
\hline & & & $(0.305)$ & & $(0.378)$ & & & $(0.280)$ & & $(0.330)$ \\
\hline & & & {$[0.003]$} & & {$[-0.090]$} & & & {$[-0.015]$} & & {$[-0.106]$} \\
\hline \multirow[t]{3}{*}{ Social Intelligence } & & & & 0.030 & 0.012 & & & & 0.022 & 0.014 \\
\hline & & & & $(0.038)$ & $(0.037)$ & & & & $(0.037)$ & $(0.038)$ \\
\hline & & & & {$[0.008]$} & {$[0.003]$} & & & & {$[0.007]$} & {$[0.004]$} \\
\hline \multirow[t]{3}{*}{ Raven Score } & & & & 0.029 & 0.055 & & & & 0.076 & 0.104 \\
\hline & & & & $(0.076)$ & $(0.074)$ & & & & $(0.081)$ & $(0.081)$ \\
\hline & & & & {$[0.007]$} & {$[0.013]$} & & & & {$[0.024]$} & {$[0.032]$} \\
\hline \multirow[t]{3}{*}{ Wonderlic Score } & & & & -0.111 & $-0.171 *$ & & & & -0.011 & -0.021 \\
\hline & & & & $(0.089)$ & $(0.095)$ & & & & $(0.079)$ & $(0.082)$ \\
\hline & & & & {$[-0.028]$} & {$[-0.041 *]$} & & & & {$[-0.004]$} & {$[-0.006]$} \\
\hline \multirow[t]{3}{*}{ SAT } & & & & 0.198 & 0.228 & & & & 0.199 & 0.171 \\
\hline & & & & $(0.192)$ & $(0.200)$ & & & & $(0.172)$ & $(0.181)$ \\
\hline & & & & {$[0.050]$} & {$[0.055]$} & & & & {$[0.062]$} & {$[0.052]$} \\
\hline $\mathrm{N}$ & 111 & 111 & 111 & 91 & 91 & 111 & 111 & 111 & 91 & 91 \\
\hline $\mathrm{R}^{2}$ & 0.132 & 0.150 & 0.138 & 0.193 & 0.235 & 0.097 & 0.104 & 0.104 & 0.128 & 0.155 \\
\hline$\chi^{2}$ & $13.230 * *$ & $16.124 * *$ & $14.353 * *$ & $17.015^{* *}$ & $22.720 *$ & $13.144 * *$ & $14.969 *$ & $13.967 * *$ & $14.909^{*}$ & 18.208 \\
\hline BIC & 129.506 & 146.050 & 138.165 & 117.289 & 140.154 & 148.786 & 166.578 & 157.197 & 136.697 & 160.642 \\
\hline
\end{tabular}

${ }^{a}$ Robust standard errors are in parentheses and marginal effects in square brackets.

*** Significant at the 0.01 level; ** at the 0.05 level; * at the 0.1 level. 
TABLE B4 ${ }^{\mathrm{a}}$

Linear regression for production (number of correct sums) for different periods and for both studies.

\begin{tabular}{|c|c|c|c|c|}
\hline Studies 1 \& 2 & $\begin{array}{l}\text { Avg Production } \\
\text { Periods } 1 \text { to } 4 \\
\end{array}$ & $\begin{array}{l}\text { Production } \\
\text { Period } 5 \\
\end{array}$ & $\begin{array}{c}\text { Production } \\
\text { Period } 6 \\
\end{array}$ & $\begin{array}{c}\text { Avg Production } \\
\text { Periods } 5 \& 6 \\
\end{array}$ \\
\hline Constant & $\begin{array}{c}21.452 * * * \\
(2.898)\end{array}$ & $\begin{array}{c}27.593 * * * \\
(5.220)\end{array}$ & $\begin{array}{c}29.761^{* * * *} \\
(6.159)\end{array}$ & $\begin{array}{c}28.677 * * * \\
(5.478)\end{array}$ \\
\hline $\begin{array}{l}\text { Stochastic } \\
\text { Treatment Dummy }\end{array}$ & $\begin{array}{l}-0.423 \\
(1.769)\end{array}$ & $\begin{array}{l}7.385^{* * *} \\
(3.178)\end{array}$ & $\begin{array}{l}\text { 6.722* } \\
(3.719)\end{array}$ & $\begin{array}{l}\text { 7.053** } \\
(3.292)\end{array}$ \\
\hline Summation Skills & $\begin{array}{c}3.763 * * * * \\
(0.193)\end{array}$ & $\begin{array}{c}3.573 * * * \\
(0.335)\end{array}$ & $\begin{array}{c}3.170^{* * * *} \\
(0.420)\end{array}$ & $\begin{array}{c}3.371 * * * \\
(0.362)\end{array}$ \\
\hline Cognitive Reflection & $\begin{array}{c}0.173 \\
(0.684)\end{array}$ & $\begin{array}{l}-2.805^{*} \\
(1.178)\end{array}$ & $\begin{array}{c}-3.018^{* *} \\
(1.354)\end{array}$ & $\begin{array}{c}-2.912 * * \\
(1.212)\end{array}$ \\
\hline Male Dummy & $\begin{array}{l}-3.113^{*} \\
(1.874)\end{array}$ & $\begin{array}{c}-15.523 * * * \\
(3.449)\end{array}$ & $\begin{array}{c}-17.231 * * * \\
(3.818)\end{array}$ & $\begin{array}{c}-16.377 * * * \\
(3.486)\end{array}$ \\
\hline Study 1 Dummy & $\begin{array}{l}-1.691 \\
(1.970)\end{array}$ & $\begin{array}{c}-17.371 * * * \\
(3.596)\end{array}$ & $\begin{array}{c}-22.465 * * * \\
(4.159)\end{array}$ & $\begin{array}{c}-19.918 * * * \\
(3.685)\end{array}$ \\
\hline $\mathrm{N}$ & 292 & 292 & 292 & 292 \\
\hline $\mathrm{R}^{2}$ & 0.610 & 0.331 & 0.270 & 0.317 \\
\hline $\mathrm{F}$ & $97.900 * * *$ & $33.819 * * *$ & $23.465^{* * *}$ & $29.195 * * *$ \\
\hline
\end{tabular}

${ }^{a}$ Robust standard errors are in parentheses.

*** Significant at the 0.01 level; ** at the 0.05 level; * at the 0.1 level. 


\section{TABLE B5 ${ }^{\mathrm{a}}$}

Production and additional controls

Linear regressions for production in the last period (number of correct sums), with additional controls for Study 1.

\begin{tabular}{|c|c|c|c|c|c|}
\hline Study $1 ; \mathbf{t}<55$ & [1] & [2] & [3] & [4] & [5] \\
\hline Constant & $\begin{array}{c}6.786 \\
(10.934)\end{array}$ & $\begin{array}{c}-91.458 \\
(143.475)\end{array}$ & $\begin{array}{c}9.722 \\
(12.113)\end{array}$ & $\begin{array}{c}28.530 \\
(55.617)\end{array}$ & $\begin{array}{c}-57.187 \\
(204.351)\end{array}$ \\
\hline $\begin{array}{l}\text { Stochastic } \\
\text { Treatment Dummy }\end{array}$ & $\begin{array}{c}14.243 * \\
(7.395)\end{array}$ & $\begin{array}{l}12.904 * \\
(7.544)\end{array}$ & $\begin{array}{c}15.826 * * \\
(7.607)\end{array}$ & $\begin{array}{l}12.046 \\
(8.429)\end{array}$ & $\begin{array}{l}13.375 \\
(8.940)\end{array}$ \\
\hline Summation skills & $\begin{array}{c}3.323 * * * \\
(0.816)\end{array}$ & $\begin{array}{c}3.374 * * * \\
(0.852)\end{array}$ & $\begin{array}{c}3.488 * * * \\
(0.801)\end{array}$ & $\begin{array}{c}3.992 * * * \\
(0.982)\end{array}$ & $\begin{array}{l}4.407 * * * \\
(1.094)\end{array}$ \\
\hline Cognitive Reflection & $\begin{array}{l}-3.766^{*} \\
(2.119)\end{array}$ & $\begin{array}{l}-4.070 * \\
(2.309)\end{array}$ & $\begin{array}{l}-3.868^{*} \\
(2.201)\end{array}$ & $\begin{array}{l}-3.492 \\
(2.718)\end{array}$ & $\begin{array}{l}-3.238 \\
(3.082)\end{array}$ \\
\hline Male Dummy & $\begin{array}{c}-25.792 * * * \\
(7.954)\end{array}$ & $\begin{array}{c}-26.760 * * * \\
(8.526)\end{array}$ & $\begin{array}{c}-27.492 * * * \\
(7.899)\end{array}$ & $\begin{array}{c}-25.657 * * * \\
(9.207)\end{array}$ & $\begin{array}{c}-28.345^{* * *} \\
(9.906)\end{array}$ \\
\hline Risk Aversion & & $\begin{array}{c}0.738 \\
(2.026)\end{array}$ & & & $\begin{array}{c}0.558 \\
(2.523)\end{array}$ \\
\hline Loss Aversion & & $\begin{array}{l}-1.347 \\
(3.064)\end{array}$ & & & $\begin{array}{l}-3.007 \\
(3.383)\end{array}$ \\
\hline $\begin{array}{l}\text { Time Preferences } \\
\text { (Beta) }\end{array}$ & & $\begin{array}{l}-37.003 \\
(45.638)\end{array}$ & & & $\begin{array}{l}-31.546 \\
(50.851)\end{array}$ \\
\hline $\begin{array}{l}\text { Time Preferences } \\
\text { (Delta) }\end{array}$ & & $\begin{array}{c}138.312 \\
(169.515)\end{array}$ & & & $\begin{array}{c}116.667 \\
(209.526)\end{array}$ \\
\hline Aheadness Aversion & & & $\begin{array}{l}-12.245 \\
(7.582)\end{array}$ & & $\begin{array}{l}-12.127 \\
(8.831)\end{array}$ \\
\hline Behindness Aversion & & & $\begin{array}{c}0.636 \\
(7.674)\end{array}$ & & $\begin{array}{c}9.852 \\
(9.105)\end{array}$ \\
\hline Social Intelligence & & & & $\begin{array}{l}-0.174 \\
(1.084)\end{array}$ & $\begin{array}{c}0.147 \\
(1.105)\end{array}$ \\
\hline Raven Score & & & & $\begin{array}{l}-2.037 \\
(2.160)\end{array}$ & $\begin{array}{l}-3.202 \\
(2.277)\end{array}$ \\
\hline Wonderlic Score & & & & $\begin{array}{l}0.875 \\
(2.325)\end{array}$ & $\begin{array}{l}1.039 \\
(2.509)\end{array}$ \\
\hline SAT & & & & $\begin{array}{l}-3.401 \\
(4.374)\end{array}$ & $\begin{array}{l}-1.538 \\
(4.665)\end{array}$ \\
\hline $\mathrm{N}$ & 111 & 111 & 111 & 91 & 91 \\
\hline $\mathrm{R}^{2}$ & 0.224 & 0.233 & 0.245 & 0.247 & 0.291 \\
\hline $\mathrm{F}$ & $9.304 * * *$ & $5.417 * * *$ & $7.845^{* * *}$ & $4.461 * * *$ & $3.469 * * *$ \\
\hline
\end{tabular}


TABLE B6 ${ }^{\mathrm{a}}$

Productivity

Linear regressions for productivity

(number of correct summations per second spent on the task).

\begin{tabular}{lccc}
\hline \hline Both studies & $\begin{array}{c}\text { Average } \\
\text { Periods 1 to 4 }\end{array}$ & Period 5 & Period 6 \\
\hline Constant & -0.008 & $-0.014 * *$ & -0.018 \\
& $(0.020)$ & $(0.006)$ & $(0.019)$ \\
Stochastic & -0.002 & 0.002 & 0.001 \\
Treatment Dummy & $(0.003)$ & $(0.006)$ & $(0.004)$ \\
Summation Skills & $0.006 * * *$ & $0.004 * * *$ & $0.005 * * *$ \\
& $(0.001)$ & $(0.001)$ & $(0.001)$ \\
Cognitive Reflection & 0.001 & -0.003 & -0.001 \\
& $(0.001)$ & $(0.002)$ & $(0.001)$ \\
Male Dummy & -0.004 & $-0.021 * * *$ & $-0.012 * *$ \\
& $(0.003)$ & $(0.007)$ & $(0.047)$ \\
Study 1 Dummy & -0.001 & $-0.014 * * *$ & $-0.014 * * *$ \\
& $(0.003)$ & $(0.006)$ & $(0.005)$ \\
Time on the task & $0.001 * *$ & $0.001 * * *$ & $0.001 * * *$ \\
(in seconds) & $(<0.001)$ & $(<0.0001)$ & $(<0.0001)$ \\
\hline $\mathrm{N}$ & 291 & 276 & 250 \\
$\mathrm{R}$ & 0.662 & 0.381 & 0.411 \\
$\mathrm{~F}$ & $88.850 * * *$ & $48.520 * * *$ & $21.640 * * *$ \\
\hline $\mathrm{a}$ & & &
\end{tabular}

${ }^{\mathrm{a}}$ Robust standard errors are in parentheses.

*** Significant at the 0.01 level; ** at the 0.05 level; * at the 0.1 level. 
TABLE B B $7^{\mathrm{a}, \mathrm{b}}$

Proportional hazards models and entropy.

\begin{tabular}{|c|c|c|c|}
\hline Studies $1 \& 2$ & [1] & [2] & [3] \\
\hline Constant & $\begin{array}{c}-10.874 * * * \\
(1.242)\end{array}$ & $\begin{array}{c}-10.722 * * * \\
(0.672)\end{array}$ & $\begin{array}{c}-20.234 \\
(116.285)\end{array}$ \\
\hline $\begin{array}{l}\text { Entropy } \\
\text { (standardized) }\end{array}$ & $\begin{array}{c}-0.219 * * \\
(0.098) \\
{[0.803 * *]}\end{array}$ & $\begin{array}{c}-0.215^{* *} \\
(0.099) \\
{\left[0.806^{* *}\right]}\end{array}$ & $\begin{array}{c}-0.191 * \\
(0.104) \\
{[0.826 *]}\end{array}$ \\
\hline $\begin{array}{l}\text { Variance } \\
\text { (standardized) }\end{array}$ & $\begin{array}{c}0.214 \\
(0.189) \\
{[1.239]}\end{array}$ & $\begin{array}{c}0.214 \\
(0.201) \\
{[1.238]}\end{array}$ & $\begin{array}{c}0.214 \\
(0.196) \\
{[1.238]}\end{array}$ \\
\hline Loss Dummy & $\begin{array}{l}-0.043 \\
(0.430) \\
{[0.958]}\end{array}$ & $\begin{array}{l}-0.042 \\
(0.476) \\
{[0.959]}\end{array}$ & $\begin{array}{l}-0.042 \\
(0.463) \\
{[0.959]}\end{array}$ \\
\hline Summation Skills & $\begin{array}{l}-0.003 \\
(0.019) \\
{[0.997]}\end{array}$ & $\begin{array}{l}-0.003 \\
(0.020) \\
{[0.997]}\end{array}$ & $\begin{array}{l}-0.003 \\
(0.019) \\
{[0.997]}\end{array}$ \\
\hline Cognitive Reflection & $\begin{array}{c}0.166^{* *} \\
(0.067) \\
{\left[1.180^{* *}\right]}\end{array}$ & $\begin{array}{c}0.170 * * * \\
(0.064) \\
{[1.186 * * *]}\end{array}$ & $\begin{array}{c}0.180 * * * \\
(0.063) \\
{[1.198 * * *]}\end{array}$ \\
\hline Male Dummy & $\begin{array}{c}1.105^{* * *} \\
(0.266) \\
{\left[3.018^{* * *}\right]}\end{array}$ & $\begin{array}{c}1.132 * * * \\
(0.243) \\
{[3.103 * * *]}\end{array}$ & $\begin{array}{c}1.120 * * * \\
(0.217) \\
{[3.063 * * *]}\end{array}$ \\
\hline Study 1 Dummy & $\begin{array}{c}1.622 * * * \\
(0.326) \\
{\left[5.065^{* * *}\right]}\end{array}$ & $\begin{array}{c}1.661 * * * \\
(0.290) \\
{[5.266 * * *]}\end{array}$ & $\begin{array}{c}1.632 * * * \\
(0.246) \\
{[5.114 * * *]}\end{array}$ \\
\hline Period & $\begin{array}{c}0.857 * * * \\
(0.158) \\
{\left[2.356^{* * *}\right]}\end{array}$ & $\begin{array}{c}0.872 * * * \\
(0.106) \\
{[2.392 * * *]}\end{array}$ & $\begin{array}{c}0.857 * * * \\
(0.086) \\
{[2.356 * * *]}\end{array}$ \\
\hline $\mathrm{N}$ & 35,681 & 35,681 & 35,681 \\
\hline 11 & -751.296 & -751.104 & -750.590 \\
\hline $\mathrm{BIC}$ & $1,607.415$ & $1,607.033$ & $1,616.486$ \\
\hline
\end{tabular}

${ }^{\text {a }}$ Robust standard errors are in parentheses and hazard ratios in square brackets.

${ }^{\mathrm{b}}$ Model [1] refers to a discrete-time proportional hazard model without unobserved individual heterogeneity (Prentice \& Gloeckler, 1978), whereas [2] and [3] assume either a gamma distribution (Meyer, 1990) or a discrete mixture distribution (Heckman \& Singer, 1984) to summarize unobserved individual heterogeneity. BIC represents the Bayesian information criterion.

*** Significant at the 0.01 level; $* *$ at the 0.05 level; * at the 0.1 level. 


\section{TABLE B8 ${ }^{\mathrm{a}}$}

Production and entropy

Linear regression for production (number of correct sums) for different periods.

\begin{tabular}{lcccc}
\hline \hline \multirow{2}{*}{ Studies 1 \& 2 } & Production & Production & Production & Production \\
& Period 1 to 4 & Period 4 & Period 5 & Period 6 \\
\hline Constant & $19.595 * * *$ & $31.117 * *$ & $35.614 * * *$ & $33.365 * *$ \\
Entropy & $(2.032)$ & $(3.447)$ & $(4.129)$ & $(3.614)$ \\
(standardized) & 0.042 & $\mathbf{2 . 4 4 3} * *$ & $\mathbf{2 . 1 1 8 *}$ & $\mathbf{2 . 2 8 1 * *}$ \\
Variance & $(0.597)$ & $\mathbf{( 1 . 0 4 4 )}$ & $\mathbf{( 1 . 2 3 9 )}$ & $\mathbf{( 1 . 0 8 8 )}$ \\
(standardized) & $-2.584 *$ & -1.519 & -2.772 & -2.145 \\
Loss Dummy & $(1.229)$ & $(1.877)$ & $(2.191)$ & $(1.939)$ \\
& -3.992 & -4.722 & -4.647 & -4.684 \\
Summation Skills & $(2.585)$ & $(4.169)$ & $(4.837)$ & $(4.327)$ \\
Cognitive Reflection & $3.599 * * *$ & $3.241 * * *$ & $2.748 * * *$ & $2.995 * * *$ \\
& $(0.148)$ & $(0.257)$ & $(0.305)$ & $(0.271)$ \\
Male Dummy & 0.807 & $-1.975 * *$ & $-2.611 * * *$ & $-2.293 * *$ \\
& $(0.529)$ & $(0.868)$ & $(1.007)$ & $(0.896)$ \\
Study 1 Dummy & -1.439 & $-11.977 * * *$ & $-16.266 * * *$ & $-14.121 * * *$ \\
& $(1.353)$ & $(2.167)$ & $(2.475)$ & $(2.230)$ \\
$\mathrm{N}$ & -1.491 & $-17.497 * * *$ & $-22.545 * * *$ & $-20.021 * * *$ \\
$\mathrm{R}^{2}$ & $(1.852)$ & $(3.467)$ & $(3.902)$ & $(3.503)$ \\
$\mathrm{F}$ & 637 & 637 & 637 & 637 \\
\hline
\end{tabular}

${ }^{a}$ Robust standard errors are in parentheses.

$* * *$ Significant at the 0.01 level; ** at the 0.05 level; * at the 0.1 level. 
TABLE B9 ${ }^{\text {a }}$

Productivity and entropy

Linear regressions for productivity

(number of correct summations per second spent on the task).

\begin{tabular}{lccc}
\hline \hline Studies 1 \& 2 & Periods 1 to 4 & Period 5 & Period 6 \\
\hline Constant & 0.002 & $-0.054 * * *$ & -0.003 \\
Entropy & $(0.012)$ & $(0.012)$ & $(0.012)$ \\
(standardized) & -0.001 & 0.001 & 0.001 \\
Variance & $(0.001)$ & $(0.001)$ & $(0.001)$ \\
(standardized) & $-0.005 * *$ & $-0.005 *$ & 0.001 \\
Loss Dummy & $(0.002)$ & $(0.003)$ & $(0.022)$ \\
& -0.002 & -0.002 & -0.003 \\
Summation Skills & $(0.002)$ & $(0.003)$ & $(0.002)$ \\
& $0.006 * * *$ & $0.004 * * *$ & $0.005 * * *$ \\
Cognitive Reflection & $(0.001)$ & $(0.001)$ & $(0.001)$ \\
& 0.001 & -0.002 & $<0.001$ \\
Male Dummy & $(0.001)$ & $(0.002)$ & $(0.001)$ \\
& -0.002 & $-0.018 * * *$ & $-0.010 * * *$ \\
Study 1 Dummy & $(0.002)$ & $(0.004)$ & $(0.002)$ \\
& -0.001 & $-0.021 * * *$ & -0.008 \\
Time on the task & $(0.003)$ & $(0.006)$ & $(0.003)$ \\
(in seconds) & $0.001 * * *$ & $0.001 * * *$ & $0.001 * * *$ \\
\hline $\mathrm{N}$ & $(<0.0001)$ & $(<0.0001)$ & $(<0.0001)$ \\
$\mathrm{R}^{2}$ & 581 & 554 & 516 \\
$\mathrm{~F}$ & 0.670 & 0.352 & 0.387 \\
\hline
\end{tabular}

${ }^{a}$ Robust standard errors are in parentheses.

*** Significant at the 0.01 level; ** at the 0.05 level; * at the 0.1 level. 
TABLE B10 ${ }^{\mathrm{a}}$

Stress and reward uncertainty

Linear regressions for stress (standardized tension scale).

\begin{tabular}{|c|c|c|c|}
\hline Studies $1 \& 2$ & [1] & [2] & [3] \\
\hline Constant & $\begin{array}{c}0.199 \\
(0.172)\end{array}$ & $\begin{array}{l}-0.491 \\
(0.447)\end{array}$ & $\begin{array}{c}0.002 \\
(0.518)\end{array}$ \\
\hline Stochastic & $0.363 * * *$ & $0.336 * * *$ & $0.348 * * *$ \\
\hline Treatment Dummy & $(0.109)$ & $(0.112)$ & $(0.111)$ \\
\hline Summation Skills & $\begin{array}{l}-0.022^{*} \\
(0.011)\end{array}$ & $\begin{array}{c}-0.025 * * \\
(0.011)\end{array}$ & $\begin{array}{c}-0.023 * * \\
(0.011)\end{array}$ \\
\hline Cognitive Reflection & $\begin{array}{c}0.002 \\
(0.036)\end{array}$ & $\begin{array}{c}0.012 \\
(0.037)\end{array}$ & $\begin{array}{c}0.013 \\
(0.037)\end{array}$ \\
\hline Male Dummy & $\begin{array}{l}-0.212^{*} \\
(0.118)\end{array}$ & $\begin{array}{l}-0.175 \\
(0.119)\end{array}$ & $\begin{array}{l}-0.194 \\
(0.121)\end{array}$ \\
\hline Study 1 Dummy & $\begin{array}{c}0.057 \\
(0.118)\end{array}$ & $\begin{array}{c}0.112 \\
(0.120)\end{array}$ & $\begin{array}{c}0.097 \\
(0.121)\end{array}$ \\
\hline $\begin{array}{l}\text { Working Time } \\
\text { on the task }\end{array}$ & & $\begin{array}{l}0.735^{*} \\
(0.438)\end{array}$ & $\begin{array}{c}0.662 \\
(0.450)\end{array}$ \\
\hline $\begin{array}{l}\text { SAM Valence } \\
\text { (before the work task) }\end{array}$ & & & $\begin{array}{c}-0.070 * * \\
(0.030)\end{array}$ \\
\hline $\mathrm{N}$ & 292 & 292 & 292 \\
\hline $\mathrm{R}^{2}$ & 0.068 & 0.077 & 0.092 \\
\hline$\chi^{2}$ & $4.425 * * *$ & $4.632 * * *$ & $5.533^{* * * *}$ \\
\hline
\end{tabular}

${ }^{a}$ Robust standard errors are in parentheses.

*** Significant at the 0.01 level; ** at the 0.05 level; * at the 0.1 level. 


\section{TABLE B11 ${ }^{\mathrm{a}}$}

Linear regressions for intrinsic motivation (Intrinsic Motivation Inventory - Self-determination theory).

\begin{tabular}{|c|c|c|c|}
\hline Studies $1 \& 2$ & [1] & {$[2]$} & {$[3]$} \\
\hline Constant & $\begin{array}{c}-1.428 * * * \\
(0.316)\end{array}$ & $\begin{array}{c}-1.457 * * * \\
(0.315)\end{array}$ & $\begin{array}{c}-1.449 * * * \\
(0.316)\end{array}$ \\
\hline $\begin{array}{l}\text { Stress } \\
\text { (standardized tension scale) }\end{array}$ & $\begin{array}{l}-0.030 \\
(0.040)\end{array}$ & & $\begin{array}{l}-0.027 \\
(0.040)\end{array}$ \\
\hline $\begin{array}{l}\text { Entropy } \\
\text { (standardized) }\end{array}$ & & $\begin{array}{l}-0.032 \\
(0.039)\end{array}$ & $\begin{array}{l}-0.029 \\
(0.039)\end{array}$ \\
\hline $\begin{array}{l}\text { Variance } \\
\text { (standardized) }\end{array}$ & $\begin{array}{l}-0.129 * \\
(0.074)\end{array}$ & $\begin{array}{l}-0.127 * \\
(0.074)\end{array}$ & $\begin{array}{l}-0.127 * \\
(0.074)\end{array}$ \\
\hline Loss Dummy & $\begin{array}{l}-0.033 \\
(0.156)\end{array}$ & $\begin{array}{l}-0.044 \\
(0.156)\end{array}$ & $\begin{array}{l}-0.043 \\
(0.157)\end{array}$ \\
\hline Summation Skills & $\begin{array}{c}0.022 * * * \\
(0.008)\end{array}$ & $\begin{array}{c}0.023 * * * \\
(0.008)\end{array}$ & $\begin{array}{c}0.022 * * * \\
(0.008)\end{array}$ \\
\hline Cognitive Reflection & $\begin{array}{c}0.038 \\
(0.026)\end{array}$ & $\begin{array}{c}0.038 \\
(0.026)\end{array}$ & $\begin{array}{c}0.038 \\
(0.026)\end{array}$ \\
\hline Male Dummy & $\begin{array}{l}-0.078 \\
(0.081)\end{array}$ & $\begin{array}{l}-0.071 \\
(0.081)\end{array}$ & $\begin{array}{l}-0.078 \\
(0.081)\end{array}$ \\
\hline Study 1 Dummy & $\begin{array}{c}-0.609 * * * \\
(0.106)\end{array}$ & $\begin{array}{c}-0.604 * * * \\
(0.106)\end{array}$ & $\begin{array}{c}-0.604 * * * \\
(0.106)\end{array}$ \\
\hline $\begin{array}{l}\text { Working Time } \\
\text { on the task }\end{array}$ & $\begin{array}{c}1.022 * * * \\
(0.249)\end{array}$ & $\begin{array}{c}1.019 * * * \\
(0.248)\end{array}$ & $\begin{array}{c}1.040 * * * \\
(0.249)\end{array}$ \\
\hline $\begin{array}{l}\text { SAM Valence } \\
\text { (before the work task) }\end{array}$ & $\begin{array}{c}0.033 \\
(0.024)\end{array}$ & $\begin{array}{c}0.036 \\
(0.023)\end{array}$ & $\begin{array}{c}0.033 \\
(0.024)\end{array}$ \\
\hline $\mathrm{N}$ & 637 & 637 & 637 \\
\hline $\mathrm{R}^{2}$ & 0.105 & 0.105 & 0.106 \\
\hline$\chi^{2}$ & $8.288 * * *$ & $8.202 * * *$ & $7.479 * * *$ \\
\hline
\end{tabular}

${ }^{\text {a }}$ Robust standard errors are in parentheses.

*** Significant at the 0.01 level; ** at the 0.05 level; * at the 0.1 level. 


\section{TABLE B12 ${ }^{\mathrm{a}}$}

Intrinsic motivation and reward uncertainty.

Linear regressions for intrinsic motivation

(Intrinsic Motivation Inventory - Self-determination theory).

\begin{tabular}{|c|c|c|c|}
\hline Studies 1 \& 2 & [1] & {$[2]$} & [3] \\
\hline Constant & $\begin{array}{c}-1.491 * * * \\
(0.569)\end{array}$ & $\begin{array}{c}-1.498 * * * \\
(0.570)\end{array}$ & $\begin{array}{c}-1.497 * * * \\
(0.567)\end{array}$ \\
\hline $\begin{array}{l}\text { Stress } \\
\text { (standardized tension scale) }\end{array}$ & $\begin{array}{l}-0.116 * \\
(0.062)\end{array}$ & & $\begin{array}{l}-0.110 * \\
(0.064)\end{array}$ \\
\hline Stochastic & & -0.098 & -0.059 \\
\hline Treatment Dummy & & $(0.116)$ & $(0.119)$ \\
\hline Summation Skills & $\begin{array}{c}0.017 \\
(0.013)\end{array}$ & $\begin{array}{c}0.020 \\
(0.013)\end{array}$ & $\begin{array}{c}0.017 \\
(0.013)\end{array}$ \\
\hline Cognitive Reflection & $\begin{array}{c}0.045 \\
(0.036)\end{array}$ & $\begin{array}{c}0.044 \\
(0.036)\end{array}$ & $\begin{array}{c}0.045 \\
(0.036)\end{array}$ \\
\hline Male Dummy & $\begin{array}{l}-0.005 \\
(0.125)\end{array}$ & $\begin{array}{c}0.019 \\
(0.125)\end{array}$ & $\begin{array}{l}-0.002 \\
(0.125)\end{array}$ \\
\hline Study 1 Dummy & $\begin{array}{c}-0.611 * * * \\
(0.125)\end{array}$ & $\begin{array}{c}-0.623 * * * \\
(0.126)\end{array}$ & $\begin{array}{c}-0.612 * * * \\
(0.126)\end{array}$ \\
\hline $\begin{array}{l}\text { Working Time } \\
\text { on the task }\end{array}$ & $\begin{array}{l}1.314 * * * \\
(0.474)\end{array}$ & $\begin{array}{l}1.270 * * * \\
(0.473)\end{array}$ & $\begin{array}{c}1.343 * * * \\
(0.474)\end{array}$ \\
\hline $\begin{array}{l}\text { SAM Valence } \\
\text { (before the work task) }\end{array}$ & $\begin{array}{c}0.020 \\
(0.036)\end{array}$ & $\begin{array}{c}0.029 \\
(0.036)\end{array}$ & $\begin{array}{c}0.022 \\
(0.036)\end{array}$ \\
\hline $\mathrm{N}$ & 292 & 292 & 292 \\
\hline $\mathrm{R}^{2}$ & 0.152 & 0.143 & 0.153 \\
\hline$\chi^{2}$ & $7.934 * * *$ & $7.178 * * *$ & $6.887 * * *$ \\
\hline
\end{tabular}




\section{TABLE B13 ${ }^{\mathrm{a}}$}

Satisfaction, stress and reward uncertainty.

Linear regressions for satisfaction measured by SAM emotional valence dimension at the end of the work task (described in Appendix A).

\begin{tabular}{|c|c|c|c|}
\hline Studies 1 \& 2 & [1] & {$[2]$} & [3] \\
\hline Constant & $\begin{array}{c}0.706 \\
(1.052)\end{array}$ & $\begin{array}{c}0.709 \\
(1.062)\end{array}$ & $\begin{array}{c}0.710 \\
(1.057)\end{array}$ \\
\hline $\begin{array}{l}\text { Stress } \\
\text { (standardized tension scale) }\end{array}$ & $\begin{array}{c}-0.259 * * \\
(0.116)\end{array}$ & & $\begin{array}{c}-0.263 * * \\
(0.119)\end{array}$ \\
\hline Stochastic & & -0.053 & 0.039 \\
\hline Treatment Dummy & & $(0.217)$ & $(0.220)$ \\
\hline Summation Skills & $\begin{array}{c}0.004 \\
(0.022)\end{array}$ & $\begin{array}{c}0.010 \\
(0.022)\end{array}$ & $\begin{array}{c}0.004 \\
(0.022)\end{array}$ \\
\hline Cognitive Reflection & $\begin{array}{c}0.000 \\
(0.074)\end{array}$ & $\begin{array}{l}-0.003 \\
(0.074)\end{array}$ & $\begin{array}{c}0.000 \\
(0.074)\end{array}$ \\
\hline Male Dummy & $\begin{array}{l}-0.037 \\
(0.223)\end{array}$ & $\begin{array}{c}0.012 \\
(0.224)\end{array}$ & $\begin{array}{l}-0.039 \\
(0.223)\end{array}$ \\
\hline Study 1 Dummy & $\begin{array}{c}-0.777 * * * \\
(0.251)\end{array}$ & $\begin{array}{c}-0.802 * * * \\
(0.251)\end{array}$ & $\begin{array}{c}-0.776 * * * \\
(0.251)\end{array}$ \\
\hline $\begin{array}{l}\text { Working Time } \\
\text { on the task }\end{array}$ & $\begin{array}{c}1.456 \\
(0.926)\end{array}$ & $\begin{array}{c}1.263 \\
(0.954)\end{array}$ & $\begin{array}{c}1.437 \\
(0.947)\end{array}$ \\
\hline $\begin{array}{l}\text { SAM Valence } \\
\text { (before the work task) }\end{array}$ & $\begin{array}{l}0.565 * * * \\
(0.065)\end{array}$ & $\begin{array}{c}0.583 * * * \\
(0.064)\end{array}$ & $\begin{array}{l}0.564 * * * \\
(0.065)\end{array}$ \\
\hline $\mathrm{N}$ & 292 & 292 & 292 \\
\hline $\mathrm{R}^{2}$ & 0.293 & 0.280 & 0.293 \\
\hline$\chi^{2}$ & $20.621 * * *$ & $19.808 * * *$ & $18.260 * * *$ \\
\hline
\end{tabular}




\section{TABLE B14 ${ }^{\text {a }}$}

Linear regressions for satisfaction measured by SAM emotional valence dimension at the end of the work task.

\begin{tabular}{lccc}
\hline \hline Studies 1 \& 2 & {$[1]$} & {$[2]$} & {$[3]$} \\
\hline Constant & $2.473^{* *}$ & $2.441^{* * *}$ & $2.507^{* *}$ \\
Stress & $(0.974)$ & $(0.970)$ & $(0.982)$ \\
(standardized tension scale) & $\mathbf{- 0 . 1 9 9 * * *}$ & & $\mathbf{- 0 . 2 0 5 * * *}$ \\
Entropy & $\mathbf{( 0 . 0 7 7 )}$ & & $\mathbf{( 0 . 0 7 7 )}$ \\
(standardized) & & 0.027 & 0.048 \\
Variance & & $(0.074)$ & $(0.073)$ \\
(standardized) & $-0.240^{*}$ & $-0.239^{*}$ & $-0.243^{*}$ \\
Loss Dummy & $(0.144)$ & $(0.145)$ & $(0.144)$ \\
& -0.015 & -0.001 & 0.002 \\
Summation Skills & $(0.317)$ & $(0.319)$ & $(0.319)$ \\
& 0.019 & 0.024 & 0.019 \\
Cognitive Reflection & $(0.016)$ & $(0.016)$ & $(0.016)$ \\
& 0.001 & -0.003 & 0.001 \\
Male Dummy & $(0.054)$ & $(0.055)$ & $(0.054)$ \\
& -0.161 & -0.108 & -0.161 \\
Study 1 Dummy & $(0.161)$ & $(0.161)$ & $(0.161)$ \\
& $-0.986^{* * *}$ & $-0.996^{* * *}$ & $-0.995^{* * *}$ \\
Working Time & $(0.222)$ & $(0.222)$ & $(0.221)$ \\
on the task & -0.407 & -0.599 & -0.437 \\
SAM Valence & $(0.799)$ & $(0.793)$ & $(0.807)$ \\
(before the work task) & $0.526^{* * *}$ & $0.546^{* * *}$ & $0.525^{* * *}$ \\
\hline $\mathrm{N}$ & $(0.052)$ & $(0.052)$ & $(0.052)$ \\
$\mathrm{R}^{2}$ & 637 & 637 & 637 \\
$\chi^{2}$ & 0.247 & 0.239 & 0.248 \\
\hline
\end{tabular}

${ }^{\text {a }}$ Robust standard errors are in parentheses.

*** Significant at the 0.01 level; ** at the 0.05 level; * at the 0.1 level. 

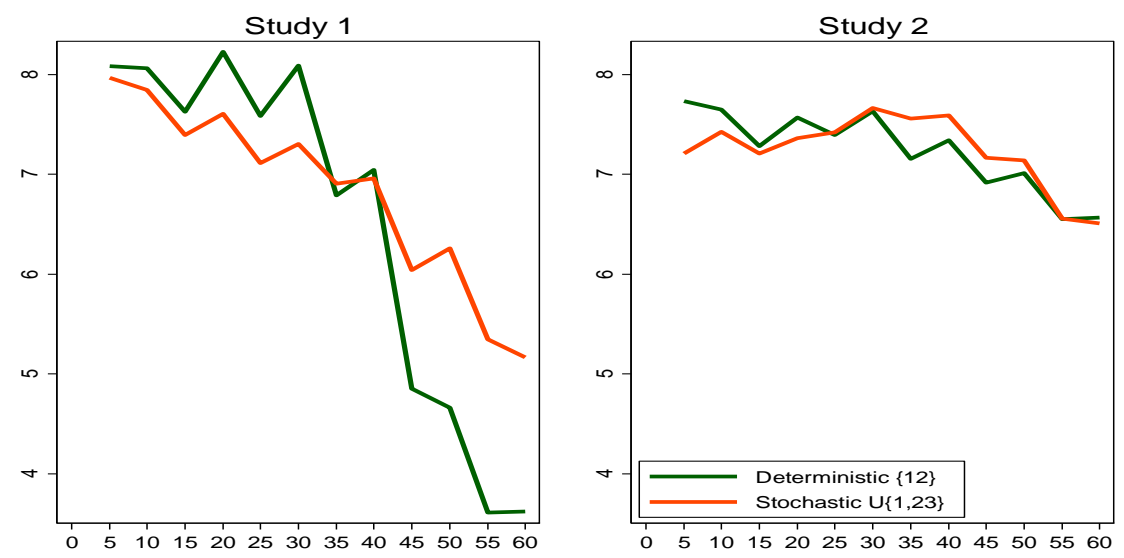

Minutes in the experiment

FIGURE B1. Average number of correct summations per minute across the two treatments for Study 1 (left panel) and Study 2 (right panel).
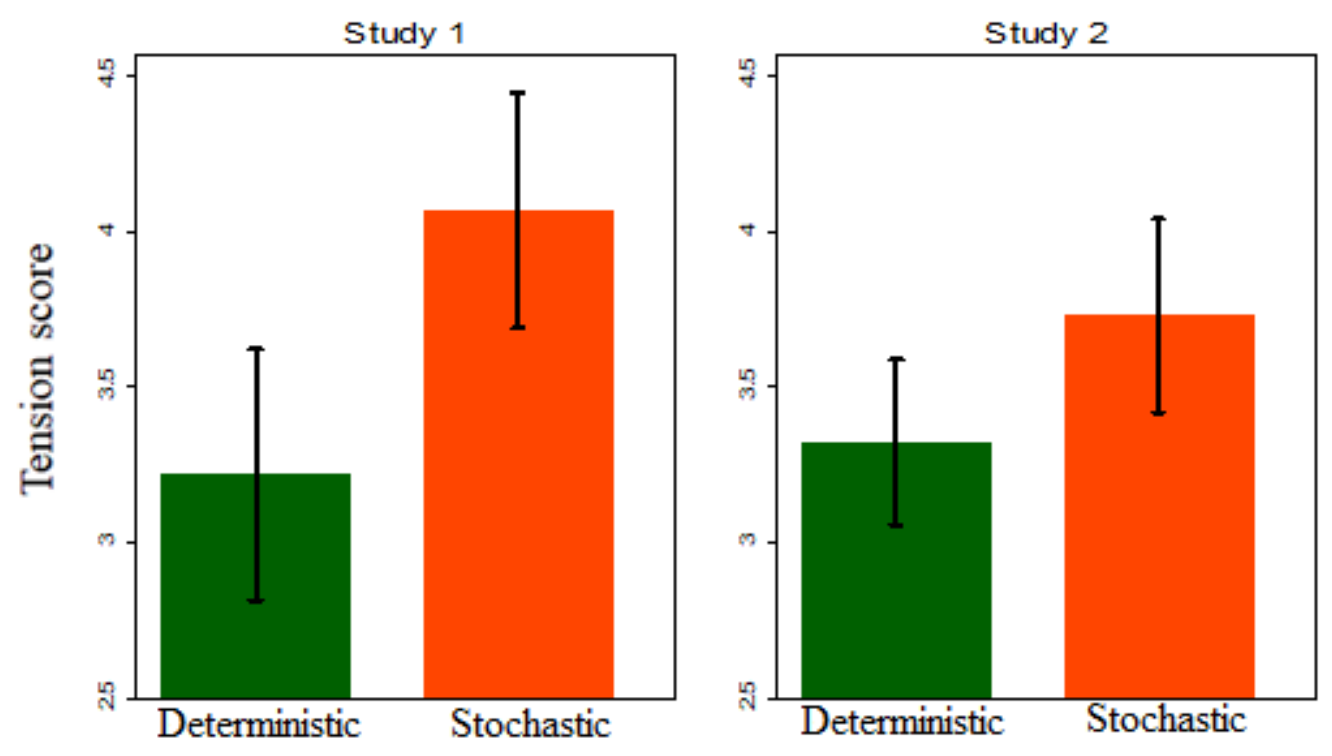

FIGURE B2. Tension and reward uncertainty. Average tension scores (from 1 to 7, see Appendix A) for the deterministic $\{12\}$ and stochastic $U\{1,23\}$ treatments. 


\section{Appendix C}

Gender analysis.

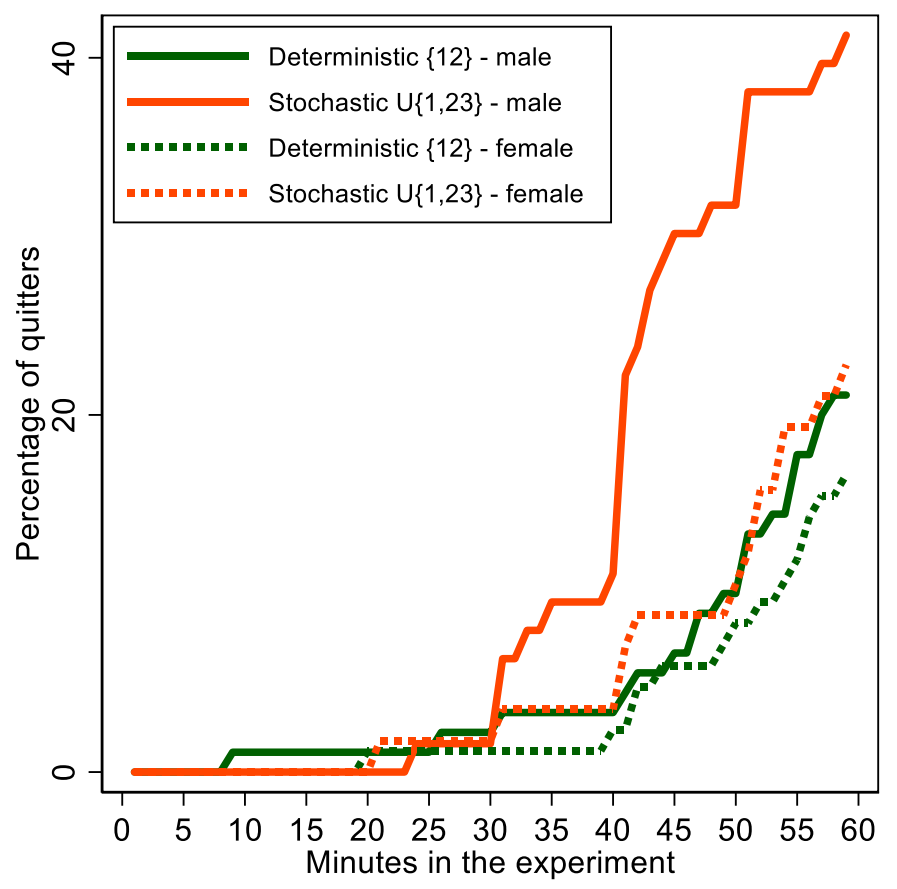

FIGURE C1. Quitting behavior and gender. Percentage of males and females who had quit the task after a given number of minutes had elapsed in the experiment across the two main treatments in both studies. 


\section{TABLE C1 ${ }^{\mathrm{a}}$}

Quitting behavior, reward uncertainty and gender

Probit regressions for the probability of quitting at different time intervals for males (left panel) and females (right panel), for the two main treatments.

\begin{tabular}{|c|c|c|c|c|c|c|}
\hline \multirow[b]{2}{*}{ Both studies } & \multicolumn{3}{|c|}{ Males } & \multicolumn{3}{|c|}{ Females } \\
\hline & $\mathrm{t}<45^{\prime}$ & $\mathrm{t}<50$ & $\mathrm{t}<55$ & $\mathrm{t}<45$, & $\mathrm{t}<50$ & $t<55^{\prime}$ \\
\hline \multirow[t]{2}{*}{ Constant } & -0.348 & -0.339 & $-0.916^{* *}$ & -0.513 & $-1.084 *$ & $-1.084^{*}$ \\
\hline & $(0.471)$ & $(0.457)$ & $(0.458)$ & $(0.743)$ & $(0.582)$ & $(0.476)$ \\
\hline Stochastic & $-1.072 * * *$ & $-1.182 * * *$ & $-0.647 * *$ & 0.201 & -0.100 & -0.129 \\
\hline \multirow[t]{2}{*}{ Treatment Dummy } & $(\mathbf{0 . 3 7 9})$ & $(\mathbf{0 . 3 7 1})$ & $(0.287)$ & $(0.327)$ & $(0.295)$ & $(0.261)$ \\
\hline & {$[-0.204 * * *]$} & {$[-0.236 * * *]$} & {$[-0.172 * *]$} & {$[0.020]$} & {$[-0.013]$} & {$[-0.023]$} \\
\hline \multirow[t]{3}{*}{ Summation Skills } & $-0.084 * *$ & $-0.075^{* *}$ & -0.023 & $-0.154 * * *$ & $-0.082 * *$ & -0.049 \\
\hline & $(0.037)$ & $(0.035)$ & $(0.028)$ & $(0.053)$ & $(0.040)$ & $(0.035)$ \\
\hline & {$[-0.016 * *]$} & {$\left[-0.015^{* *}\right]$} & {$[-0.006]$} & {$\left[-0.015^{* *}\right]$} & {$[-0.011 * *]$} & {$[-0.009]$} \\
\hline \multirow{3}{*}{$\begin{array}{l}\text { Cognitive Reflec- } \\
\text { tion }\end{array}$} & $0.201 *$ & $0.200^{* *}$ & $0.233 * * *$ & 0.183 & 0.134 & 0.003 \\
\hline & $(0.103)$ & $(0.099)$ & $(0.077)$ & $(0.113)$ & $(0.098)$ & $(0.100)$ \\
\hline & {$\left[0.038^{* *}\right]$} & {$[0.040 * *]$} & {$[0.062 * * *]$} & {$[0.018]$} & {$[0.018]$} & {$[0.001]$} \\
\hline \multirow[t]{3}{*}{ Study 1 Dummy } & $1.149 * * *$ & $1.105 * * *$ & $0.782 * * *$ & $0.699 * *$ & $1.000 * * *$ & $1.159 * * *$ \\
\hline & $(0.323)$ & $(0.315)$ & $(0.282)$ & $(0.350)$ & $(0.308)$ & $(0.282)$ \\
\hline & {$[0.219 * * *]$} & {$[0.221 * * *]$} & {$[0.208 * * *]$} & {$\left[0.069^{*}\right]$} & {$[0.135 * * *]$} & {$\left[0.204^{* * *}\right]$} \\
\hline $\mathrm{N}$ & 119 & 119 & 119 & 173 & 173 & 173 \\
\hline $\mathrm{R}^{2}$ & 0.294 & 0.297 & 0.209 & 0.164 & 0.149 & 0.159 \\
\hline Prob $>\chi^{2}$ & $24.020 * * *$ & $26.104 * * *$ & $26.078 * * *$ & $15.951 * * *$ & $18.245 * * *$ & $18.452 * * *$ \\
\hline
\end{tabular}

${ }^{a}$ Robust standard errors are in parentheses and marginal effects in square brackets.

$* * *$ Significant at the 0.01 level; ** at the 0.05 level; * at the 0.1 level. 
TABLE C2 ${ }^{\mathrm{a}}$

Quitting behavior, entropy and gender

Probit regressions for the probability of quitting at different time intervals for males (left panel) and females (right panel), for all treatments.

\begin{tabular}{|c|c|c|c|c|c|c|}
\hline \multirow[b]{2}{*}{ Both studies } & \multicolumn{3}{|c|}{ Males } & \multicolumn{3}{|c|}{ Females } \\
\hline & $\mathrm{t}<45^{\prime}$ & $\mathrm{t}<50^{\prime}$ & $t<55$, & $\mathrm{t}<45$, & $\mathrm{t}<50^{\prime}$ & $t<55$, \\
\hline Constant & $\begin{array}{c}-1.421 * * * \\
(0.322)\end{array}$ & $\begin{array}{c}-1.428 * * * \\
(0.306)\end{array}$ & $\begin{array}{c}-1.085^{* * *} \\
(0.275)\end{array}$ & $\begin{array}{c}-1.394 * * * \\
(0.454)\end{array}$ & $\begin{array}{c}-1.635^{* * * *} \\
(0.416)\end{array}$ & $\begin{array}{c}-1.490 * * * \\
(0.342)\end{array}$ \\
\hline $\begin{array}{l}\text { Entropy } \\
\text { (standardized) }\end{array}$ & $\begin{array}{c}-\mathbf{0 . 3 3 8} * * * \\
(0.120) \\
{[-\mathbf{0 . 0 5 9} * * *]}\end{array}$ & $\begin{array}{c}-\mathbf{0 . 3 6 5} * * * \\
(0.114) \\
{[-0.072 * * *]}\end{array}$ & $\begin{array}{c}-\mathbf{0 . 1 9 8} * * \\
(0.092) \\
{[-0.057 * *]}\end{array}$ & $\begin{array}{c}-0.014 \\
(0.105) \\
{[-0.001]}\end{array}$ & $\begin{array}{c}-0.087 \\
(0.102) \\
{[-0.009]}\end{array}$ & $\begin{array}{c}-0.083 \\
(0.092) \\
{[-0.012]}\end{array}$ \\
\hline $\begin{array}{l}\text { Variance } \\
\text { (standardized) }\end{array}$ & $\begin{array}{c}-0.105 \\
(0.184) \\
{[-0.018]}\end{array}$ & $\begin{array}{c}-0.035 \\
(0.179) \\
{[-0.007]}\end{array}$ & $\begin{array}{c}0.223 \\
(0.166) \\
{[0.064]}\end{array}$ & $\begin{array}{c}-0.203 \\
(0.296) \\
{[-0.018]}\end{array}$ & $\begin{array}{c}-0.187 \\
(0.290) \\
{[-0.020]}\end{array}$ & $\begin{array}{c}-0.126 \\
(0.208) \\
{[-0.018]}\end{array}$ \\
\hline Loss Dummy & $\begin{array}{c}0.404 \\
(0.407) \\
{[0.071]}\end{array}$ & $\begin{array}{c}0.132 \\
(0.410) \\
{[0.026]}\end{array}$ & $\begin{array}{c}-0.178 \\
(0.386) \\
{[-0.051]}\end{array}$ & $\begin{array}{c}0.144 \\
(0.529) \\
{[0.013]}\end{array}$ & $\begin{array}{c}0.089 \\
(0.506) \\
{[0.009]}\end{array}$ & $\begin{array}{c}0.283 \\
(0.409) \\
{[0.041]}\end{array}$ \\
\hline Summation Skills & $\begin{array}{c}-0.035 \\
(0.022) \\
{\left[-0.006^{*}\right]}\end{array}$ & $\begin{array}{c}-0.027 \\
(0.020) \\
{[-0.005]}\end{array}$ & $\begin{array}{c}-0.011 \\
(0.016) \\
{[-0.003]}\end{array}$ & $\begin{array}{c}-0.038 \\
(0.032) \\
{[-0.003]}\end{array}$ & $\begin{array}{c}-0.020 \\
(0.027) \\
{[-0.002]}\end{array}$ & $\begin{array}{c}-0.016 \\
(0.023) \\
{[-0.002]}\end{array}$ \\
\hline $\begin{array}{l}\text { Cognitive Reflec- } \\
\text { tion }\end{array}$ & $\begin{array}{c}0.175^{* * *} \\
(0.066) \\
{[0.031 * * *]}\end{array}$ & $\begin{array}{c}0.209 * * * \\
(0.064) \\
{\left[0.041^{* * *}\right]}\end{array}$ & $\begin{array}{c}0.190 * * * \\
(0.054) \\
{[0.054 * * *]}\end{array}$ & $\begin{array}{l}-0.022 \\
(0.090) \\
{[-0.002]}\end{array}$ & $\begin{array}{l}0.001 \\
(0.081) \\
{[0.000]}\end{array}$ & $\begin{array}{c}-0.030 \\
(0.077) \\
{[-0.004]}\end{array}$ \\
\hline Study 1 Dummy & $\begin{array}{c}1.031 * * * \\
(0.267) \\
{[0.180 * * *]}\end{array}$ & $\begin{array}{c}0.883 * * * \\
(0.262) \\
{[0.174 * * *]}\end{array}$ & $\begin{array}{c}0.787 * * * \\
(0.240) \\
{[0.226 * * *]}\end{array}$ & $\begin{array}{c}0.528 * * \\
(0.269) \\
{[0.048 *]}\end{array}$ & $\begin{array}{c}0.863 * * * \\
(0.252) \\
{[0.092 * * *]}\end{array}$ & $\begin{array}{c}1.053 * * * \\
(0.233) \\
{[0.152 * * *]}\end{array}$ \\
\hline $\mathrm{N}$ & 284 & 284 & 284 & 353 & 353 & 353 \\
\hline $\mathrm{R}^{2}$ & 0.178 & 0.171 & 0.109 & 0.060 & 0.111 & 0.119 \\
\hline Prob $>\chi^{2}$ & $35.097 * * *$ & $37.517 * * *$ & $34.732 * * *$ & 7.495 & $18.423^{* * *}$ & $25.352 * * *$ \\
\hline
\end{tabular}

${ }^{a}$ Robust standard errors are in parentheses and marginal effects in square brackets.

*** Significant at the 0.01 level; ** at the 0.05 level; * at the 0.1 level. 


\section{Appendix D}

Work addicts analysis.

Analysis of Work Addiction according to the Bergen Work Addiction Scale (BWAS). Here we study work addiction as a moderator of the relationship between the effect of stochastic rewards on work behavior. We define work addicts (non-addicts) those who score above (below) the median on the Bergen Work Addiction Scale (Andreassen et al., 2012). It is important to note that work addiction scores do not differ across genders (WRS, p-value $=0.333$ ) thus stressing that any direct effect of addiction on work behavior cannot be attributed to gender differences.

\section{Study 2}

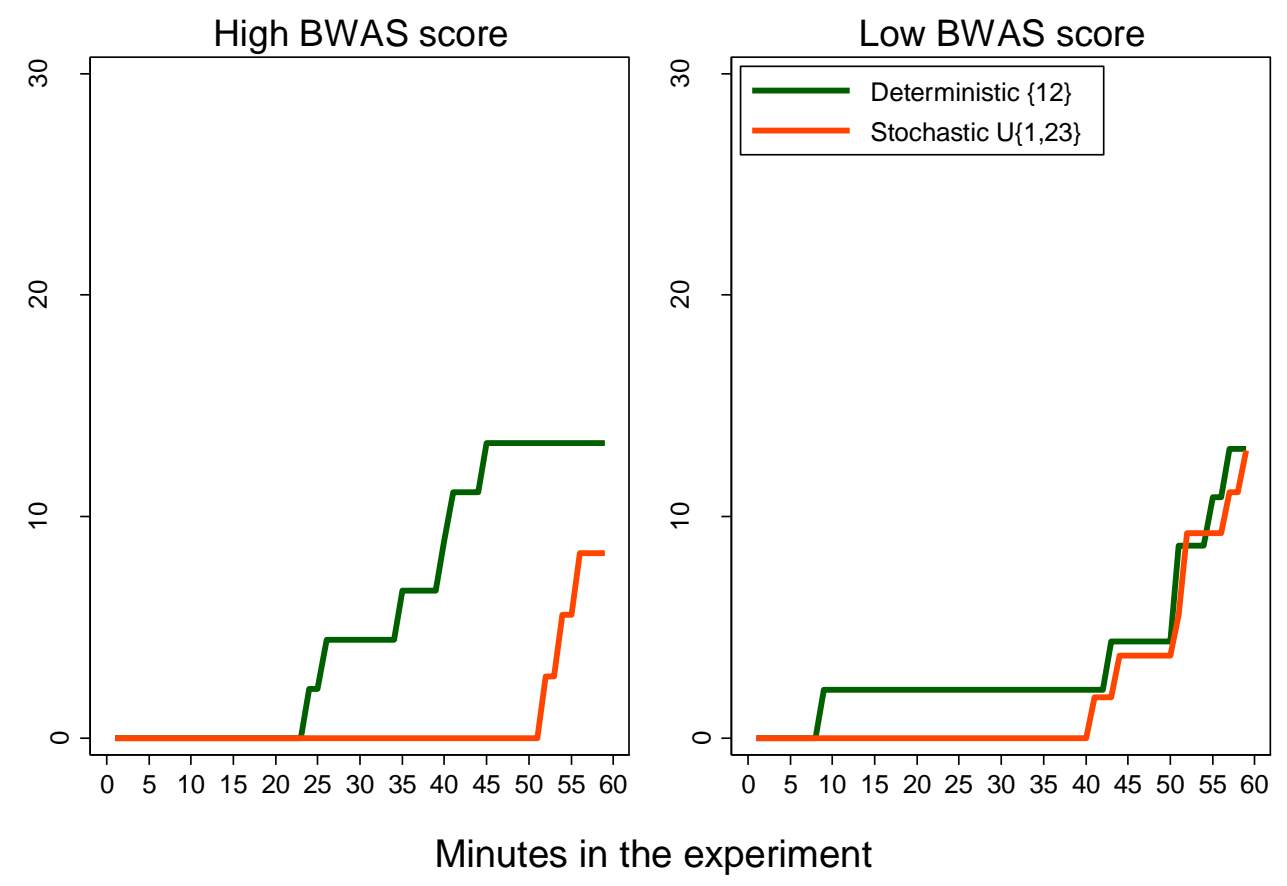

FIGURE D1. Quitting behavior, reward uncertainty, and work addiction.

Percentage of work addicts (above median scores) -left panel- and non-work addicts -right panelwho had quit the task after a given number of minutes had elapsed in the experiment in Study 2. 


\section{TABLE D1 ${ }^{\mathrm{a}}$}

Quitting behavior, reward uncertainty and work addiction

Probit regressions for the probability of quitting at different time intervals.

\begin{tabular}{|c|c|c|c|c|c|c|}
\hline & \multicolumn{3}{|c|}{ High BWAS score ${ }^{\mathrm{b}}$} & \multicolumn{3}{|c|}{ Low BWAS score } \\
\hline & $\mathrm{t}<45$ & $\mathrm{t}<50$ & $\mathrm{t}<55$ & $\mathrm{t}<45$ & $\mathrm{t}<50$ & $\mathrm{t}<55$ \\
\hline \multirow[t]{2}{*}{ Constant } & -1.357 & $-1.723 *$ & $-2.501 * *$ & -1.060 & -1.060 & $-1.751 * * *$ \\
\hline & $(1.037)$ & $(1.005)$ & $(1.010)$ & $(0.679)$ & $(0.679)$ & $(0.577)$ \\
\hline Stochastic & & & $-0.930 * *$ & 0.068 & 0.068 & 0.142 \\
\hline \multirow[t]{2}{*}{ Treatment Dummy } & & & $(0.417)$ & $(0.481)$ & $(0.481)$ & $(0.366)$ \\
\hline & & & {$[-0.127 * *]$} & [0.004] & [0.004] & {$[0.021]$} \\
\hline \multirow[t]{3}{*}{ Summation Skills } & -0.057 & -0.021 & 0.021 & $-0.177 * *$ & $-0.177 * *$ & -0.036 \\
\hline & $(0.063)$ & $(0.054)$ & $(0.046)$ & $(0.079)$ & $(0.079)$ & $(0.041)$ \\
\hline & {$[-0.009]$} & {$[-0.004]$} & {$[0.003]$} & {$[-0.012 *]$} & {$[-0.012 *]$} & {$[-0.005]$} \\
\hline \multirow[t]{3}{*}{ Cognitive Reflection } & 0.153 & 0.123 & $0.227 *$ & $0.639 * * *$ & $0.639 * * *$ & $0.284 *$ \\
\hline & $(0.178)$ & $(0.170)$ & $(0.133)$ & $(0.203)$ & $(0.203)$ & $(0.157)$ \\
\hline & {$[0.025]$} & [0.022] & {$\left[0.031^{*}\right]$} & {$[0.042 * *]$} & {$[0.042 * *]$} & {$\left[0.041^{*}\right]$} \\
\hline \multirow[t]{3}{*}{ Male Dummy } & $1.055^{* *}$ & $1.165^{* *}$ & $1.126^{* *}$ & -0.223 & -0.223 & 0.404 \\
\hline & $(0.518)$ & $(0.507)$ & $(0.492)$ & $(0.552)$ & $(0.552)$ & $(0.376)$ \\
\hline & {$[0.171 *]$} & {$\left[0.213^{* *}\right]$} & {$\left[0.154^{* *}\right]$} & {$[-0.015]$} & {$[-0.015]$} & [0.058] \\
\hline $\mathrm{N}$ & 81 & 81 & 81 & 100 & 100 & 100 \\
\hline $\mathrm{R}^{2}$ & 0.144 & 0.153 & 0.224 & 0.266 & 0.266 & 0.122 \\
\hline$\chi^{2}$ & 5.806 & 5.950 & $8.413^{* *}$ & $15.025^{* * *}$ & $15.025 * * *$ & 5.312 \\
\hline
\end{tabular}

${ }^{a}$ Robust standard errors are in parentheses and marginal effects in square brackets.

b The stochastic treatment variable cannot be estimated for participants with a high BWAS score for $\mathrm{t}<45^{\prime}$ or $\mathrm{t}<50$ ' as none of them quitted in the stochastic treatment before $t<55$, versus $13.3 \%$ (6 out of 45 ) in the baseline treatment. *** Significant at the 0.01 level; ** at the 0.05 level; * at the 0.1 level. 


\section{TABLE D2 ${ }^{\mathrm{a}}$}

Quitting behavior, entropy and work addiction

Probit regressions for the probability of quitting at different time intervals, by participants' scores in the BWAS test of addiction.

\begin{tabular}{|c|c|c|c|c|c|c|}
\hline & \multicolumn{3}{|c|}{ High BWAS score } & \multicolumn{3}{|c|}{ Low BWAS score } \\
\hline & $\mathrm{t}<45^{\prime}$ & $\mathrm{t}<50$ & $\mathrm{t}<55$ & $\mathrm{t}<45^{\prime}$ & $\mathrm{t}<50$ ' & $\mathrm{t}<55$ \\
\hline Constant & $\begin{array}{c}-3.024 * * * \\
(0.735)\end{array}$ & $\begin{array}{c}-3.107 * * * \\
(0.669)\end{array}$ & $\begin{array}{c}-2.699 * * * \\
(0.477)\end{array}$ & $\begin{array}{c}-1.668 * * * \\
(0.339)\end{array}$ & $\begin{array}{c}-1.720 * * * \\
(0.332)\end{array}$ & $\begin{array}{c}-1.474 * * * \\
(0.288)\end{array}$ \\
\hline $\begin{array}{l}\text { Entropy } \\
\text { (standardized) }\end{array}$ & $\begin{array}{c}-0.753 * \\
(0.412) \\
{[-0.058 *]}\end{array}$ & $\begin{array}{c}-\mathbf{0 . 6 4 4} * * \\
(0.296) \\
{[-0.056 * *]}\end{array}$ & $\begin{array}{c}-0.193 \\
(0.154) \\
{[-0.026]}\end{array}$ & $\begin{array}{c}-0.135 \\
(0.126) \\
{[-0.017]}\end{array}$ & $\begin{array}{c}-0.161 \\
(0.121) \\
{[-0.023]}\end{array}$ & $\begin{array}{c}-0.083 \\
(0.106) \\
{[-0.018]}\end{array}$ \\
\hline $\begin{array}{l}\text { Variance } \\
\text { (standardized) }\end{array}$ & $\begin{array}{c}0.284 \\
(0.178) \\
{[0.022]}\end{array}$ & $\begin{array}{c}0.257 \\
(0.183) \\
{[0.022]}\end{array}$ & $\begin{array}{c}0.203 \\
(0.208) \\
{[0.028]}\end{array}$ & $\begin{array}{c}-0.253 \\
(0.209) \\
{[-0.032]}\end{array}$ & $\begin{array}{c}-0.146 \\
(0.201) \\
{[-0.021]}\end{array}$ & $\begin{array}{c}0.075 \\
(0.166) \\
{[0.017]}\end{array}$ \\
\hline Loss Du & $\begin{array}{c}-0.349 \\
(0.268) \\
{[-0.027]}\end{array}$ & $\begin{array}{c}-0.482 \\
(0.293) \\
{[-0.042]}\end{array}$ & $\begin{array}{c}-0.042 \\
(0.477) \\
{[-0.006]}\end{array}$ & $\begin{array}{c}0.473 \\
(0.426) \\
{[0.060]}\end{array}$ & $\begin{array}{c}0.234 \\
(0.437) \\
{[0.033]}\end{array}$ & $\begin{array}{c}0.012 \\
(0.378) \\
{[0.003]}\end{array}$ \\
\hline Summation Skills & $\begin{array}{c}0.009 \\
(0.033) \\
{[0.001]}\end{array}$ & $\begin{array}{c}0.025 \\
(0.030) \\
{[0.002]}\end{array}$ & $\begin{array}{c}0.016 \\
(0.025) \\
{[0.002]}\end{array}$ & $\begin{array}{c}-0.027 \\
(0.023) \\
{[-0.003]}\end{array}$ & $\begin{array}{c}-0.028 \\
(0.022) \\
{[-0.004]}\end{array}$ & $\begin{array}{c}-0.018 \\
(0.018) \\
{[-0.004]}\end{array}$ \\
\hline Cognitive Reflection & $\begin{array}{c}0.092 \\
(0.103) \\
{[0.007]}\end{array}$ & $\begin{array}{c}0.091 \\
(0.095) \\
{[0.008]}\end{array}$ & $\begin{array}{c}0.131 \\
(0.086) \\
{[0.018]}\end{array}$ & $\begin{array}{c}0.139 * \\
(0.077) \\
{[0.018 *]}\end{array}$ & $\begin{array}{c}0.209 * * * \\
(0.079) \\
{[0.030 * * *]}\end{array}$ & $\begin{array}{c}0.156 * * \\
(0.069) \\
{[0.034 * *]}\end{array}$ \\
\hline Male Dummy & $\begin{array}{c}1.099 * * * \\
(0.390) \\
{[0.084 * *]}\end{array}$ & $\begin{array}{c}1.137 * * * \\
(0.383) \\
{[0.099 * * *]}\end{array}$ & $\begin{array}{c}1.173 * * * \\
(0.300) \\
{[0.160 * * *]}\end{array}$ & $\begin{array}{c}0.277 \\
(0.253) \\
{[0.035]}\end{array}$ & $\begin{array}{c}0.382 \\
(0.246) \\
{[0.054]}\end{array}$ & $\begin{array}{c}0.686 * * * \\
(0.211) \\
{[0.151 * * *]}\end{array}$ \\
\hline $\mathrm{N}$ & 250 & 250 & 250 & 276 & 276 & 276 \\
\hline $\begin{array}{l}\mathrm{R}^{2} \\
\chi^{2}\end{array}$ & $\begin{array}{c}0.203 \\
13.090 *\end{array}$ & $\begin{array}{c}0.209 \\
16.715^{* *}\end{array}$ & $\begin{array}{c}0.186 \\
23.239 * * *\end{array}$ & $\begin{array}{l}0.051 \\
6.265\end{array}$ & $\begin{array}{c}0.082 \\
10.297\end{array}$ & $\begin{array}{c}0.096 \\
18.511^{* * * *}\end{array}$ \\
\hline
\end{tabular}

${ }^{a}$ Robust standard errors are in parentheses and marginal effects in square brackets.

*** Significant at the 0.01 level; ** at the 0.05 level; * at the 0.1 level. 


\section{E1. Related models}

\section{Appendix E}

Our conceptual framework relates to the theory of rational addiction in economics (see e.g., Stigler \& Becker, 1977; Iannaccone, 1986; Becker \& Murphy, 1988). These works put forth the idea of 'adjacent complementarity' according to which past consumption of an addictive good raises its future consumption. Our model differs from the theory of rational addiction because we assume people are boundedly rational suffering attention costs à la Sims (2003). Our model provides novel predictions regarding the effect of uncertainty on work addiction and workers' stress levels.

Our model also relates to the work of Brocas \& Carillo (2008), who propose a dual-system model of incentive salience by using a principal-agent framework to represent the conflict between the 'liking' system (System 1) and the 'wanting' system (System 2). The agent (the 'liking' system) experiences the feeling of pleasure and pain whereas the principal can decide on which strategy to deploy to complete the task. As in a standard principal-agent model, the two key elements of their model are the conflict in goals between systems (the agent looks for immediate rewards whereas the principal is forward-looking) and the asymmetry of information between the two systems. We depart from Brocas \& Carrillo (2008) by considering that there is no conflict of interest between System 1 and System 2. Instead, we can interpret our model as one in which attentional costs might prevent a person from switching from System 1 (that implements the habitual action) to System 2 (that implements the alternative action). These attentional switching costs could be understood as anatomical constraints of neuronal information transmission (see e.g., Dimitrov, Lazar \& Victor, 2011). These anatomical constraints prevent System 2 to continually adjust the level of effort to be implemented (see Abeless \& Lass, 1975; Lass \& Abeless, 1975 for early contributions). This literature stresses that the costs of transmitting information from one part of the brain to another via neuronal connections can be modeled with the tools of information theory. The communication costs in the brain are tightly linked to the uncertainty of the environment which is modeled using the concept of entropy (e.g., Dimitrov et al., 2011; Friston et al., 2013; 2015; 2017a,b). A vast literature in dual-system models have also stressed that updating one's action is costly (e.g., Evans, 2003; Kahneman, 2011; Stanovich, 2009). ${ }^{30}$ This is the case because

\footnotetext{
30 The dual-system approach has been successfully applied to economics to explain self-control issues and the crowding-out of intrinsic motivation (e.g., Bénabou and Tirole, 2002; Benhabib \& Bisin, 2005; Bernheim \& Rangel, 2004; Fudenberg \& Levine, 2006; Thaler \& Sheffrin, 1981).
} 
switching from a habitual response to a deliberative one requires engaging scarce attentional resources (see e.g., Hasher et al., 2007; Toplak et al., 2011).

Finally, Dean et al., (2017) have shown that, in the presence of attentional constraints, statusquo options (continue to work on the task in our setup) are more likely to be considered than other alternatives (leave the task). This work can thus explain why quitting rates might be low in our setup but it cannot account for the crucial role of uncertainty on work persistence. An implication of our work to this literature is that the status-quo bias would tend to be more pronounced when the entropy of the default option is high compared to alternative options.

\section{E2. Related designs}

In our setup, the probabilistic structure of rewards is known. This design differs from economic studies assessing the effect of stochastic rewards (Hogarth \& Villeval, 2014) and feedback (Bereby-Meyer \& Roth, 2006) on learning the frequency of rewards. Even if participants in our setup had difficulties understanding stated probabilities (see Goldstein \& Rothschild, 2014), they would experience a large number of draws, thus downplaying the role of learning in explaining a participant's decision to quit the task after monetary rewards become negligible. ${ }^{31}$

Hogarth \& Villeval (2014) assessed the extent to which participants continued to exert effort in a repetitive letter-searching task after monetary rewards had been removed. In their design, participants did not know whether their work in a given (2-minute) period would be rewarded or not. After an unknown number of periods, rewards were effectively removed. The main task for participants was to learn, over repeated trials, whether work was going to be rewarded or not in a given period and thus identify the occurrence of a regime shift after which work was no longer paid. At the beginning of each period, participants could decide whether to continue working on the task in which case they had to pay a fee to participate. Using simulations of a reinforcement learning model, the authors predicted that participants would quit right after the no-reward regime shift occurred in the case in which work was rewarded at a known and fixed value. In that case, the absence of a reward immediately signaled that the no-reward regime shift was in place. In their other two treatments (fixed and random intermittent incentive treatments), work was not rewarded every period even before the no-reward regime applied, thus making one's learning about the regime shift slower and leading participants to quit the work task at a later time than in the baseline.

\footnotetext{
${ }^{31}$ In the baseline, participants completed on average about 80 sums per period of 10 minutes.
} 
The authors confirmed their predictions with experimental data. In our setting, the issue of learning about the distribution of rewards is absent because this distribution is given to the participants and displayed on their screen at all times.

The idea that learning tends to be hampered by stochastic feedback is also captured in BerebyMeyer \& Roth (2006), who showed that the presence of stochastic payoffs prevents participants from learning about the decay of cooperation in an otherwise standard prisoners' dilemma. 